\title{
Impacto de la formación tecnológica en producción ganadera ofertado por el SENA en el desarrollo del sector Agropecuario de un departamento de Colombia, 2015-2018
}

\author{
José Nicolás Barrios Sierra
}

Tesis para optar por el grado de Magíster en Políticas de Desarrollo

Director: Dr. Álvaro Sánchez Caraballo, UNICOR - Col

Co-director: M.Sc. Matías Causa, UNLP

Noviembre 10 de 2020 


\section{Contenido}

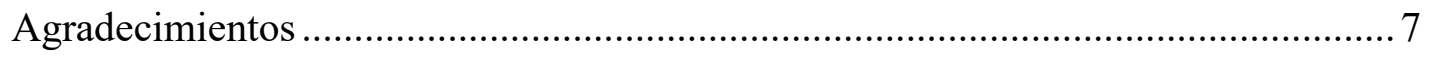

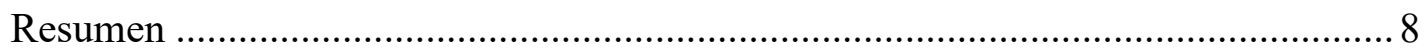

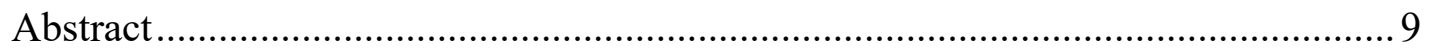

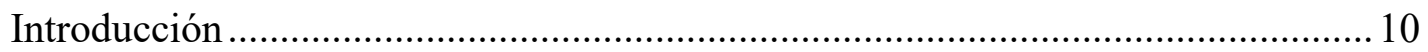

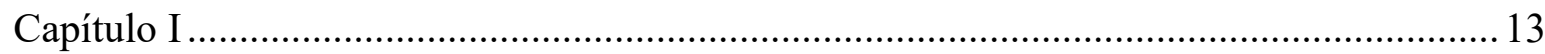

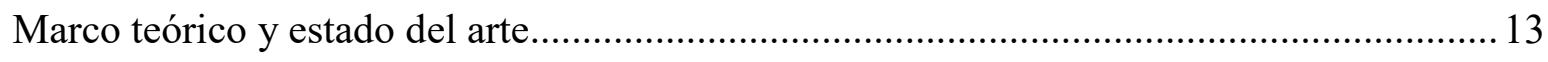

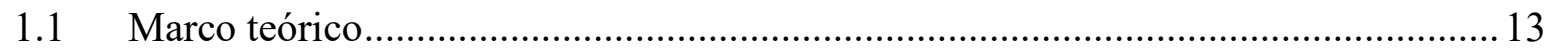

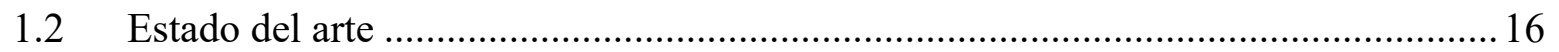

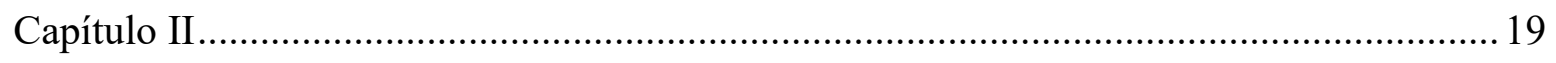

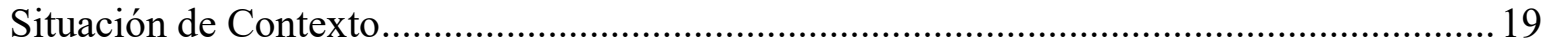

2.1 Generalidades del departamento de Córdoba .................................................... 20

2.2 Sistema Educativo Colombiano .................................................................... 24

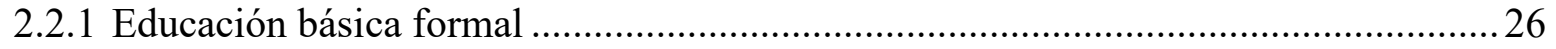

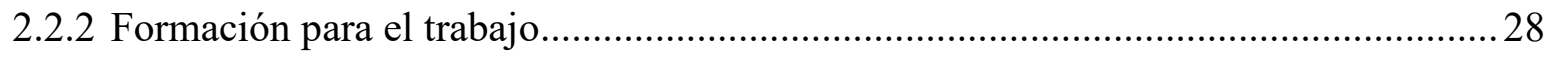

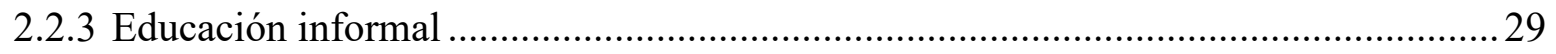

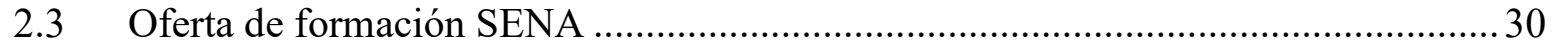

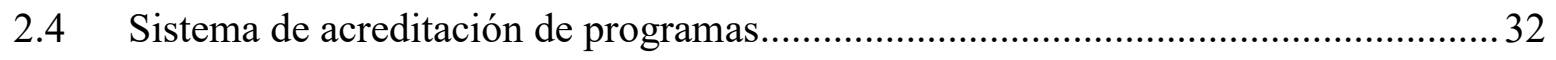

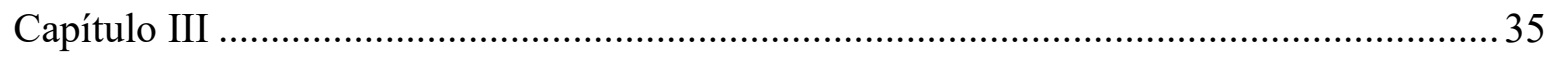

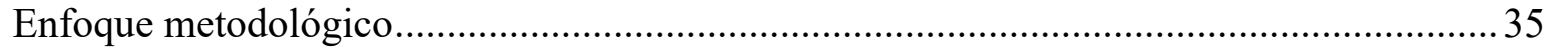

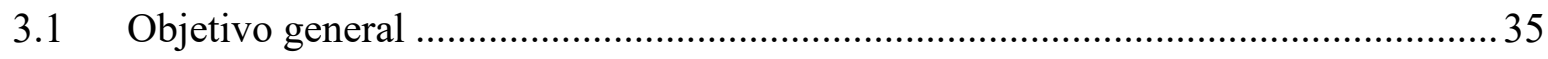

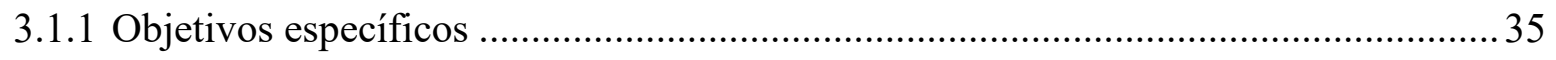

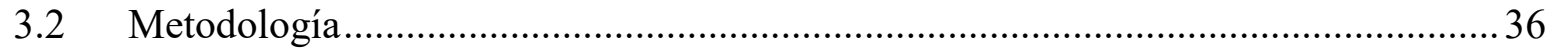

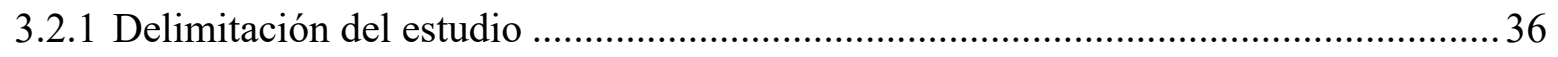

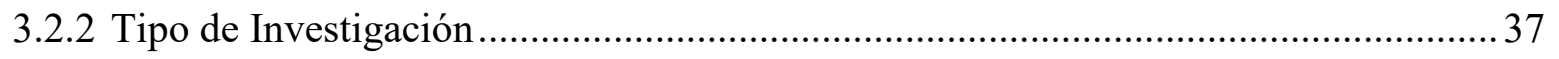

3.2.3 Consideraciones para determinar el tamaño de la muestra ..................................... 38

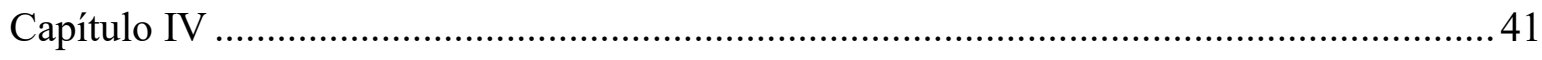

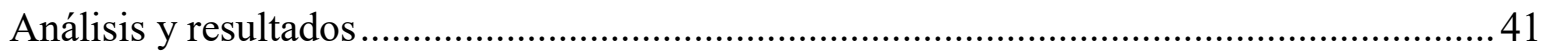


4.1 Nivel de empleabilidad de los egresados del programa tecnólogo en producción ganadera ofertado por el Centro Agropecuario y de biotecnología "El Porvenir" del Servicio Nacional de Aprendizaje SENA frente a los parámetros establecidos en el Plan Nacional de Desarrollo Pacto por Colombia, Pacto por la Equidad” 2018 - 2022.

4.2 Inserción de egresados del programa de formación en el mercado laboral Agropecuario del departamento de Córdoba

4.3 Impacto generado por la inserción de Tecnólogos Profesionales del SENA en Empresas Agropecuarias del departamento de Córdoba. 61

4.3.1 Cumplimiento de los parámetros establecidos del plan nacional de desarrollo 64

4.4 Nivel de satisfacción de empresarios y egresados sobre el programa de formación. 69 4.5 Describir la contribución del programa de formación sobre la calidad de vida de los egresados. 81

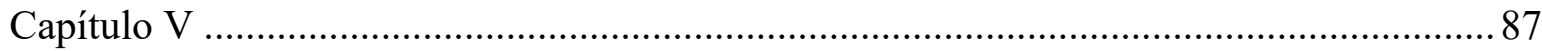

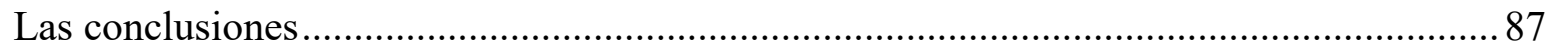

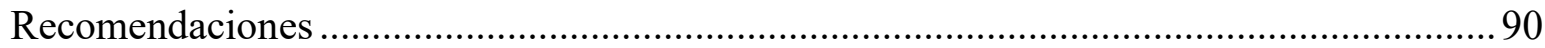

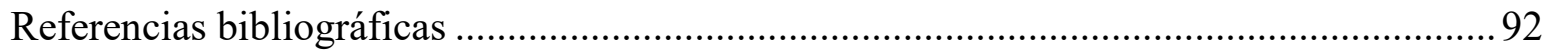

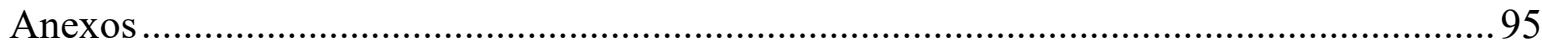

Anexo 1. Ficha técnica la encuesta aprendices......................................................... 96

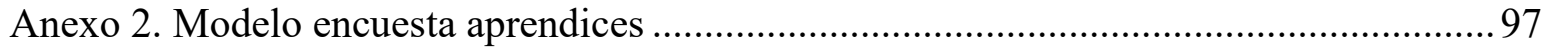

Anexo 3. Ficha técnica encuesta empresarios ............................................................. 100

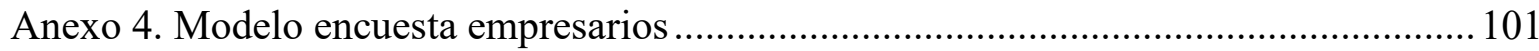




\section{Listado de figuras}

No 1. Distribución porcentual por uso potencial del suelo..........................................2 21

No 2. Distribución porcentual por uso potencial de suelo en actividades productivas ........22

No 3. Distribución porcentual de las actividades productivas del departamento de Córdoba.

No 1. Esquema de la educación básica formal .............................................................. 28

No 2. Esquema de la formación para el trabajo.........................................................29

No 3. Sistema de acreditación nacional ..................................................................... 33

Figura No 4. Empleabilidad: oportunidad del primer empleo .......................................... 42

Figura No 5. Nivel de empleabilidad de los egresados en situación laboral activa ............43

Figura No 6. Tipo de actividad de la empresa (Misional) ............................................44

Figura No 7. Empleabilidad: Trabajo en el área de formación ..................................... 45

Figura No 8. Empleabilidad: Grado de formalidad del trabajo en el área de formación......47

Figura No 9. Empleabilidad: Permanencia en el trabajo del área de formación ..................48

Figura No 10. Empleabilidad. Ingresos mensuales .................................................... 49

Figura No 11. Ubicación por departamento de las empresas empleadoras .......................52

Figura No 12. Ubicación las empresas empleadoras de los Tecnólogos por Región...........53

Figura No 13. Tamaño de las empresas empleadoras de los Tecnólogos .........................54

Figura No 14. Tipo de contratación de los Tecnólogos..................................................55

Figura No 15. Condición del trabajo del Tecnólogo en Producción Ganadera ...................56

Figura No 16. Sector en que laboran los Tecnólogos en Producción Ganadera ..................57

Figura No 17. Tipo de vinculación laboral ..............................................................58 
Figura No 18. Razones por las cuales no ha conseguido empleo ..................................59

Figura No 19. Origen de las condiciones de inactividad laboral .....................................60

Figura No 20. Recomendaría el Programa .................................................................... 70

Figura No 21. Recomendaría Programas del sector Agropecuario .................................. 71

Figura No 22. Satisfacción con el cumplimiento de las actividades laborales....................73

Figura No 23. Satisfacción con el cumplimiento de los objetivos empresariales ............... 75

Figura No 24. Opinión de los empleadores: Capacidades requeridas en los Tecnólogos....77

Figura No 25. Opinión de los empleadores: Capacidades requeridas en los Tecnólogos ....78

Figura No 26. Opinión sobre mejora en la calidad de vida ........................................... 82

Figura No 27. Procedencia de los graduados ............................................................. 84 


\section{Listado de tablas}

Tabla No 1 Medición de impacto social, económico y productivo ........................ 62

Tabla No 2 Ficha técnica la encuesta aprendices ...............................................96

Tabla No 3 Ficha técnica la encuesta empresarios ............................................... 100 


\title{
Agradecimientos
}

\begin{abstract}
Al Servicio Nacional de Aprendizaje - SENA y al Centro Agropecuario y de Biotecnología EL Porvenir por su valioso apoyo en la consecución de la información.
\end{abstract}

A los doctores Álvaro Sánchez y Matías Causa por el constante apoyo y direccionamiento en este trabajo. De igual forma al doctor Patricio Narodowski por la guía durante todo el proceso de formación al igual que a Leyla Chaín.

A Juan Sebastián, Juan José y María Carolina mis motores y quienes con su tiempo aportaron a este desarrollo. A mi madre y padre por sus motivaciones y mi hermana por su ejemplo.

A la Universidad Nacional de La Plata, mi nueva "Alma Mater" por este gran proceso de aprendizaje permanente. 


\section{Resumen}

Este trabajo tuvo como objetivo principal determinar la pertinencia del programa tecnólogo en producción ganadera ofertado por el Centro Agropecuario y de Biotecnología “El Porvenir" del SENA. La evaluación se realizó en el periodo comprendido entre los años 2015 - 2018, para lo que se consideraron los lineamientos del Ministerio de Educación Nacional de Colombia (MEN) en materia de proceso de acreditación de programas de formación en el país.

En el desarrollo de la investigación, se evaluaron aspectos como nivel de ingresos de los egresados, tiempo para la vinculación después de finalizar la formación, relación del programa con el trabajo que realizan, expectativas y grado de satisfacción de los empresarios, entre otros.

Para la aplicación de instrumentos de recolección de información, se consideró como población la totalidad de egresados y empresarios asociados al Centro de formación en el periodo objeto de estudio, en el ejercicio se evidenció movilidad de los egresados al identificar la presencia de estos en municipios y ciudades diferentes al departamento de Córdoba.

Dentro de las posibles utilidades de los resultados de este proyecto se encuentra la posibilidad de mejorar las condiciones de pertinencia de la formación en el departamento de Córdoba, principalmente lo que al sector Agropecuario se refiere; de tal manera que en un trabajo posterior, se pueda ampliar el alcance de la investigación e incluir en la población objeto otras instituciones de educación superior con una oferta igual o similar a la del Centro Agropecuario y de Biotecnología El Porvenir. 
Palabras clave: Formación tecnóloga, vinculación laboral, pertinencia

\begin{abstract}
The main objective of this work was to determine the relevance of the livestock production technology program offered by the Centro Agropecuario y de Biotecnología El Porvenir. The evaluation was carried out in the period between 2015 and 2018, considering the guidelines of the Ministerio de Educación Nacional (MEN) regarding the process of accreditation of training programs in the country.
\end{abstract}

Throughout the development of the investigation, different aspects were such as: graduates economic level, time for bonding once they finish their educational process, relationship between the program they study and the work they do every day, expectations and degree of satisfaction of the industrialists, among others, were evaluated.

For applying instruments for collecting information, the graduates and businessmen associated with the Training Center in the period under study were the object of study. During this activity, the mobility of the graduates was evidenced by identifying their presence in municipalities and cities other than the department of Cordoba.

Among the possible benefits of the outcome of this project is the possibility to improve the conditions of the relevance of training in the department of Córdoba, mainly the one referring to the agricultural sector, so that in a previous job, you can expand the reach of the research and include in the target population other higher education institutions with an offer equal or similar to the Centro Agropecuario y de Biotecnología El Porvenir.

Keywords: technological training, employment relationship, relevance. 


\section{Introducción}

El concepto de calidad en la educación superior hace referencia a un atributo del servicio público de la educación en general y, en particular, al modo como ese servicio se presta, según el tipo de institución de que se trate evaluada con base a su misión y desempeño de programas de formación en el contexto social, económico, ambiental y cultural en el cual se inserta y cobra sentido (Comisión Nacional de Acreditación, CNA Colombia).

De igual forma, es importante indicar que de acuerdo con los lineamientos de la CNA, los criterios sobre los cuales opera el Sistema Nacional de Acreditación para los programa técnicos y tecnólogos corresponden a: Universalidad, Integridad, Equidad, Idoneidad, Responsabilidad, Coherencia, Transparencia, Pertinencia, Eficacia, Eficiencia, Participación, Cobertura o Sostenibilidad, Flexibilidad, Identidad y Satisfacción, los cuales se complementa y potencian entre sí, sirviendo como base al juicio sobre la calidad. Esta (la calidad) es medida

mediante ocho (8) factores, siendo el séptimo el correspondiente a Egresado e impacto en el medio.

En Colombia, los programas académicos ofertados deben dar respuesta a las necesidades del sector productivo de tal manera que se contribuya a aumentar la productividad de la región y sean competitivos en un entorno global.

Uno de los aspectos de calidad a evaluar en los procesos formativos es la pertinencia de los programas de formación impartidos. A nivel mundial, los países desarrollados 
evidenciaron la deficiente relación y articulación entre la educación y el trabajo lo que se reflejaba en respuestas poco pertinentes de la formación profesional a las demandas de los sistemas productivos, económicos y sociales y además la desactualización de muchos programas de la oferta educativa y técnica (SENA, 2001).

Este trabajo se centró en la medición del impacto de la formación tecnológica del programa producción ganadera ofertado por el SENA en el desarrollo del sector Agropecuario del departamento de Córdoba Colombia, 2015-2018, acorde con los lineamientos de evaluación de la calidad de los procesos de acreditación del Consejo Nacional de Acreditación (CNA).

En virtud de lo anterior, se realizó la evaluación de uno de los atributos de calidad de la educación, como es el caso de la pertinencia de un programa formación tecnólogo profesional impartido por una Institución de carácter público cuya función principal es la formación para el trabajo supliendo las necesidades del sector productivo de la región. Para esta investigación, se seleccionó el programa Producción Ganadera del Servicio Nacional de Aprendizaje SENA ofertado por el Centro Agropecuario y de Biotecnología “El Porvenir" el cual responde a través de la formación a las necesidades del sector Agropecuario del departamento de Córdoba Colombia. Con el análisis realizado, se pretendió dar respuesta a interrogantes como: ¿Cuál es nivel de empleabilidad de los egresados del programa tecnólogo en producción ganadera ofertado por el Centro Agropecuario y de Biotecnología "El Porvenir" del Servicio Nacional de Aprendizaje SENA - frente a la calidad y pertinencia 
determinada? ¿Cómo ha sido la inserción laboral de los aprendices egresados del programa? ¿Se ha logrado generar algún impacto por la inserción laboral de estos aprendices? ¿Cuál es el nivel de satisfacción de empresarios y egresados sobre el programa de formación? ¿Se ha logrado mejorar la calidad de vida de los aprendices egresados?\}

Con el fin de dar respuesta a estos interrogantes, y buscando medir indicadores tales como niveles de empleabilidad, grado de inserción laboral, niveles de satisfacción de los empresarios y egresados sobre el programa de formación y la contribución del programa de formación sobre la calidad de vida de los egresados, se desarrollaron los siguientes capítulos: capítulo I, marco teórico y estado del arte en el que se describe de forma detallada los trabajos o estudios que anteceden y sirven de base y referente para el desarrollo de la investigación; capítulo II, aborda el contexto general del departamento y el sistema educativo Colombiano bajo el cual se evaluó el impacto de la formación de los egresados del programa de formación objeto del estudio de caso; capítulo III, explica el origen de los datos y metodología empleada para su análisis; capítulo IV, aborda el análisis y resultados del trabajo realizado; y finalmente, el capítulo $\mathrm{V}$, expone las conclusiones y recomendaciones de la investigación. 


\section{Capítulo I}

\section{Marco teórico y estado del arte}

\subsection{Marco teórico}

El ser humano en su continuo proceso generador de interrogantes y de la manera como resolver los mismos, puede en su devenir llegar a estar cargado de interés e incluso preocupación y de hecho, esto es una forma de validación en la relación hombre y universo que desde luego, puede permitir enfrentar esa relación según la complejidad y amplitud del momento histórico en que se encuentra la humanidad Tobón (2015). Esto amerita una reorientación de los procesos formativos independientemente de sus niveles, básico, técnico, tecnológico, universitario e incluso posgradual en un mundo que está direccionado hacia la globalización, complejidad y búsqueda de un futuro sostenible, que nos exige indagar y aplicar con acierto nuevas perspectivas encaminadas hacia el desarrollo humano integral, ya que de ello dependen muchas de las posibilidades de mejora de la calidad de vida de millones y millones de seres humanos.

A su vez la formación como proceso debe estar relacionada natural $\mathrm{y}$ metodológicamente con la investigación, con las formas de proyectar las políticas públicas en materia educativa en espacios institucionales y desde luego con la articulación de estrategias curriculares en escenarios reales de aprendizaje Bachelard (1993).

Cabe resaltar como se mencionó anteriormente, que la formación como proceso tiene implicaciones prácticas dentro y fuera del aula, y a través de ella se puede llegar a modificar 
la relación entre los seres humanos, e incluso a establecer diferencias sobre todo conceptuales y prácticas acerca de la manera como se deben establecer relaciones sociales de producción y desde luego de supervivencia. Los procesos formativos deben entonces, estar mediados por elementos favorecedores de convivencia y supervivencia en una sociedad NISIS (1997).

Para el caso de Colombia C.P. (1991), la formación se establece por intermedio de una directriz institucional estatal amparada en la Carta Magna de nuestro país. Precisamente, el establecimiento de la educación como derecho y como servicio público con función social, permite al proceso formativo catalogarse con una función social y desde luego se puede llegar a establecer en el caso colombiano y desde luego, en un porcentaje significativo del resto de países del mundo y en especial de Latinoamérica que el acceso al conocimiento debe contar con carácter ético y de idoneidad tanto para los formadores como los formados.

Ahora bien, la formación como elemento constitutivo del proceso de aprendizaje es un asunto complejo que involucra un gran número de factores. Es un acto personal e individual que permite al aprendiz transformar la información que recibe desde el entorno en conocimiento, entendido este como la inserción introspectiva de la información, con un carácter significativo en sus estructuras mentales García, Rodríguez \& Forero (2018). Por ello, el aprendizaje pueda considerarse como el resultado de la integración de nueva información en las estructuras mentales del individuo, que inicialmente no estaban ligadas entre sí, formando una nueva estructura que permite procesar más información. 
En algunos países la relación entre las empresas y el sector formativo independientemente del nivel en que se ejerza, ha originado un cierto clima de inconformidad, por el tipo de formación y su consonancia con los actuales requerimientos del mundo del trabajo. Es posible entonces, que las familias y los propios jóvenes presenten cierta disconformidad que puede estar alterando su proyecto vital, Braslavsky (1999). Sin embargo, es la dinámica social y la interacción entre las diferentes instituciones lo que puede llegar a posibilitar un adecuado proceso formativo. Sin embargo, y de acuerdo con lo sostenido por Vessuri, "la difusión de nuevas tecnologías en el aparato productivo y en el sector servicios cambia las experiencias requeridas de los asalariados en direcciones que aún son objeto de debates". (Vessuari, 1993, p.1).

En tal sentido, se debe reconocer que el docente del siglo XXI, que se desempeña en instituciones como el SENA debe mínimamente configurarse como un profesional atento a todas las posibilidades para hacer atractivo el proceso de enseñanza-aprendizaje. Igualmente debe consolidarse como un profesional capaz de reflexionar críticamente, acerca de su propia práctica pedagógica en busca de guiar a sus estudiantes al logro de competencias necesarias para la inserción en la sociedad, la cual, por supuesto está en permanente evolución, y que además exigen entre otras, competencias docentes que se configuran desde lo humano y lo profesional Arteaga, Meneses, \& Luna (2015). Por tanto, se debe tener presente que el proceso de enseñanza produce transformaciones sistemáticas en los individuos, de manera gradual y ascendente, convirtiéndolo en un proceso progresivo, dinámico y transformador. A su vez, el aprendizaje es un proceso de naturaleza compleja, cuya esencia es la adquisición de un nuevo conocimiento, habilidad o capacidad; en este caso particular, el desarrollo de estrategias didácticas como competencia docente. 


\subsection{Estado del arte}

Actualmente en Colombia, todos los programas tecnólogos ofertados por instituciones de educación, deben contar con registro calificado dado que es un requisito obligatorio del Ministerio de Educación Nacional. Y además deben tener pertinencia social, esta se refiere a la congruencia, orientación, vinculación, inherencia, oportunidad; para las universidades la pertinencia es un principio donde se fundamenta su responsabilidad social.

Uno de los indicadores para medir la calidad de la formación de estos programas es la aplicación de pruebas de conocimiento conocidas como pruebas saber pro en la que se evalúan aspectos como: comprensión lectora, comprensión escrita, inglés, solución de problemas, entendimiento interpersonal y pensamiento crítico. Como se evidencia, en esta prueba no se identifica ningún aspecto relacionado con el mercado laboral en el cual los estudiantes se desempeñan o con la satisfacción de los mismos sobre el programa, al igual que la pertinencia del mismo con el respectivo sector productivo; limitando la evaluación solamente a aspectos técnicos, y aptitudinales de los estudiantes.

El Ministerio de Educación Nacional en su proyecto "Fortalecimiento de la educación técnica y tecnológica” en el período 2005-2009, buscó fortalecer la educación técnica y tecnológica mediante el mejoramiento de la cobertura, calidad y pertinencia de este tipo de formación de tal forma que estuviera más acorde con las necesidades del sector productivo y el desarrollo nacional y regional. Para esto, se impulsó la creación de alianzas estratégicas entre sectores productivos, instituciones de educación media y superior, gobiernos locales y 
regionales, así como otros aliados como el Servicio Nacional de Aprendizaje SENA, en las que se trabajó la modificación de programas técnicos profesionales en la educación media o superior, con un diseño curricular basado en competencias para responder a las necesidades de los sectores productivos estratégicos del país: agroindustrial, Agropecuario, industrial, software y turismo (Ministerio de Educación Nacional, 2006).

Se establecieron como alianzas pioneras: Alianza Software; Alianza Tecnológica en Información y Telecomunicaciones; Alianza Logística Portuaria y Operación de Transporte Multimodal; Alianza Acuícola y Alianza Agroindustrial y Forestal con las que se buscaban sectorizar saberes específicos para satisfacer necesidades del país en diferentes zonas (Ministerio de Educación Nacional, 2008).

En ese mismo orden de ideas, el Plan Nacional de Desarrollo "Pacto por Colombia, Pacto por la Equidad” 2018 - 2022 establece que en cuanto a modernización y coordinación institucional se debe consolidar un arreglo institucional para el fomento de la CTeI, Colciencias, la Presidencia de la República, el Departamento Nacional de Planeación (DNP) y el Departamento Administrativo de la Función Pública (DAFP), en coordinación con las entidades, proponen liderar el ajuste de la estructura organizacional y de la oferta de instrumentos en Ciencia Tecnología e Innovación (CTeI) de Colciencias, el Ministerio de Educación, el Servicio Nacional de Aprendizaje (SENA), y demás entidades involucradas. Todo este ajuste se realizará a partir de una división funcional que tenga en cuenta los lineamientos derivados del enfoque de presupuesto orientado a resultados, las recomendaciones del Banco Mundial sobre análisis de gasto público, del Programa Colombia 
+ Competitiva sobre la gobernanza del SNCI y de órganos consultivos, como el Comité Ejecutivo del SNCI. Berrio, Espitia, Ferrari, González, Hernández, Tassara, \& Zafra (2020).

La presentación de una secuenciación cronológica acerca de la diversidad de estudios acerca de la evaluación del SENA en términos de su contribución al aumento o construcción del capital social de los egresados de la institución se inicia en el año 2007 con la investigación acerca de la evaluación de la incidencia que tiene el Servicio Nacional de Aprendizaje SENA sobre las personas que han desarrollado cursos largos en variables indirectas y directas que capturan la acumulación de capital social.

Durante el año 2008 el SENA estableció un convenio de cooperación técnica con Fedesarrollo que tuvo como objetivo el diseño de una metodología de evaluación de impacto para cuatro de sus principales programas: Formación de Técnicos y Tecnólogos (FT-T), Formación Especializada del Recurso Humano Vinculado a las Empresas (FE), Innovación y Desarrollo Tecnológico con el Medio Externo a la Entidad (IDT) y Jóvenes Rurales Emprendedores (JRE) Steiner, Rojas, \& Millán (2010)..

De la misma manera la investigación realizada por García (2016) evaluó el impacto del programa Jóvenes Rurales Emprendedores del Sena (JRE). A través de la metodología Propensity Score Matching (PSM), se encontró que participar de cursos del programa de JRE tiene efectos positivos en el ingreso laboral por hora de los egresados. Adicionalmente, los graduados presentan una mayor probabilidad de conseguir empleo entre un 13 y $14 \%$ 
comparado con el grupo de control. En síntesis, el programa JRE ha tenido impactos positivos en áreas importantes relacionadas con las condiciones laborales de sus beneficiarios, que se destaca por el hecho que va dirigido a personas de zonas rurales y de origen en los segmentos más vulnerables de la población.

Dentro de la misma línea evaluativa Camargo \& Rivera Lázaro (2019), evaluaron la ejecución del programa Jóvenes Rurales Emprendedores que en el período del año 2012 al año 2015, adelantó en el departamento de Boyacá en el Centro de Desarrollo Agropecuario y Agroindustria CEDEAGRO, esto desde la perspectiva de emprendimiento rural, el desarrollo sostenible local, la migración en las comunidades, la empleabilidad juvenil y la incorporación de la población vulnerable a actividades económicas agropecuarias y agroindustriales, en los municipios donde hizo presencia el SENA a través de este programa.

\section{Capítulo II}

\section{Situación de Contexto}

La comprensión del sistema educativo de cualquier nación, implica el conocimiento de su contexto social y económico, considerando que los cambios en la educación a lo largo de la historia se han visto acompañados de cambios políticos y económicos (Belth, 1971). La evolución de la percepción de la educación permitió su entendimiento como un derecho fundamental del ser humano el cual debe ser respetado y promovido por todos los Estados (ONU, 1948), pasó de ser vista como mecanismo para la conservación de los estratos sociales 
hasta llegar a un ser concebida como estrategia para garantizar la igualdad de oportunidades (Rodríguez Martínez, 2006). En este capítulo, inicialmente se muestran las generalidades del departamento de Córdoba por la naturaleza del trabajo y además, se realiza un recorrido sobre la evolución normativa del sistema educativo en Colombia, enfatizando y describiendo cada uno de los niveles que la conforman.

\subsection{Generalidades del departamento de Córdoba}

El departamento de Córdoba, se encuentra localizado en el norte de la región caribe colombiana, con una extensión territorial de $23.980 \mathrm{~km} 2$, un total de treinta (30) municipios y una población de 1'838.371 (2020 p) de habitantes. De acuerdo con el informe del Consejo de Competitividad 2019, el puntaje alcanzado por el Departamento alcanzó la calificación de 4.5 ocupando el puesto 22 de 33 departamentos incluidos y analizados en el informe. Conforme a la composición sectorial del PIB al cierre del 2018 el tercer renglón de la economía corresponde al de la ganadería, agricultura, pesca y silvicultura, con una participación de 10,5 frente a un 6 que representa este sector a nivel nacional.

El Departamento cuenta con un área total de 2’485.549,86 hectáreas (Gobernación de Córdoba, 2010), cuya distribución por uso potencial (Ver Gráfico No1. Distribución Porcentual por Uso Potencial de Suelo) registra que un 39,72\% corresponde a uso agroforestal, 23,29\% agrícola, 15,98\% manejo especial, 10,53\% ganadero, 7,41\% forestal, $2,15 \%$ cuerpos de agua, $0,55 \%$ conservación de suelos y el $0,39 \%$ para otros usos. 


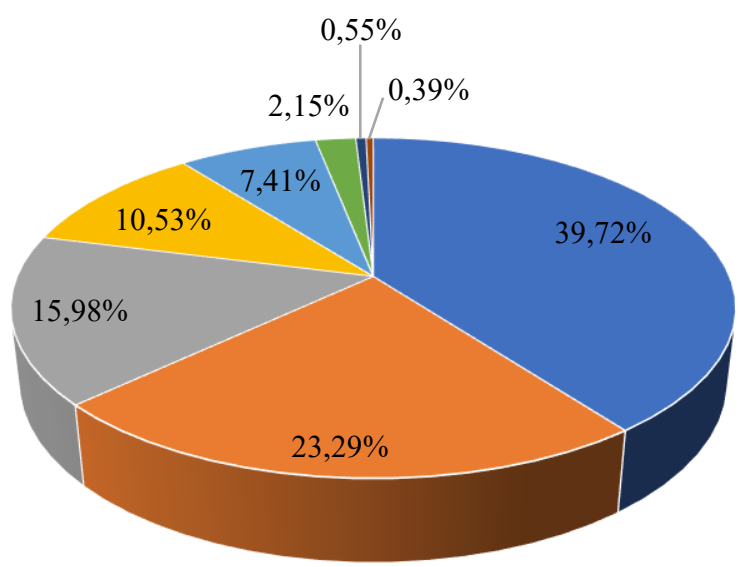

- AGROFORESTAL

- MANEJO ESPECIAL

- FORESTAL

- CONSERVACIÓN RECUPERACION
- AGRICOLA

- GANADERO

- CUERPOS DE AGUA

- OTROS USOS

No 1. Distribución porcentual por uso potencial del suelo

Fuente: Elaboración propia a partir de datos de mapas de tipología de suelos de Agustín Codazzi

Si bien en el gráfico anterior se muestra la distribución porcentual por uso potencial del suelo en el Departamento, es importante, establecer la potencialidad productiva, identificada por aquellos tipos que representen posible utilidad para el desarrollo de actividades productivas, desde esta óptica, se tiene que en el 74,26\% es posible la realización de actividades agropecuarias, el $25,74 \%$ son suelos destinados a otros tipos de uso incluidos los centros poblados. La distribución porcentual indica que el 53,49\% del suelo que podría ser empleado en actividades productivas del Departamento puede ser desatinado a actividades agroforestales, $31,37 \%$ a actividades agrícola, 14,17\% actividades ganaderas y el 0,97\% a actividades forestales (Ver Gráfico No 2. Distribución porcentual por uso potencial de suelo en actividades productivas). 


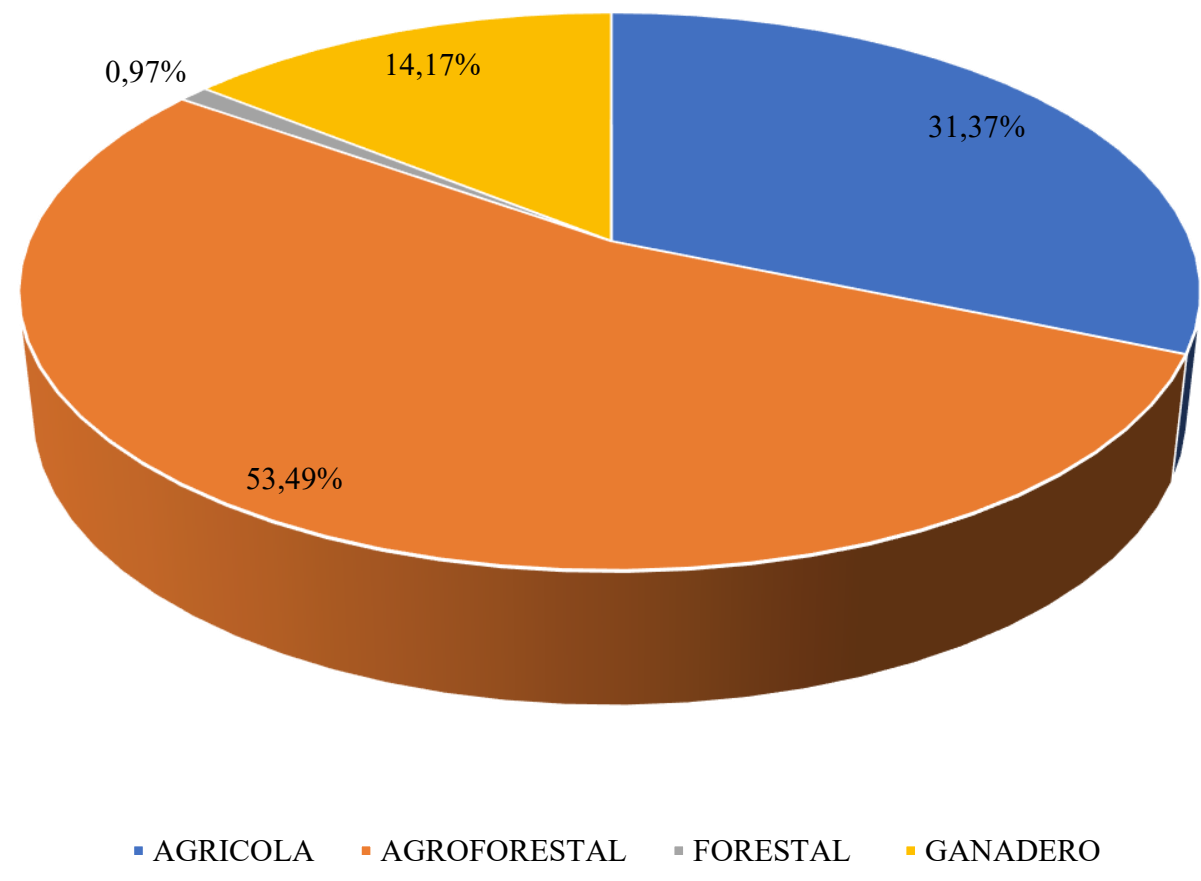

No 2. Distribución porcentual por uso potencial de suelo en actividades productivas Fuente: Elaboración propia a partir de datos de mapas de tipología de suelos de Agustín Codazzi

En cuanto a los cuerpos de agua que representan un 2,15\% (53337,68 ha) del área total del Departamento corresponden a embalses, lagunas, pantanos y ciénagas, los cuales, a pesar de tener un potencial productivo por la disponibilidad y posibilidad para la pesca, no son incluidos por la poca disponibilidad de información que permita verificar la producción acuícola.

Finalmente, en lo que respecta a la distribución de las actividades productivas del departamento el siguiente gráfico (gráfico No 3) muestra la participación porcentual por rama de actividad dentro del PIB del Departamento: 


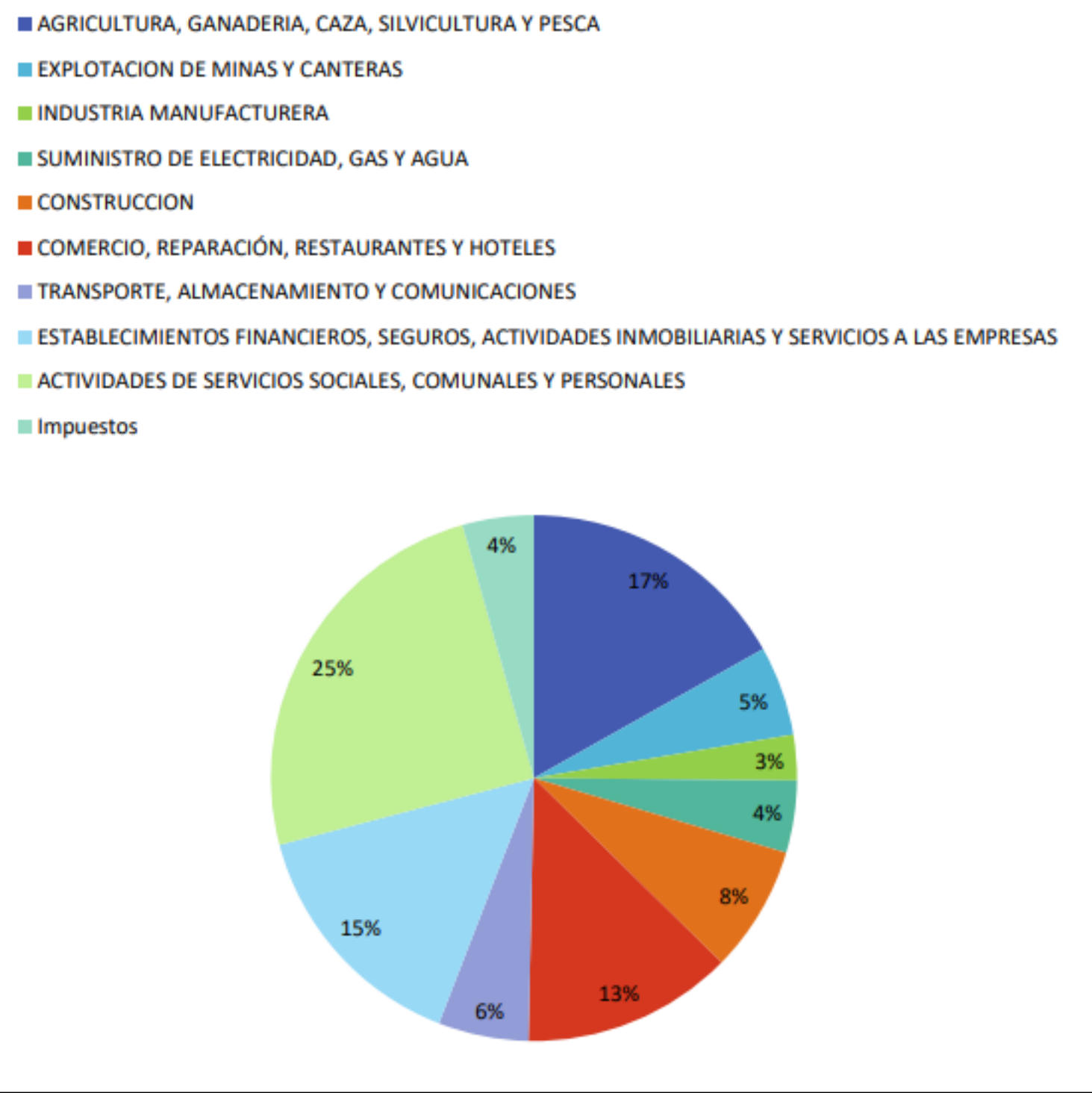

No 3. Distribución porcentual de las actividades productivas del departamento de Córdoba. Fuente: (Cámara de Comercio de Montería, 2017)

Como se puede observar en el gráfico No 3, las principales actividades corresponden a actividades de servicios sociales, comunales y personales (25\%), agricultura, ganadería, caza, silvicultura y pesca $(17 \%)$, establecimientos financieros, seguros, actividades inmobiliarias y servicios a las empresas $(15 \%)$ y comercio, reparación, restaurantes y hoteles $(13 \%)$. 


\subsection{Sistema Educativo Colombiano}

En Colombia, la constitución política establece los fundamentos de la naturaleza del servicio educativo mediante el artículo 67, el cual señala: “La educación es un derecho de la persona y un servicio público que tiene una función social; con ella se busca el acceso al conocimiento, a la ciencia, a la técnica, y a los demás bienes y valores de la cultura...corresponde al Estado regular y ejercer la suprema inspección y vigilancia de la educación con el fin de velar por su calidad, por el cumplimiento de sus fines y por la mejor formación moral, intelectual y fisica de los educandos; garantizar el adecuado cubrimiento del servicio y asegurar a los menores las condiciones necesarias para su acceso y permanencia en el sistema educativo. La Nación y las entidades territoriales participarán en la dirección, financiación y administración de los servicios educativos estatales, en los términos que señalen la Constitución y la ley".

Hasta 1880 los asuntos educativos eran atendidos mediante la Secretaría del Exterior, con la entrada en vigencia de la Ley $10^{\mathrm{a}}$ de 1880 el congreso de los estados unidos de Colombia realiza la creación de siete secretarías de estado entre las cuales se encontraba la Secretaría de Instrucción Pública que en adelante se encargaría de las funciones educativas (Ministerio del Gobierno Colombiano, 1880); el 25 de agosto mediante la Ley 7 de 1886, el consejo nacional legislativo decreta la división del despacho administrativo del gobierno en ocho (8) ministerios incluyendo el Ministerio de Instrucción Pública (Ministerio del Gobierno Colombiano, 1886); a partir de junio de 1923, el nombre del Ministerio de Instrucción Pública cambia a Ministerio de Instrucción y Salubridad Pública y, el 10 de noviembre con la disposición de la Ley 56 de 1927 durante la presidencia de Miguel Abadía 
Méndez se le identifica con el nombre de Ministerio de Educación Nacional (MEN), nombre que se ha mantenido vigente hasta la actualidad.

De acuerdo con el artículo 1 de la Ley 115 de 1994, la educación en Colombia es: “un proceso de formación permanente, personal cultural y social que se fundamenta en una concepción integral de la persona humana, de su dignidad, de sus derechos y de sus deberes, conformado por: la educación inicial, la educación preescolar, la educación básica (primaria cinco grados y secundaria cuatro grados), la educación media (dos grados y culmina con el título de bachiller.), y la educación superior" (Congreso de la república de Colombia, 1994,p.1)

La conformación de la educación en el país ha ido desarrollándose paulatinamente, desde 1980 con la expedición del Decreto 80, se organiza el sistema de educación postsecundaria, tomando en consideración que hasta esa fecha las instituciones que impartían la formación técnica lo hacían de manera informal, con expedición de la ley 115 de 1994 y ley 30 de 1992, se definen propiamente tres niveles principales de formación: la educación básica formal, la educación para el trabajo y la educación informal. En 1998, con el ánimo de dar forma a la educación para el trabajo, por medio del decreto 0641 el Ministerio de Educación crea la misión de Educación Técnica, Tecnológica y Formación Profesional (Ministerio de Educación Nacional, 1998), esta última modalidad entendida como la denomina el SENA desde su fundación en 1957. 
Mediante el CONPES 3527 de 2008, se establece la Política Nacional de Competitividad y productividad, dentro del cual fijó el plan de acción en educación y competencias laborales, con el fin estratégico de lograr el establecimiento de la educación técnica y tecnológica (Consejo Nacional de Política Económica y Social, 2008), y con la finalidad de lograr la articulación entre la educación y los sistemas productivos, en el 2016 mediante el Plan de Desarrollo Nacional 2016 - 2019, la MEN crea el Sistema Nacional de Educación terciaria - SNET, la cual en determinada forma mejorar la ruta de la formación profesional, incluyendo como pilares la educación técnica y la tecnológica superior. El SNET, genera dos rutas de educación correspondientes a la Educación Universitaria y a la Formación Profesional (técnica) diferenciadas por la orientación académica u ocupacional (Uriel \& Cárdenas, 2016).

\subsubsection{Educación básica formal}

La educación básica formal, es definida en el artículo 10 de la Ley 115 de 1994, como: “... aquella que se imparte en establecimientos educativos aprobados, en una secuencia regular de ciclos lectivos, con sujeción a pautas curriculares progresivas, y conducente a grados y títulos" (Congreso de la república de Colombia, 1994), se encuentra conformada por niveles y subniveles (Figura 1) reglamentadas por la Ley 115 de 1994 y la Ley 30 de 1992. En sus distintos niveles, busca lograr que los estudiantes logren el desarrollo de sus conocimientos, habilidades, aptitudes y valores mediante los cuales las personas puedan fundamentar su desarrollo en forma permanente. 
En el caso de los niveles de preescolar, educación básica y educación media los ciclos de formación son medidos en grados ejecutados anualmente, a través de colegios y jardines con licencia de funcionamiento. El preescolar exige mínimo un grado de formación; la educación básica primaria y básica secundaria se desarrollan en cinco (5) y cuatro (4) grados respectivamente; y la educación media en dos (2) grados correspondientes a 10 y 11 grado.

La educación superior, se encuentra dividida en formación de pregrado y formación de posgrado con ciclos de formación semestral; en el primer caso, la formación se encuentra a cargo de las universidades, las instituciones de educación superior y el SENA, los subniveles que la constituyen son: formación técnica profesional, tecnológica y profesional; en el segundo caso, la formación es ejecutada a través de las Universidades y las instituciones de educación superior, sus subniveles corresponden a: especialización, maestría y doctorado. 


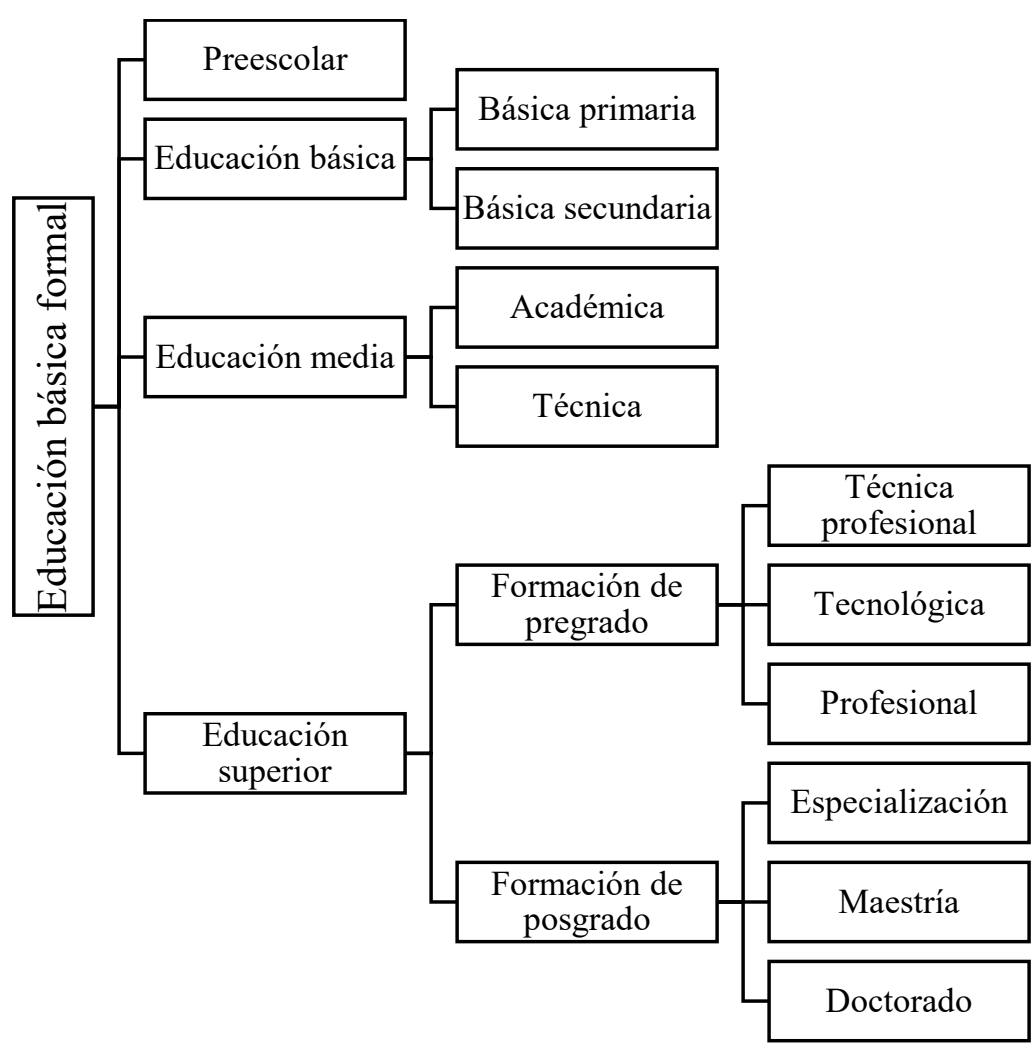

No 4. Esquema de la educación básica formal

Fuente: Elaboración propia a partir de la normatividad vigente

\subsubsection{Formación para el trabajo}

La formación para el trabajo y el desarrollo humano, se encuentra reglamentada por los decretos 2888 y 4904 de 2007; es entendida como un nivel de formación complementario, que aporta a las personas conocimientos en aspectos académicos o laborales, no está obligada a los grados de la educación formal, sin embargo, está regida por los currículos aprobados para cada programa por las secretarias de educación y deben ser cumplidos unos mínimos para obtener una certificación en este nivel (Ministerio de Educación Nacional de Colombia, 2007).

Se encuentra constituida por dos niveles (figura 2): el programa de formación laboral, que tiene por objetivo la preparación de las personas en áreas específicas de los sectores productivos y alcanzar el desarrollo de competencias laborales específicas, que faciliten la 
realización de actividades productivas de manera individual o colectiva; y el programa de formación académica, busca preparar a las personas para impulsar procesos de autogestión, de participación, de formación democrática y en general de organización del trabajo comunitario e institucional (Ministerio de Educación Nacional, 2007).
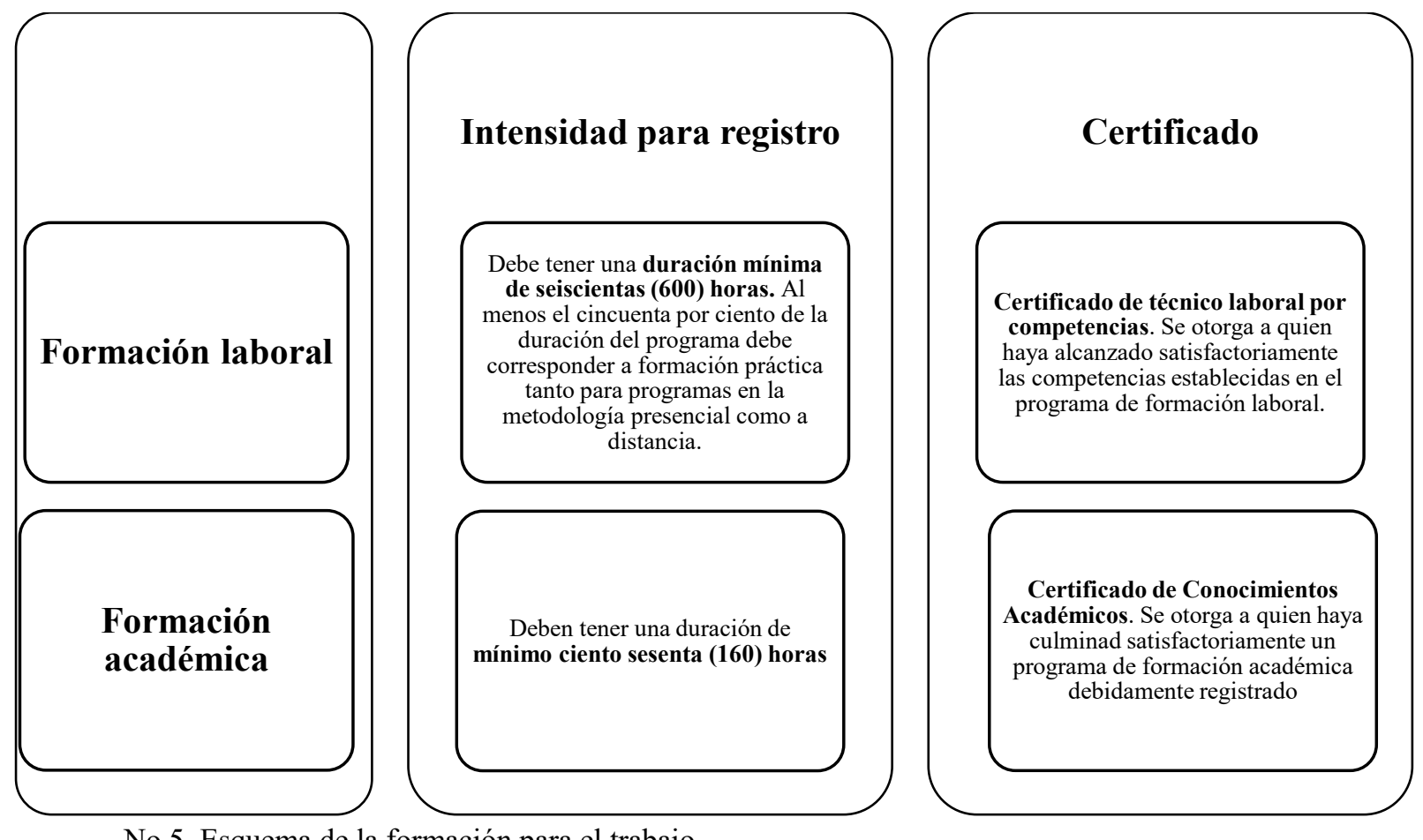

No 5. Esquema de la formación para el trabajo

Fuente: Elaboración propia a partir de la normatividad vigente

\subsubsection{Educación informal}

La educación informal, se encuentra reglamentada mediante el artículo 47 del Decreto 2150 de 1995, debe tener una duración inferior a ciento sesenta (160) horas, su organización, oferta y desarrollo no requieren de registro por parte de la secretaría de educación de la entidad territorial certificada y solo darán lugar a la expedición de una constancia de asistencia, sin embargo, la persona natural o jurídica que pretenda ofrecer cursos de educación informal, debe cumplir con los requisitos especiales establecidos por el respectivo municipio donde va a desarrollar el curso (Presidencia de la república colombiana, 1995). 


\subsection{Oferta de formación SENA}

El procedimiento para la planeación y publicación de la oferta indicativa (Servicio Nacional de Aprendizaje - SENA, 2013), tiene como objetivo establecer los lineamientos para realizar el alistamiento, publicación y divulgación de la oferta educativa del SENA, de acuerdo con las políticas y directrices institucionales establecidas, con el fin de divulgar las opciones de formación que ofrece la entidad.

1. Las actividades determinadas en este procedimiento se deben ejecutar estrictamente, dando cumplimiento a lo establecido en el calendario académico y de labores de la entidad y los cronogramas de cada convocatoria, así como, a lo programado en el plan operativo de cada Centro para las ofertas de formación. El responsable de las ofertas educativas es el subdirector del Centro

2. El SENA realiza convocatorias de oferta titulada y complementaria, abiertas y cerradas, publicadas a través del portal Web, de los programas en estado 'en ejecución' del catálogo nacional. Dichas convocatorias se definen de la siguiente forma:

Oferta Abierta de Formación Titulada, corresponde a los programas de formación en los niveles de: Auxiliar, Operario, Técnico, Tecnólogo, Profundización Técnica y Especialización Tecnológica. Se publica de acuerdo con la Resolución del Calendario Académico y de Labores de los Centros de Formación de cada vigencia. La oferta se definirá por las redes de conocimiento con los insumos que aporten los centros y tiene proceso de 
selección consistente en pruebas web aplicadas por los centros con apoyo de la Dirección de Formación de acuerdo con los requisitos de ingreso.

Concertar y planear la oferta: Generar para cada convocatoria la propuesta de oferta de formación del centro, basado en las necesidades sectoriales, planes de desarrollo regionales y locales, plan de acción anual de los Centros de Formación, y para los niveles que se requieran, aprobación del registro calificado. Presentar el proyecto de oferta de centro al director regional y los demás subdirectores de centro para la concertación y aprobación de la oferta regional.

Esto se basa en sendas circulares por parte de la Dirección de Formación del SENA, en donde se expresa "Planeación oferta e ingreso" y reiteran asuntos como:

- Los directores regionales y subdirectores de centro deberán liderar el estudio, presentación y aprobación de la "programación indicativa de formación titulada, orientándola al cumplimiento de la meta institucional.

- Los Centros de Formación tendrán la responsabilidad de formular el plan de la oferta institucional, para ello, debe construir una propuesta incorporando la visión del sector sectorial y regional.

- Los Centros de Formación analizan la pertinencia de la oferta a través de los siguientes insumos; Planes de desarrollo nacional, departamental y los municipales, estudio de identificación del cierra de brechas de capital humano, agendas de competitividad, planes de acción de políticas públicas económicas y sociales "CONPES”, estudios de diferentes sectores y ramas, en particular las aportadas por las mesas sectoriales, análisis ocupacional, en especial, los productos suministrados por el observatorio laboral, autoevaluación de los programas de formación, intereses del sector social (empleo digno 
y cualificación deseada), apuestas estratégicas nacionales y regionales, (megaproyectos y proyectos estratégicos que demandarán personal calificado), según condiciones particulares de una región. el sector y las capacidades de los centros de formación.

- Se debe tener en cuenta el comportamiento histórico de las inscripciones del mismo trimestre en los dos últimos años, buscando el cumplimiento de las metas de formación de la vigencia y los cupos nuevos proyectados por parte de los centros de formación.

\subsection{Sistema de acreditación de programas}

En Colombia, la acreditación corresponde a la forma como el estado da testimonio de la calidad de un programa o institución educativa, basado en un proceso de evaluación en la que interviene institución, las comunidades académicas y el Consejo Nacional de Acreditación (CNA) (Consejo Nacional de Acreditación, 2015).

De acuerdo con el artículo 53 de la ley 30 de 1992, el Sistema Nacional de Acreditación (SNA) es el conjunto de políticas, estrategias, procesos y organismos cuyo objetivo fundamental es garantizar a la sociedad que las instituciones de educación superior que hacen parte del sistema cumplen con los más altos requisitos de calidad y que realizan sus propósitos y objetivos.

En la figura 3, se muestran los componentes que conforman el SNA, la calidad se encuentra escalonada en dos niveles correspondientes a: el registro calificado es otorgado por la Comisión Nacional Intersectorial de Aseguramiento de la Calidad de la Educación Superior (CONACES), en un proceso regulado por la ley 118 de 2008 y el decreto 2566 de 2003, y que busca la verificación de las condiciones mínimas para la oferta y desarrollo de

programas académicos; y la acreditación de alta calidad, otorgada por la CNA, para iniciar 
este proceso la institución debe expresar la voluntad y demostrar el cumplimiento de las condiciones normativas, académicas y administrativas para su consecución.

El registro calificado es concedido inicialmente una vez se evidencien las condiciones mínimas de los programas de formación, son evaluadas considerando diferente componentes: condiciones del programa a nivel de investigación, innovación y creación artística, autoevaluaciones, bienestar universitario, contenidos curriculares, relaciones con el sector externo y medios educativos; entre varios aspectos, la renovación del registro debe tener en cuenta las fortalezas y evidenciar el desarrollo y madurez de un programa, así como las oportunidades de mejora, planes de mejoramiento y su ejecución, conservando a relación con el sector externo y considerando los aporte de los egresados y del sector empleador como parte de la validación de pertinencia del programa en el medio (Ministerio de Educación Nacional, 2013).

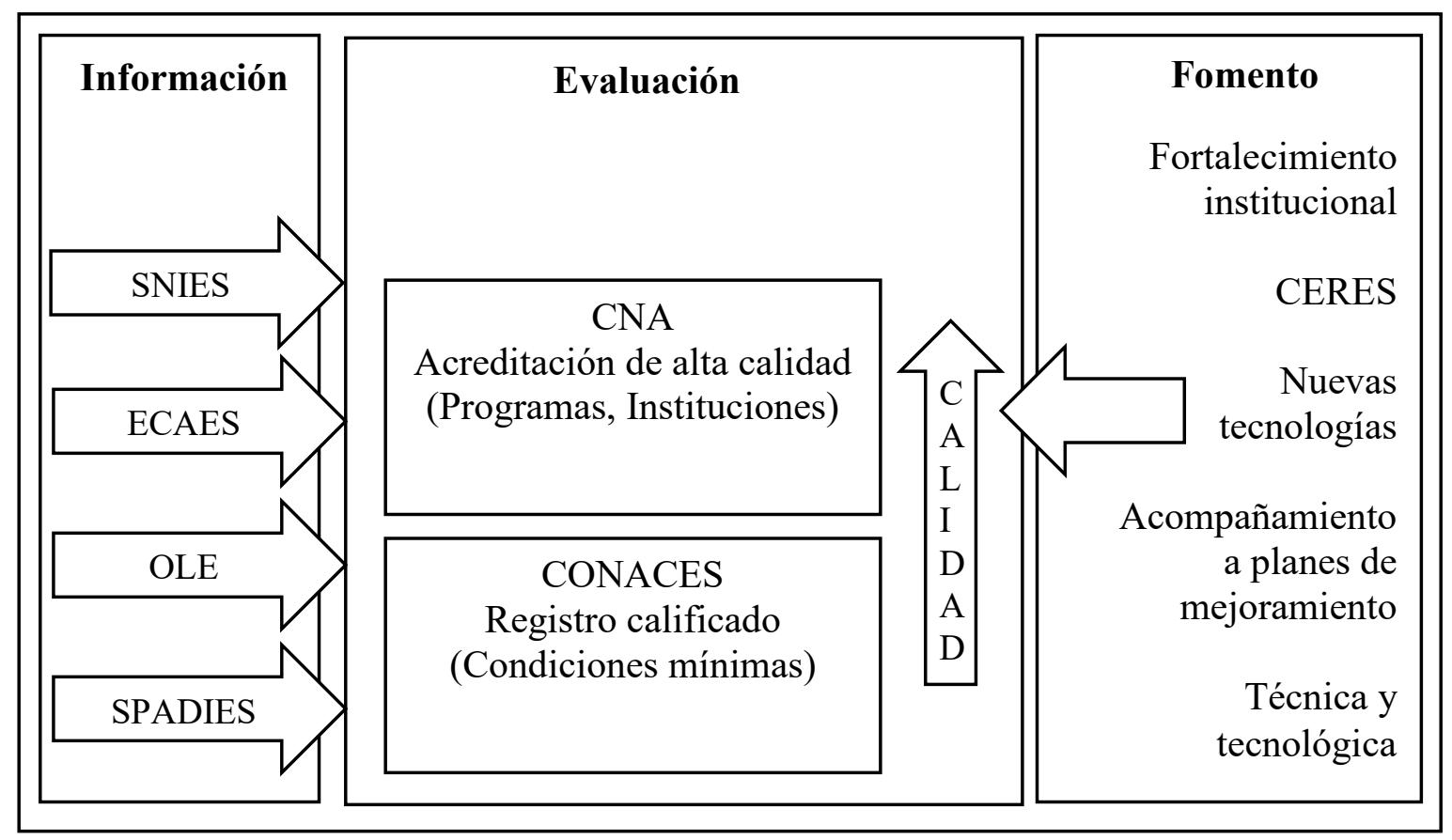

No 6. Sistema de acreditación nacional Fuente: (Consejo Nacional de Acreditación, 2015) 
Finalmente, es válido indicar que el sistema de acreditación tiene efecto o aplicabilidad sobre la formación superior (figura 1), con lo cual las universidades, las instituciones de educación superior y el SENA encargadas de impartir la formación deben cumplir con los requerimientos normativos en materia de calidad, en el caso del SENA aplica sobre aquellos programas de formación incluidos en este nivel y no los que corresponden a formación para el trabajo. 


\section{Capítulo III}

\section{Enfoque metodológico}

\subsection{Objetivo general}

Determinar la pertinencia del programa tecnólogo en producción ganadera que ofrece

el Centro Agropecuario y de Biotecnología "El Porvenir" del SENA para el sector Agropecuario del departamento de Córdoba, desde la perspectiva de empresarios y egresados del programa en el período 2015 - 2018 .

\subsubsection{Objetivos específicos}

- Identificar el nivel de empleabilidad de los egresados del programa tecnólogo en producción ganadera ofertado por el Centro Agropecuario y de biotecnología "El Porvenir" del Servicio Nacional de Aprendizaje SENA frente a los parámetros establecidos en el Plan Nacional de Desarrollo Pacto por Colombia, Pacto por la Equidad” 2018 - 2022.

- Describir la inserción de egresados del programa de formación en el mercado laboral Agropecuario del departamento de Córdoba

- Establecer el impacto generado por la inserción de Tecnólogos Profesionales del SENA en Empresas Agropecuarias del departamento de Córdoba.

- Describir el nivel de satisfacción de empresarios y egresados sobre el programa de formación.

- Describir la contribución del programa de formación sobre la calidad de vida de los egresados. 


\subsection{Metodología}

\subsubsection{Delimitación del estudio}

Se considera la población de egresados del programa de formación Tecnólogos en Producción Ganadera del Centro Agropecuario y de Biotecnología en el periodo comprendido entre 2015 y 2017, los cuales corresponden a un total de 73 aprendices certificados en el periodo, esta deferencia deriva del objetivo general del trabajo de investigación propuesto. Sin embargo, es preciso indicar, que el cuestionario posibilita su ajuste y utilización para trabajos futuros que permitan la evaluación de programas u horizontes temporales diferentes.

De otra parte, en lo que corresponde al análisis del desempeño y grado de incidencia e importancia para los empresarios de los egresados del Centro, se considera un total de 45 empresas que durante el periodo de estudio emplearon aprendices de este programa de formación titulada.

En lo referente a la delimitación espacial, se circunscribe al programa de formación ofertado en el Departamento de Córdoba, dado que la medición se realiza sobre el programa ofertado por el Centro Agropecuario y de Biotecnología El Porvenir; se hace importante indicar que en el caso de las empresas la delimitación no se circunscribe al departamento tomando en consideración que estas se encuentran en cualquier lugar del país que han contratado egresados. 


\subsubsection{Tipo de Investigación}

Con el fin de lograr el desarrollo de los objetivos, la investigación considerada correspondió al tipo descriptivo, la cual consiste en la recopilación de datos que describen los acontecimientos y luego organiza, tabula, representa y describe la recopilación de datos (Glass \& Hopkins, 1996), por su parte, Hernández, Fernández y Baptista (2010), señalan: "los estudios descriptivos buscan especificar las propiedades, las características y los perfiles de personas, grupos, comunidades, procesos, objetos o cualquier otro fenómeno que se someta a un análisis".

Conforme al tratamiento de la información, se consideró un estudio mixto, que integra las técnicas documentales, las cuantitativas y las cuantitativas; en el primer caso, se toman los históricos del Centro de formación e información suministrada por Administración Educativa; en el segundo caso, distintas aplicaciones de encuestas según las variables que motivan la investigación; y en el último caso, entrevistas y grupos focales, según las categorías de indagación.

La selección de estudio mixto, se debió a que la medición del impacto de los egresados y sus características, implica no sólo el conocimiento sobre variables específicas, sino que, además, debe hacerse lectura de las tendencias e históricos de las bases de datos. La mezcla de las técnicas cualitativas y cuantitativas, facilita el recorrido metodológico teniendo un acercamiento de una parte sobre la aplicación de estadísticas que permitan la descripción de las tendencias generales y de otra parte la utilización de grupos focales para entender el fenómeno social desde la perspectiva de los egresados y la forma en que interactúa con el contexto (Galeano, 2004). 


\subsubsection{Consideraciones para determinar el tamaño de la muestra}

A continuación, se describen las especificaciones consideradas para el establecimiento de la muestra de las encuestas.

\subsubsection{Encuesta Aprendices}

Como se señaló anteriormente, la población corresponde a un total de 73 aprendices, con el fin de lograr una validez estadística se toma en consideración un nivel de confianza del $95 \%$ y margen de error del 4,5\%, sin dejar de lado, que el esfuerzo y realidad de este trabajo en relación al contacto con los egresados toma en cuenta los siguientes aspectos:

- Del total de egresados, se desconoce el total de desconectado de los sistemas de información o de comunicación con el SENA.

- Al momento de la graduación, no se actualizaron los correos electrónicos y teléfonos.

- El seguimiento en tiempo real es complejo, dado que tecnológicamente no se cuenta con las herramientas que posibiliten la actualización continua de los datos, lo cual se encuentra supeditado a la voluntad de los egresados de contribuir con los registros

- Dificultad para el acceso a los registros públicos y/o privados de información, considerando la determinación en materia de protección de la información por parte del Estado

- La movilidad de los egresados, tanto de los sitios de residencia como de los lugares de trabajo y variación en las relaciones inmediatas, dificultan la interacción con el Aprendiz. 
Para calcular el tamaño de la muestra se empleó la siguiente fórmula, teniendo en cuenta que la muestra es finita:

$$
n=\frac{N * Z^{2} * p * q}{e^{2}(N-1)+Z^{2} * p * q}
$$

Donde:

n: representa el tamaño de muestra

Z: representa el nivel de confianza

e: constituye el error de muestreo. Normalmente este valor oscila entre $\pm 4 \% \mathrm{y} \pm 10 \%$.

En este caso se utilizó un valor de 4,5\%.

p: es la probabilidad a favor $(50 \%)$

q: es la probabilidad en contra $(50 \%)$

$\mathbf{N}$ : Es el tamaño total de la población

Para la investigación propuesta, el tamaño de la muestra es el siguiente:

$$
n=\frac{73 *(1.96)^{2} * 0.5 * 0.5}{(0.045)^{2}(73-1)+(1.96)^{2} * 0.5 * 0.5} \cong 63
$$

Conforme a la fórmula estadística el tamaño de la muestra corresponder a 63 , lo cual implica que se tendrán que aplicar un total de 63 encuestas del total de egresados.

\subsubsection{Encuesta Empresarios}

Conforme a la información suministrada por la Oficina de Administración Educativa del Centro Agropecuario y de Biotecnología El Porvenir, durante el periodo de estudio se 
encontraban suscritas 45 empresas del Sector relacionadas al programa de formación Tecnólogos en Producción Ganadera, la relación con las misma se ha conservado hasta la actualidad, lo que posibilitó el desarrollo y aplicación de la encuesta.

De forma análoga con lo desarrollado con los aprendices, para calcular el tamaño de la muestra se empleó la siguiente fórmula, teniendo en cuenta que la muestra es finita:

$$
n=\frac{N * Z^{2} * p * q}{e^{2}(N-1)+Z^{2} * p * q}
$$

Donde:

n: representa el tamaño de muestra

Z: representa el nivel de confianza

e: constituye el error de muestreo. Normalmente este valor oscila entre $\pm 4 \% \mathrm{y} \pm 10 \%$.

En este caso se utilizó un valor de 4,5\%.

p: es la probabilidad a favor $(50 \%)$

Para la investigación propuesta, el tamaño de la muestra es el siguiente:

$$
n=\frac{45 *(1.96)^{2} * 0.5 * 0.5}{(0.045)^{2}(45-1)+(1.96)^{2} * 0.5 * 0.5} \cong 41
$$

Considerando el valor de $n$ calculado, se envía la encuesta a la totalidad de empresarios y la valides de los resultados se lograría con al menos un total de 41 encuestas. 


\section{Capítulo IV}

\section{Análisis y resultados}

\subsection{Nivel de empleabilidad de los egresados del programa tecnólogo en producción}

ganadera ofertado por el Centro Agropecuario y de biotecnología "El Porvenir" del Servicio Nacional de Aprendizaje SENA frente a los parámetros establecidos en el Plan Nacional de Desarrollo Pacto por Colombia, Pacto por la Equidad" $2018-2022$.

Según la Organización Internacional del Trabajo (OIT), la empleabilidad es un concepto que engloba "la aptitud de la persona para encontrar y conservar un trabajo, para progresar en el trabajo y para adaptarse al cambio a lo largo de la vida profesional"

En tal sentido, la empleabilidad integra varios aspectos como la capacidad personal para encontrar empleo y para adaptarse al mercado laboral de tal manera que se evite el desempleo, esto es la capacidad o condiciones para mantener la continuidad en el trabajo de su área de conocimiento; por lo anterior en el presente estudio, para analizar la empleabilidad se analizarán aspectos relativos a las oportunidades laborales y su tiempo de permanencia en un determinado puesto laboral conforme se espera en el marco de las políticas de desarrollo de los entes territoriales.

Desde estas perspectivas teóricas, la empleabilidad depende no solo de la formación expresada en conocimientos y cualificaciones, sino también de los comportamientos tenga el 
trabajador, del modo que la persona se sirve de ellos y de cómo presenta sus potencialidades y requerimientos al empresario.

El primero de estos indicadores es la oportunidad de acceder a un empleo; la cual en el presente estudio ha sido medida con base en el tiempo que transcurrió entre la graduación y el primer empleo. Los resultados permiten identificar que $68.42 \%$ de quienes han conseguido trabajo $(\mathrm{n}=38)$ lo han hecho en menos de tres meses del egreso; 10,53\% entre 3 a 6 meses, $5.26 \%$ de 7 a 9 meses, de 10 a 12 meses y más de 12 meses obtuvieron 15,79\% respectivamente (Figura No 4). CARBIAR ESTA FIGURA

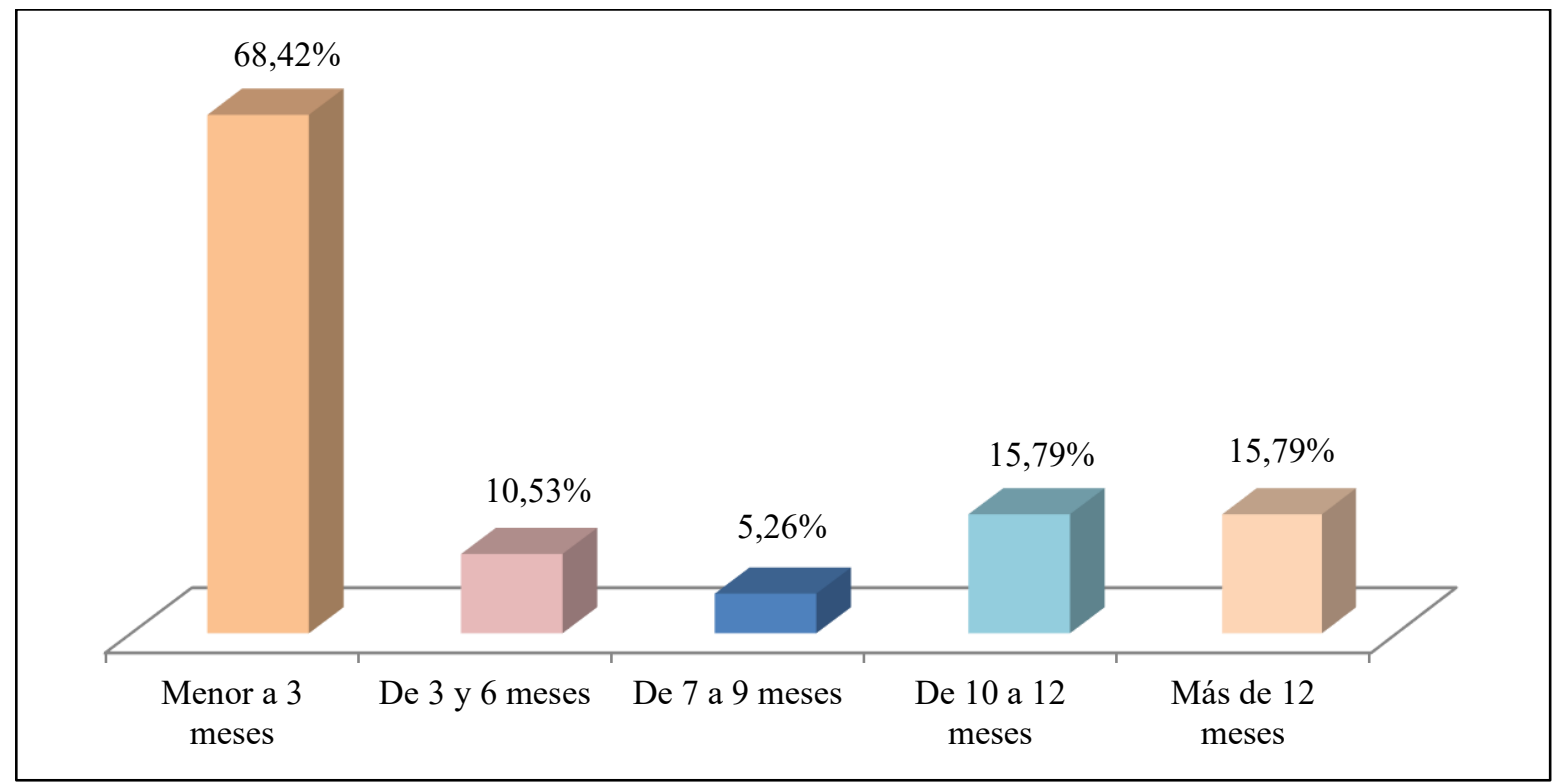

Figura No 7. Empleabilidad: oportunidad del primer empleo

Fuente: Elaboración propia, con datos de la entrevista.

Al dimensionar esta misma información conforme el procedimiento definido en la metodología tomando en consideración los datos de quienes se han mantenido en situación laboral activa $(\mathrm{n}=38)$ se puede apreciar que la empleabilidad en el área de la Tecnología en Producción Ganadera es alta el obtener 78.95\% de egresados en situación laboral activa que 
han conseguido su primer empleo en el área entre los primeros 6 meses del egreso del programa analizado (Figura No 5).

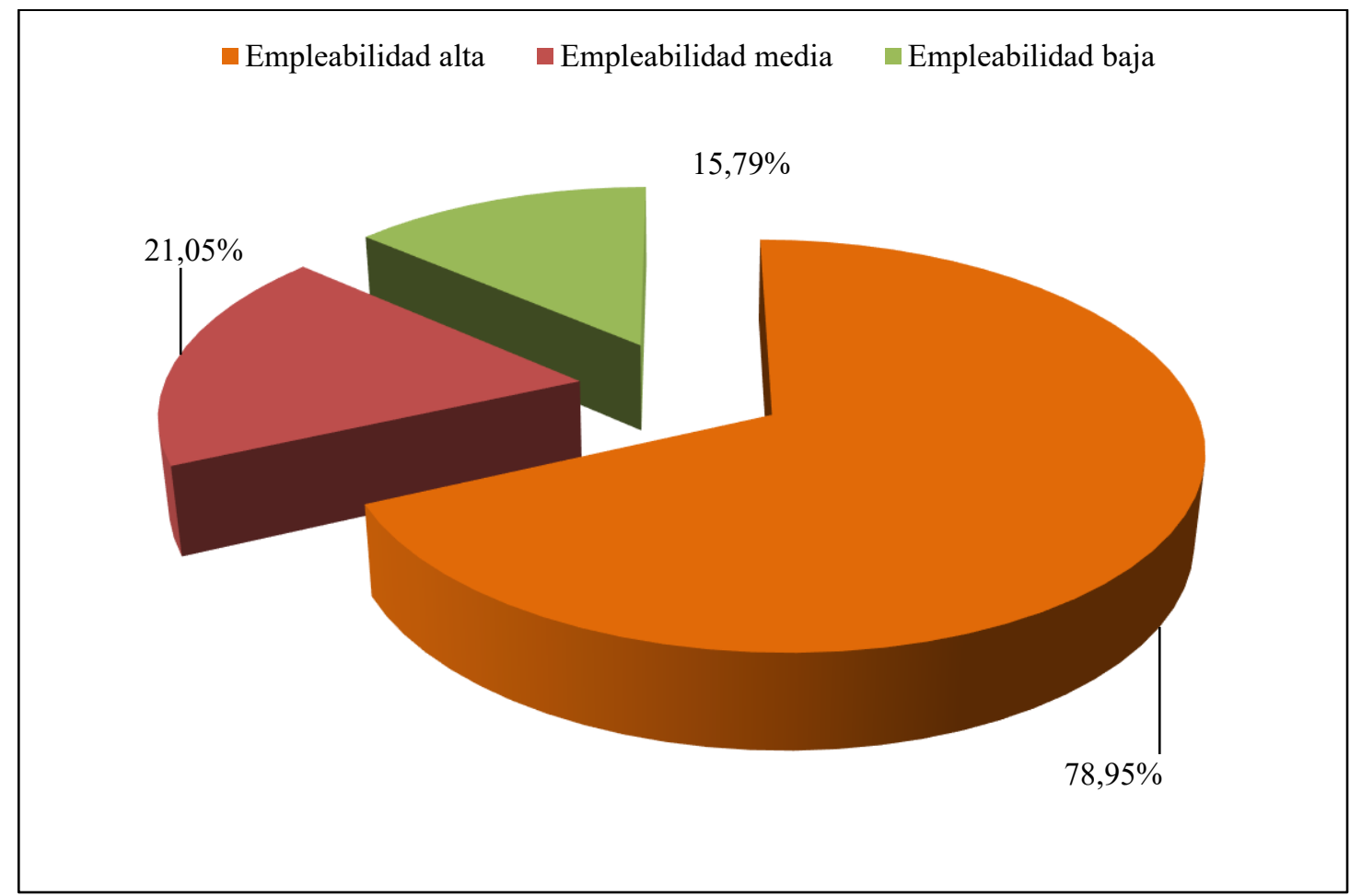

Figura No 8. Nivel de empleabilidad de los egresados en situación laboral activa Fuente: Elaboración propia, con datos de la entrevista.

La empleabilidad para el resto de la muestra se mantuvo en nivel medio $(21.05 \%)$ al transcurrir entre 7 y 12 meses y $15.79 \%$ baja al igualar o superar los 13 meses. Recordando que quienes se encuentran clasificados en "Situación laboral activa" son aquellos graduados que están buscando activamente empleo.

La situación laboral ha sido contrastada con el tipo de actividad misional de las empresas en las cuales se desempeñan, obteniéndose como resultados de interés que la actividad laboral del $42.86 \%$ tiene relación directa con la formación recibida en el Programa Tecnología en Producción Ganadera el Centro Agropecuario y de Biotecnología "El Porvenir” del Servicio 
Nacional de Aprendizaje SENA; para la mayoría (57.14\%) la actividad laboral se relaciona de manera indirecta o no se relaciona con la formación recibida. En tal sentido el indicador relativo al trabajo en el área de formación o de conocimientos presenta falencias en dos de cada tres graduados que están laborando (Figura No 6).

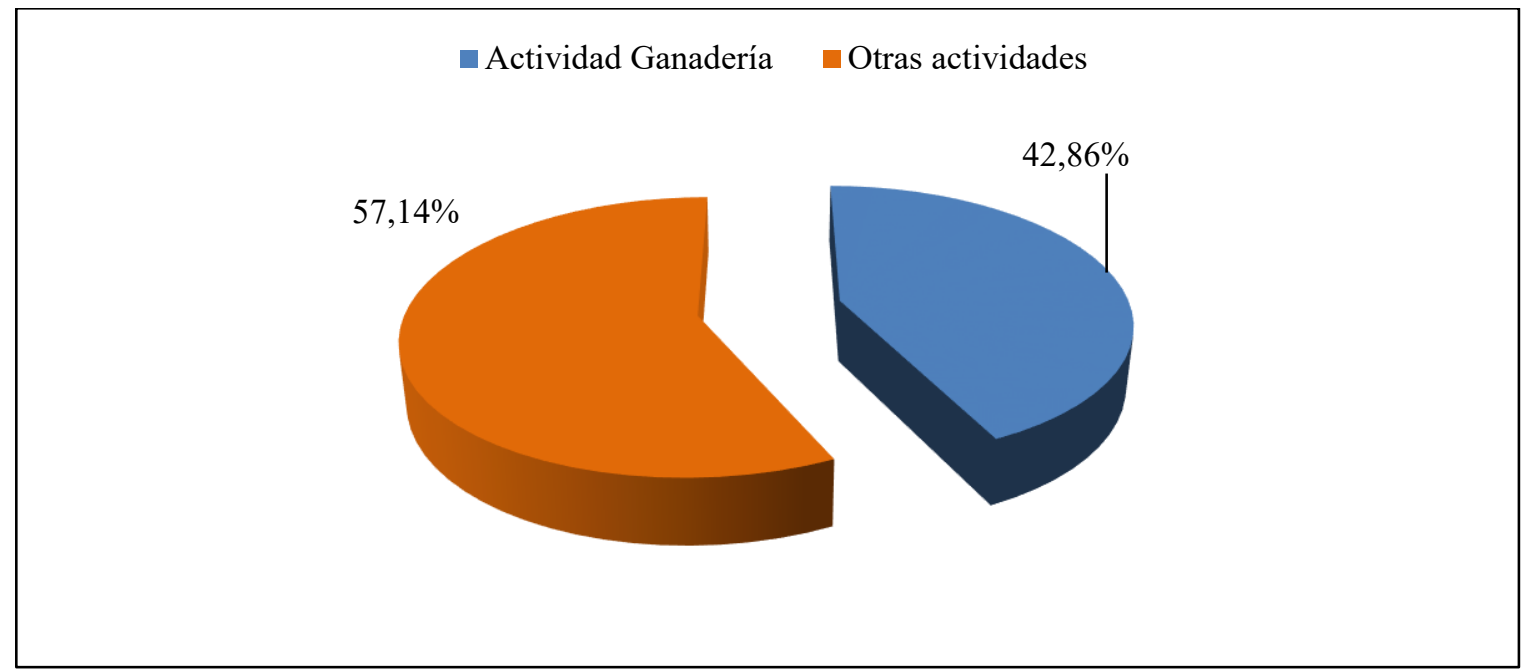

Figura No 9. Tipo de actividad de la empresa (Misional)

Fuente: Elaboración propia, con datos de la entrevista.

Entre las actividades laborales directamente relacionadas con la formación se encuentran actividades de comercio de insumos y tecnología ganadera, participación en la industria de procesamiento de alimentos cárnicos y lácteos, servicios directos en campo como levante, ceba, cría, reproducción asistida (Figura No 7). 


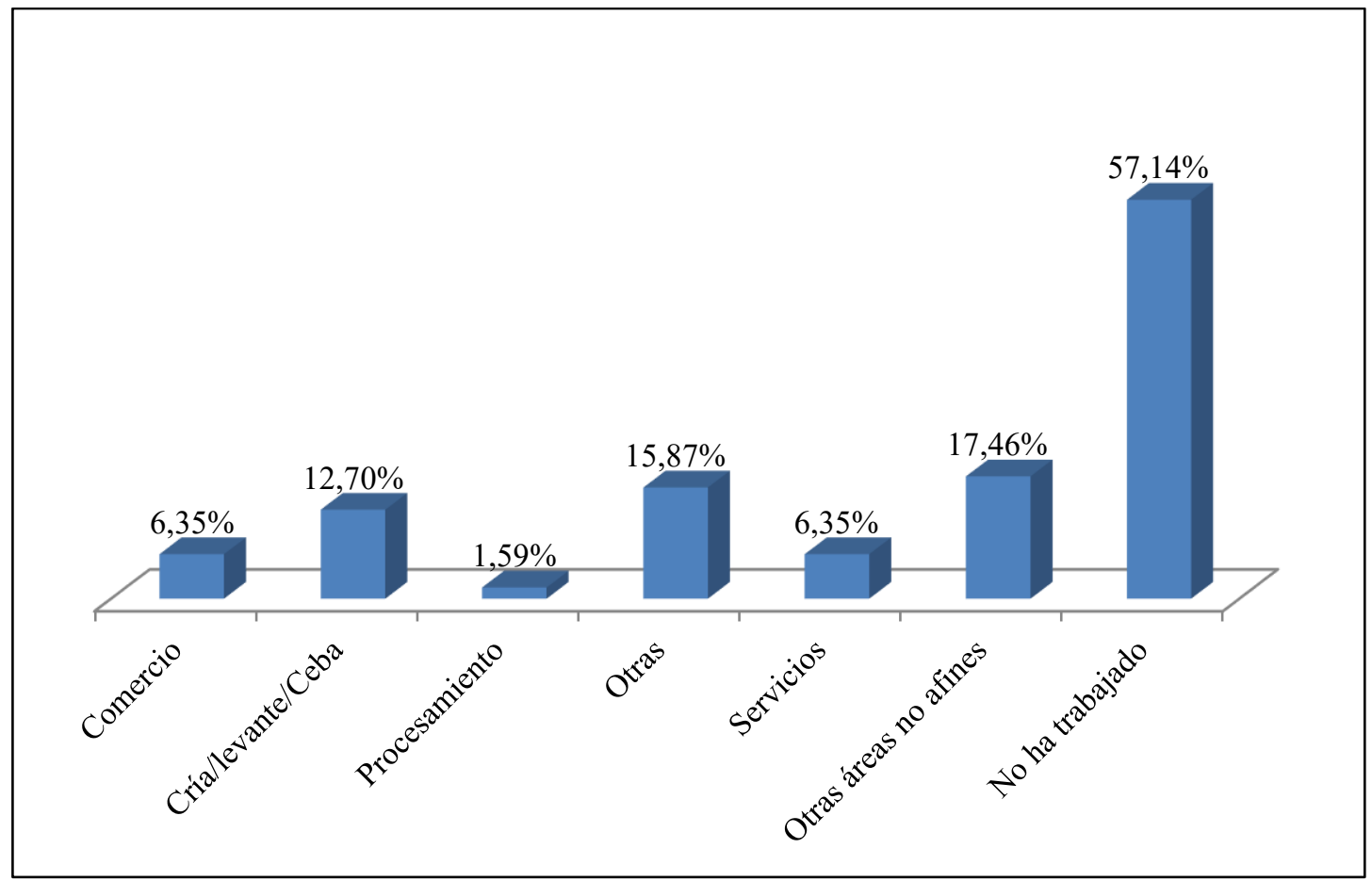

Figura No 10. Empleabilidad: Trabajo en el área de formación Fuente: Elaboración propia, con datos de la entrevista.

A pesar del nivel de empleabilidad de la Tecnología en Producción Ganadera, es preocupante observar que las actividades laborales que realizan los entrevistados, se relacionan o son pertinentes con la formación en solo uno de cada tres graduados del Programa Tecnología en Producción Ganadera el Centro Agropecuario y de Biotecnología "El Porvenir" del Servicio Nacional de Aprendizaje SENA, lo cual como indicador de desarrollo y de cumplimiento de las políticas representa un resultado desfavorable.

Lo anterior puede ser debido a problemas relacionados con el contexto, ya que los empleos en el sector de la producción ganadera corresponden al sector privado, los ganaderos de manera habitual contratan personal sin formación para retribuir con bajos salarios o por fuera de lo establecido en las normas nacionales definidas para fomento del desarrollo del 
campo y de la reducción de la pobreza entre las comunidades campesinas; de tal manera que los propietarios de las haciendas contratan de preferencia "jornaleros" o "cuidanderos" para que estén al tanto de las actividades de las fincas, cuyos ingresos son liquidados por jornal (o a destajo).

En términos de costos, para el ganadero cinco jornaleros que realizan de manera empírica las mismas actividades que un tecnólogo les significa mayor efectividad (en término de número de actividades) al tiempo que representan un considerable ahorro por el no pago de salarios completos, ni prestaciones sociales, denotando para los hacendados una forma de ganancia.

Si bien es cierto las normas nacionales establecen la obligatoriedad de vincular Médicos Veterinarios y Tecnólogos en Producción Ganadera para garantía de la aplicabilidad de la ciencia y la tecnología en la producción de alimentos inocuos, esta situación tiene una barrera del contexto que impide que se haga realidad, máxime cuando no existen controles o seguimientos al cumplimiento de estas políticas que propenden por el desarrollo de la población y de los entes territoriales.

Lo anterior incide de manera negativa en el tipo de trabajos a los que tienen acceso real los tecnólogos, en la gráfica 8 se aprecia que entre quienes trabajan en el área de producción ganadera solo $51.62 \%$ tiene un trabajo que puede ser clasificado como formal al tener acceso a salario de demás prestaciones de ley. 


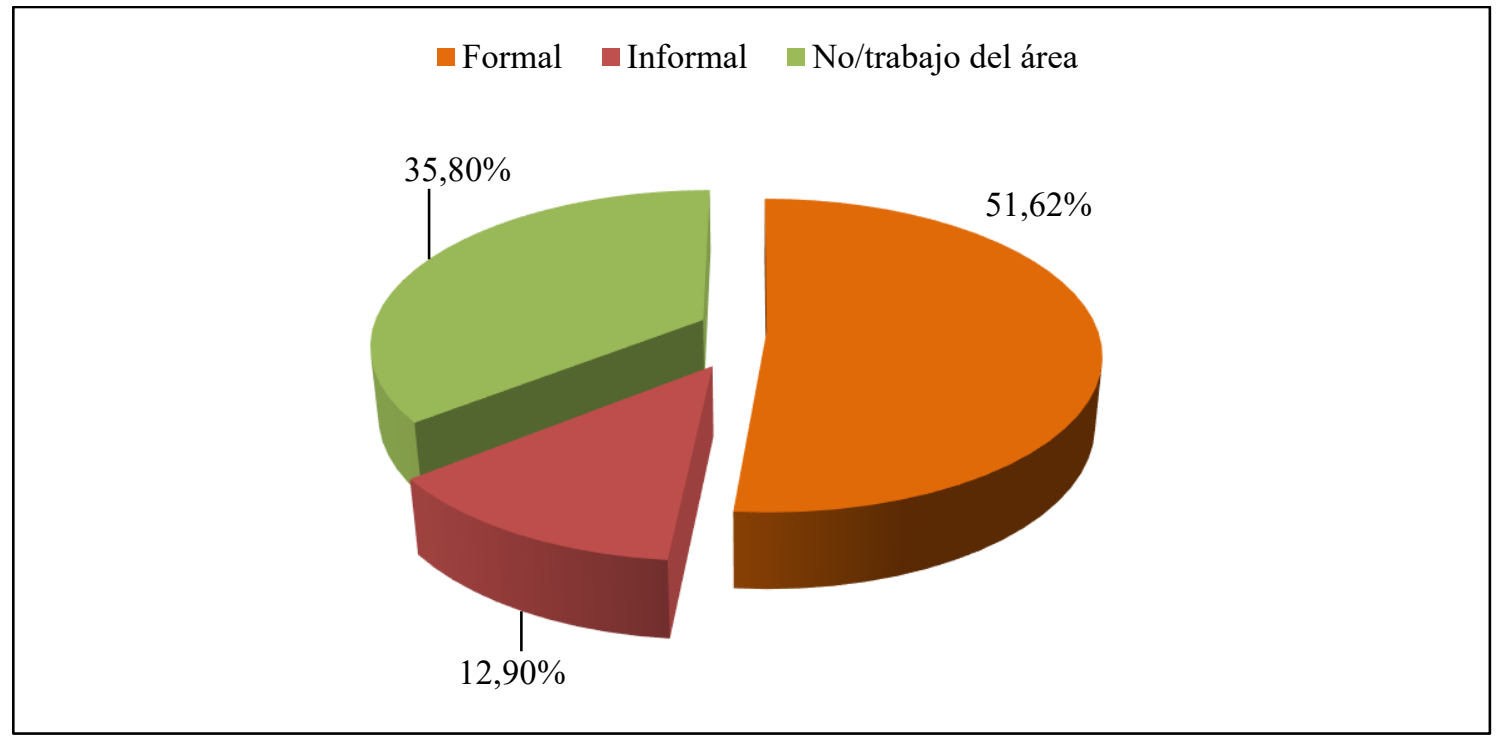

Figura No 11. Empleabilidad: Grado de formalidad del trabajo en el área de formación Fuente: Elaboración propia, con datos de la entrevista.

Esta situación de informalidad laboral de los profesionales de nivel tecnológico, es por tanto producto de la falta o deficiente aplicación o exigencias para el cumplimiento de las normas nacionales que han sido emitidas para favorecer el desarrollo de los sectores mediante la formulación de políticas claras.

Resolver esta situación demanda de la voluntad política de los entes encargados del control del cumplimiento de las normas; de mantener la tendencia en las cifras de informalidad del trabajo realizado por los egresados, la formación que se realiza al interior del Programa Tecnología en Producción Ganadera el Centro Agropecuario y de Biotecnología “El Porvenir” del Servicio Nacional de Aprendizaje SENA, puede ser asumido como "no pertinente" pues aunque la empleabilidad es alta no contempla las mejores condiciones laborales para quienes se desempeñan de manera expedita en su área de formación profesional. 
Lo anterior puede ser asumido desde el análisis de los datos relativos al tercer indicador de la empleabilidad, esto es la capacidad de conservar el empleo; al respecto entre quienes trabajan en la actividad económica del sector primario en la producción ganadera de alimentos, levante, cría, ceba, reproducción y demás se aprecia que el tiempo de permanencia de "más de un año" apenas si alcanza una quinta parte de la muestra de entrevistados (19.05\%), seguida en orden de frecuencias relativas por "menos de tres meses" y "siete a doce meses" cada uno con $12.70 \%$ respectivamente (Figura No 9).

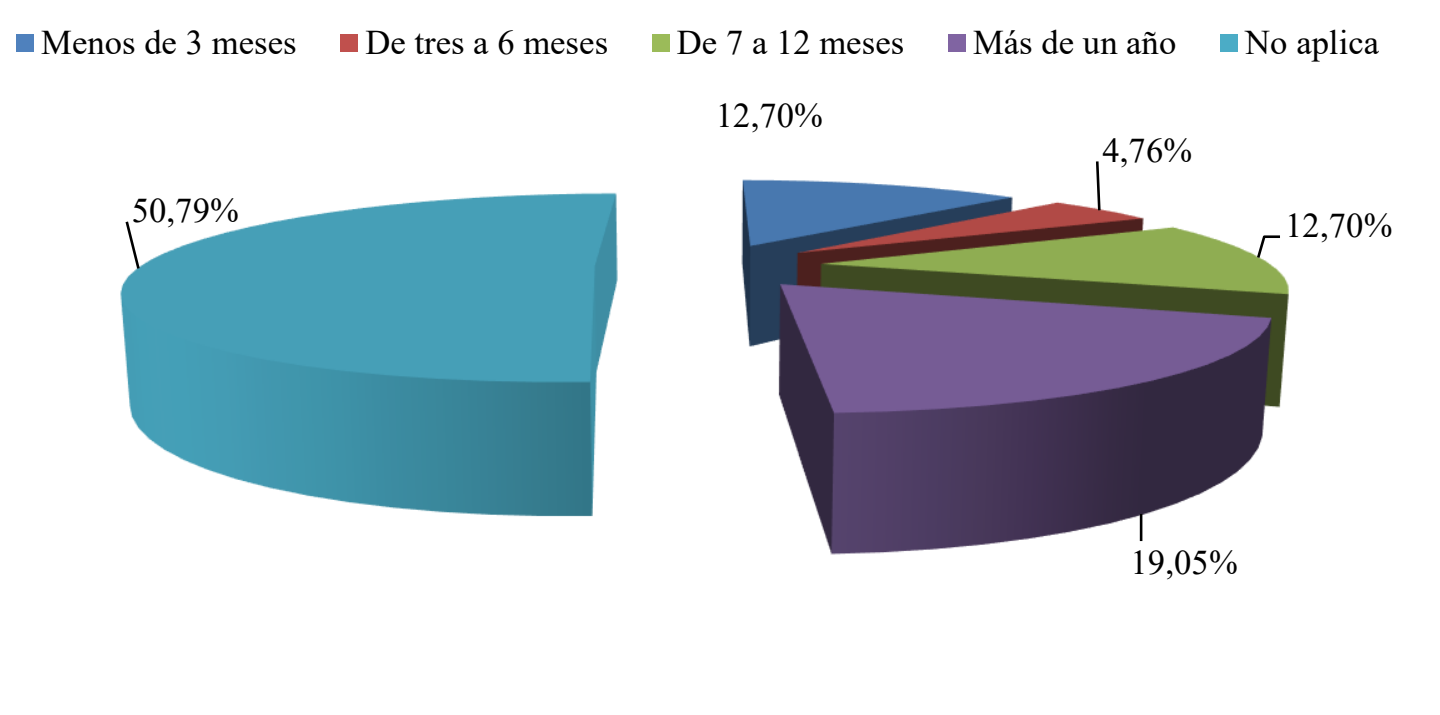

Figura No 12. Empleabilidad: Permanencia en el trabajo del área de formación Fuente: Elaboración propia, con datos de la entrevista.

Las menores frecuencias se encontraron en periodo de tiempo de tres a 6 meses $(4.76 \%)$. Las cifras evidencian que dos de cada cinco graduados han evidenciado su capacidad de conservar el empleo, más allá de la media de tiempo que se acostumbra en la región que sirve de escenario al estudio.

Situación preocupante si se entiende que los participantes de la muestra tenían entre uno y cinco años de haber egresado de su formación a nivel tecnológico. 
Al respecto es claro entonces, que el nivel de empleabilidad se relaciona con la actividad económica predominante en la región que es la ganadería; pero que existen razones de contexto, de hábitos y costumbres de los hacendados en cuanto a la vinculación del personal con formación profesional que impiden se haga realidad el beneficio personal, económico y de desarrollo al que se aspira al estudiar y culminar con éxito la formación en un área de las ciencias.

La apreciación anterior puede ser sustentada desde el efecto negativo que provoca el empleador sobre el egresado al analizar la retribución económica mensual que devengan los graduados del Programa Tecnología en Producción Ganadera el Centro Agropecuario y de Biotecnología "El Porvenir" del Servicio Nacional de Aprendizaje SENA.

La información que presenta la gráfica 10 permite identificar en primer lugar que $47.62 \%$ de los entrevistados no percibe un ingreso mensual del cual pueda dar cuenta, lo cual permite deducir que los ingresos son inestables o "al día".

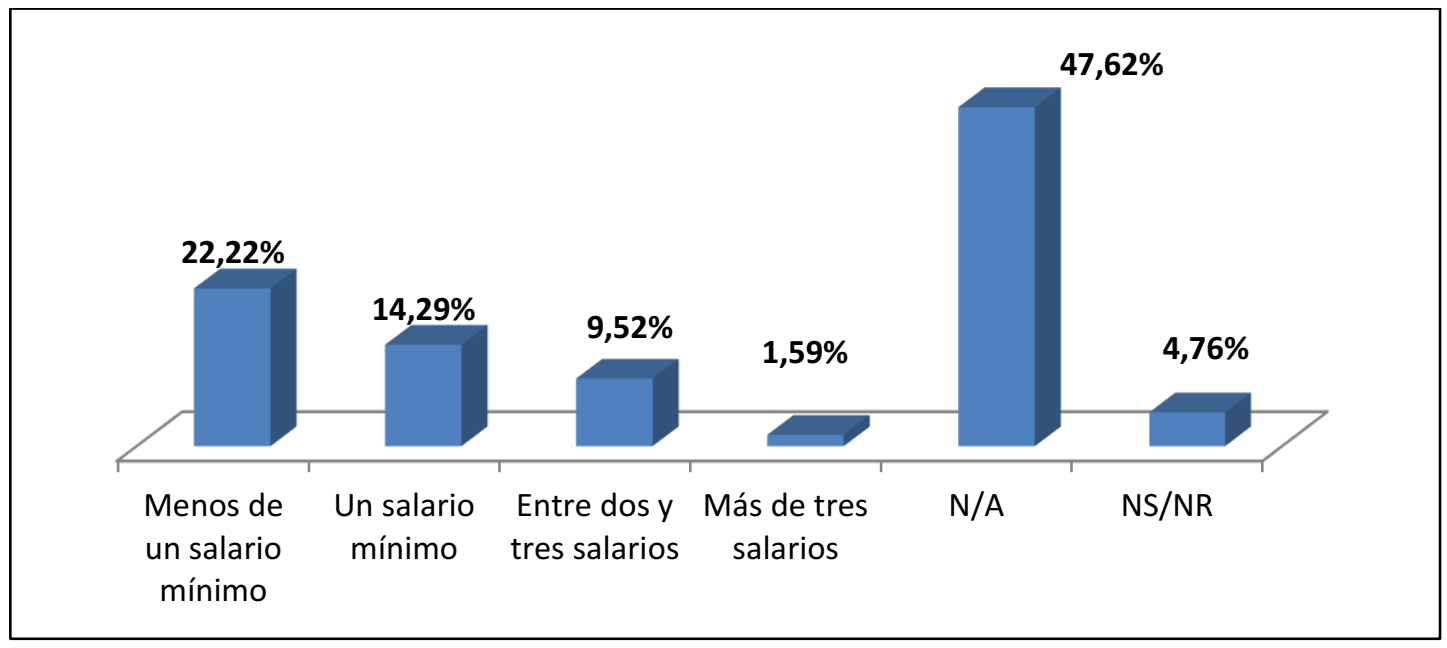

Figura No 13. Empleabilidad. Ingresos mensuales Fuente: Elaboración propia, con datos de la entrevista. 
Es de especial interés que solo $22,22 \%$ de los encuestados devenga menos de un salario mínimo mensual legal vigente (SMMLV) en Colombia que al año 2020 corresponde a la suma de ochocientos setenta y siete mil ochocientos tres pesos (\$877.803) pesos colombianos (equivalentes a USD\$241.4 a la fecha del corte: julio 23 de 2020).

Se entiende inicialmente que en Colombia ningún trabajador debería devengar menos del SMMLV por lo que el hecho que $22.22 \%$ de las personas entrevistadas tengan esa remuneración indica la presencia de un incumplimiento de las políticas salariales del país.

En otro sentido del mismo análisis, en este estudio la población y muestra corresponde a profesionales del nivel tecnológico. Al respecto el sueldo medio para el puesto de Tecnólogo en Colombia en 2020 es de \$1.232.026 al mes, por lo que se estima que este dos de cada 10 entrevistados recibe $71.25 \%$ de la remuneración que le corresponde.

Desde esta base de media salarial de $\$ 1.232 .026$ al mes se aprecia que $36.51 \%$ de los entrevistados reciben menos y hasta un SMMLV, siendo el salario inferior al que le corresponde a su nivel de formación tecnológica. Encontrándose entonces la presencia de explotación laboral entre un tercio de los graduados del Programa Tecnología en Producción Ganadera el Centro Agropecuario y de Biotecnología "El Porvenir" del Servicio Nacional de Aprendizaje SENA que reportan tener un empleo; situación que puede incidir de manera negativa en el impacto económico de la formación recibida pues los empleados al iniciar a laborar tienen como expectativa que su nivel de estudios y la experiencia se reflejen en forma directamente proporcional en la remuneración económica recibida. ${ }^{1}$

\footnotetext{
${ }^{1}$ Enlace Profesional - Red de Comunidades de Egresados de Antioquia
} 
En este mismo sentido, se localizó la última información actualizada del Observatorio Laboral de la Educación (OLE), que corresponde al año 2016, En la información del OLE acerca del Ingreso Base de Cotización (IBC) por parte de los tecnólogos en Colombia oscilaba en ese año en el rango entre 1.116 .167 y $1.726 .043^{2}$.

Esta situación del análisis de la remuneración implica una búsqueda de valores para equiparar el salario recibido en la actualidad. Acerca del tema se encontró una publicación del año 2009 publicado en la Revista Portafolio, en la cual se indica que según estimaciones del sector económico "un tecnólogo sin recorrido laboral ganaría 800.000 pesos, a diferencia de otro con experiencia y bilingüe, en cuyo caso devengaría alrededor de 1.375.000 pesos". ${ }^{3}$ De manera que al extrapolar los valores a los percibidos por los tecnólogos en la actualidad (año 2020), se aprecia que 36.51\% de los tecnólogos están recibiendo los ingresos mensuales equivalentes a 11 años antes para su mismo nivel de formación (sin experiencia laboral); denotando que la depreciación del valor del peso colombiano debe influir de manera severa en la capacidad adquisitiva del Tecnólogo en Producción Ganadera.

Lo anterior, permite deducir que si bien el Programa Tecnología en Producción Ganadera el Centro Agropecuario y de Biotecnología "El Porvenir" del Servicio Nacional de Aprendizaje SENA es pertinente a la región en cuanto a la necesidad sentida de estos

${ }^{2}$ Colombia. Ministerio de Educación Nacional. Observatorio Laboral de la Educación. Estadísticas. En: https://ole.mineducacion.gov.co/portal/

3 Revista Portafolio. Cuánto gana un profesional, según su grado de educación y experiencia https://www.portafolio.co/economia/finanzas/gana-profesional-grado-educacion-experiencia-282444. Publicado agosto 03 de 2009 - 05:00 a.m. 
profesionales, las condiciones laborales del contexto en cuanto a empleabilidad, permanencia en el empleo y escala salarial alteran la dinámica de la pertinencia; pues según los hallazgos los profesionales tecnólogos graduados tienen serias dificultades para encontrar y mantenerse en los empleos en el sector de la producción ganadera, no por falta de capacidades o méritos sino por la existencia de patrones culturales arraigados en los ganaderos hacendados quienes incumplen lo establecido en la política nacional.

De otra parte, del total de 41 empresas encuestadas, $43,9 \%$ se encuentran localizadas en el departamento de Antioquia, 29,27\% en Córdoba, 12,20\% en Bogotá; el porcentaje de empresas restantes $(14,63 \%)$ se encuentran localizadas en otros departamentos del país (Figura No 11).

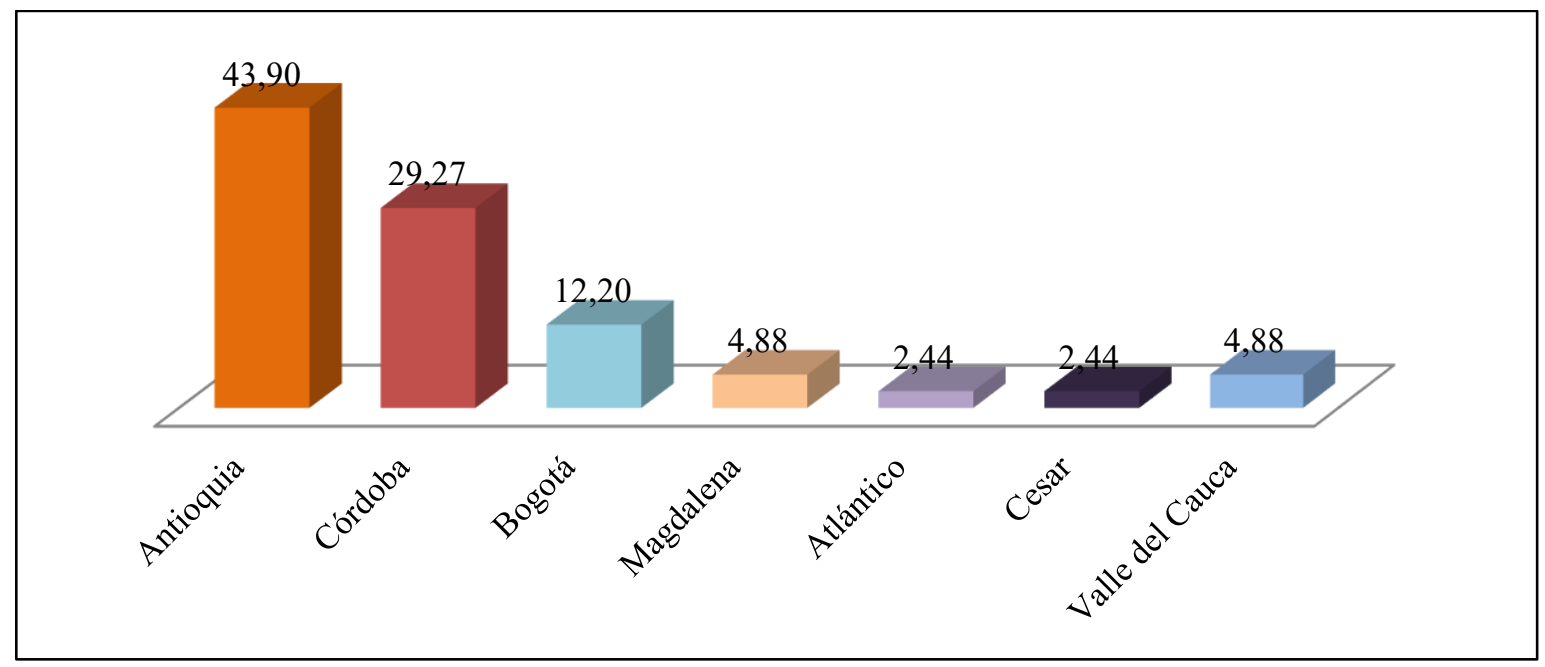

Figura No 14. Ubicación por departamento de las empresas empleadoras Fuente: Elaboración propia, con datos de la entrevista.

Al categorizar los datos de ubicación de los empleadores de los pasantes y graduados del Programa Tecnología en Producción Ganadera el Centro Agropecuario y de Biotecnología "El Porvenir" del Servicio Nacional de Aprendizaje SENA, se encuentra que 
incluidos los departamentos por región 32,09\% de los mismos se encuentran en la Región Costa Caribe de Colombia, 56,1\% se encuentra ubicada en la Región Andina y 4,88\% en la Región Costa Pacífica de Colombia (Figura No 12).

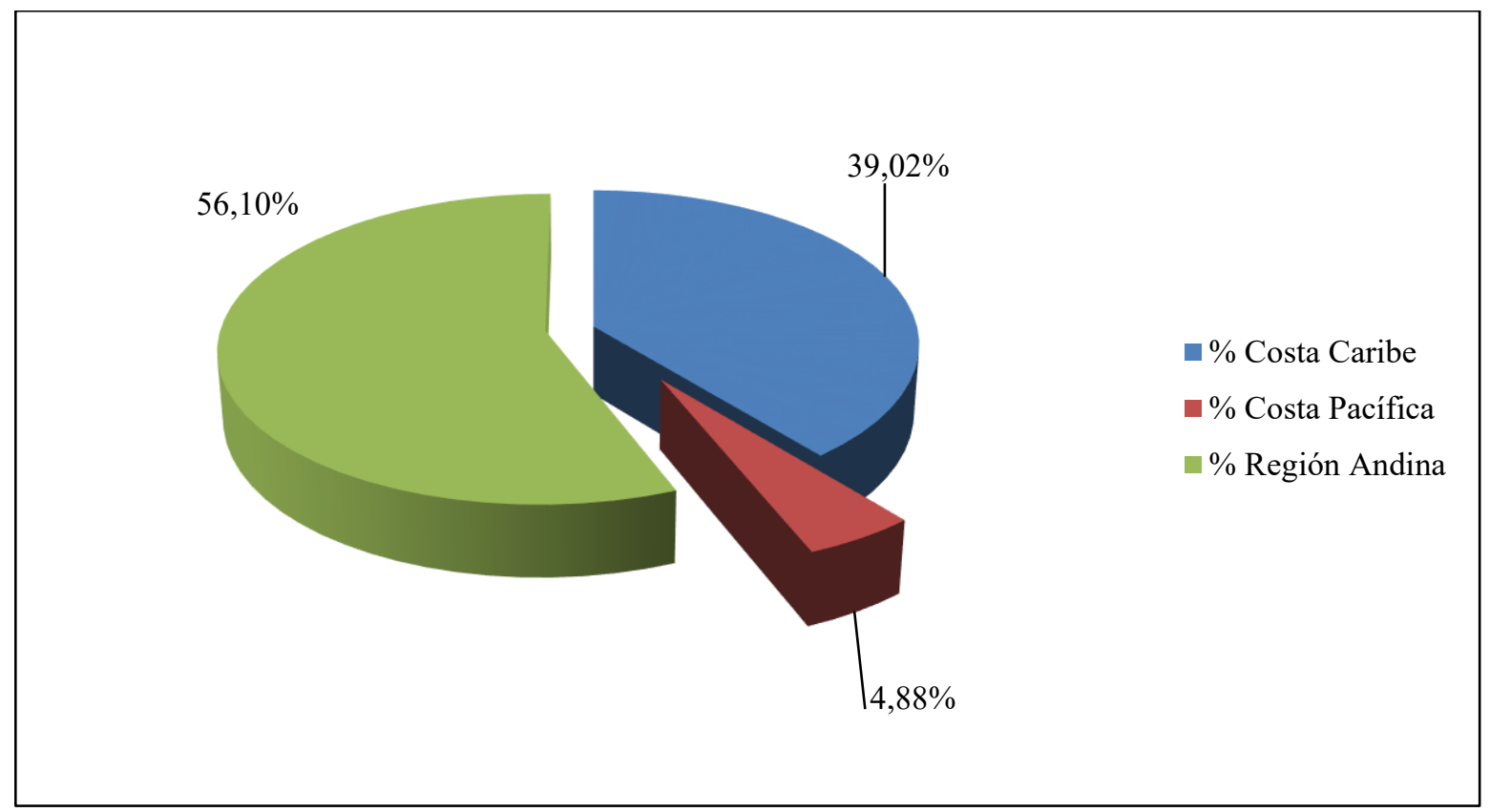

Figura No 15. Ubicación las empresas empleadoras de los Tecnólogos por Región Fuente: Elaboración propia, con datos de la entrevista.

De los resultados de ubicación regional se desprende que los pasantes y graduados del Programa Tecnología en Producción Ganadera el Centro Agropecuario y de Biotecnología "El Porvenir" del Servicio Nacional de Aprendizaje SENA tienen una amplia aceptación en la Región Costa Caribe y la Región Andina ambas destacadas por la importancia económica de la producción ganadera que los caracteriza. Este dato de ubicación aporta bastante claridad en cuanto a la pertinencia del programa para el sector de la producción ganadera en Colombia al estar localizadas las empresas empleadoras en 3 de las $6(50 \%)$ de las regiones naturales de Colombia. 
En Colombia el segmento empresarial está clasificado en micro, pequeñas, medianas y grandes empresas, esta clasificación está reglamentada en la Ley 590 de 2000 conocida como la Ley Mipymes y sus modificaciones (Ley 905 de 2004); tal clasificación se realiza con base en sus activos en términos de salarios mínimos mensuales legales vigentes en Colombia.

En relación con el tamaño de las empresas encuestadas se identifica que 48,78\% de ellas se encuentran dentro de la clasificación de "mediana empresa" $(\mathrm{n}=20), 26,83 \%$ son grandes $(\mathrm{n}=11), \quad 19,51 \%$ son pequeñas empresas $(\mathrm{n}=8)$ y el $4,88 \%$ son clasificadas como microempresas $(\mathrm{n}=2)$ (Figura No 13).

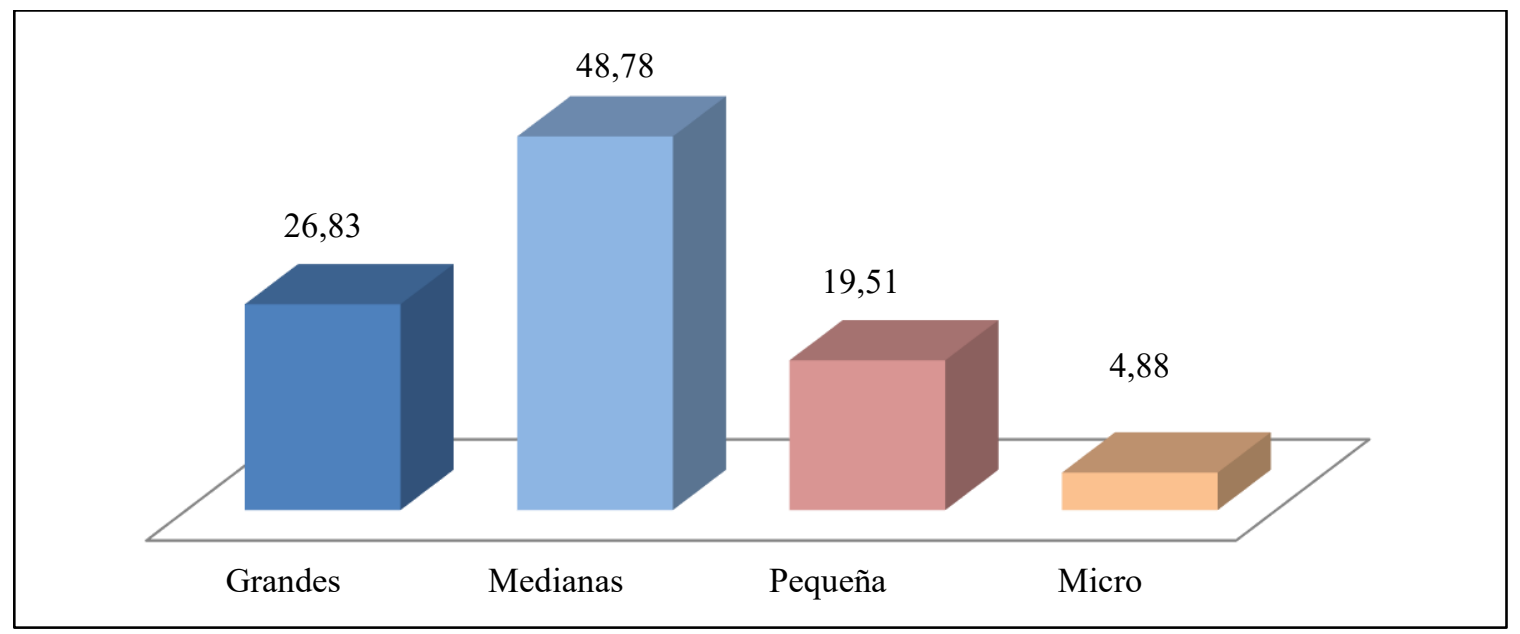

Figura No 16. Tamaño de las empresas empleadoras de los Tecnólogos Fuente: Elaboración propia, con datos de la entrevista.

Lo anterior permite evidenciar el reconocimiento y la necesidad de este tipo de profesionales por la mediana y gran empresa que juntas conglomeran el equivalente a tres cuartiles $(75.61 \%)$ de la distribución de las empresas empleadoras según el tamaño de las mismas; tal situación desde esta perspectiva también es un aporte de interés para la pertinencia económica del Programa Tecnología en Producción Ganadera el Centro Agropecuario y de Biotecnología "El Porvenir" del Servicio Nacional de Aprendizaje SENA. 
La principal modalidad empleada por los empresarios, corresponde a los contratos de aprendizaje con $68.75 \%$, seguido por las pasantías (16.67\%) y finalmente los contratos de trabajo (14.58\%) (Figura No 14).

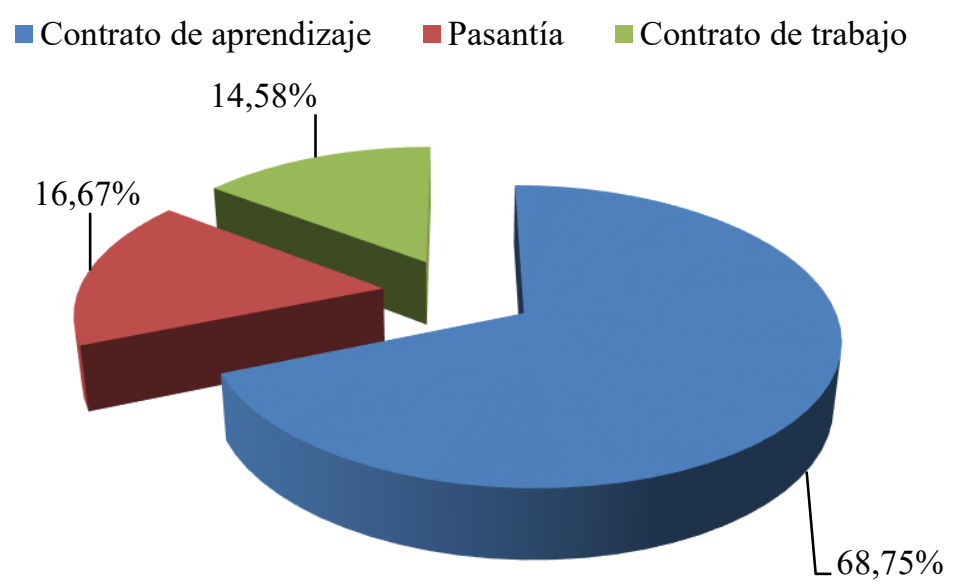

Figura No 17. Tipo de contratación de los Tecnólogos

Fuente: Elaboración propia, con datos de la entrevista.

En los resultados se aprecia una razón estadística que enuncia que 7 de cada 10 empleos que ofrece el sector de la producción ganadera a los estudiantes y egresados del Programa Tecnología en Producción Ganadera el Centro Agropecuario y de Biotecnología "El Porvenir" del Servicio Nacional de Aprendizaje SENA corresponde a contratos de aprendizaje, figura legal que implica la adquisición o la disposición de mano de obra calificada a bajo costo; lo cual representa para los empresarios del sector unas facilidades para el desempeño de las finanzas en el sector; sin embargo, esta misma situación no apoya el trabajo de los graduados, con lo cual se explica de manera parcial los pobres resultados obtenidos en la empleabilidad de los graduados ya tratados antes. 


\subsection{Inserción de egresados del programa de formación en el mercado laboral Agropecuario del departamento de Córdoba}

Al momento de la entrevista, 49,21\% tenían una actividad económicamente productiva, de entre ellos $30.16 \%$ trabaja como empleado mediante un empleo formalizado con acceso a prestaciones sociales, $19,05 \%$ trabaja de forma independiente como contratista a tiempo definido sin acceso a seguridad social y $50.79 \%$ tiene condiciones laborales diferentes como es el trabajo informal, o está en busca de trabajo o está desempleado.

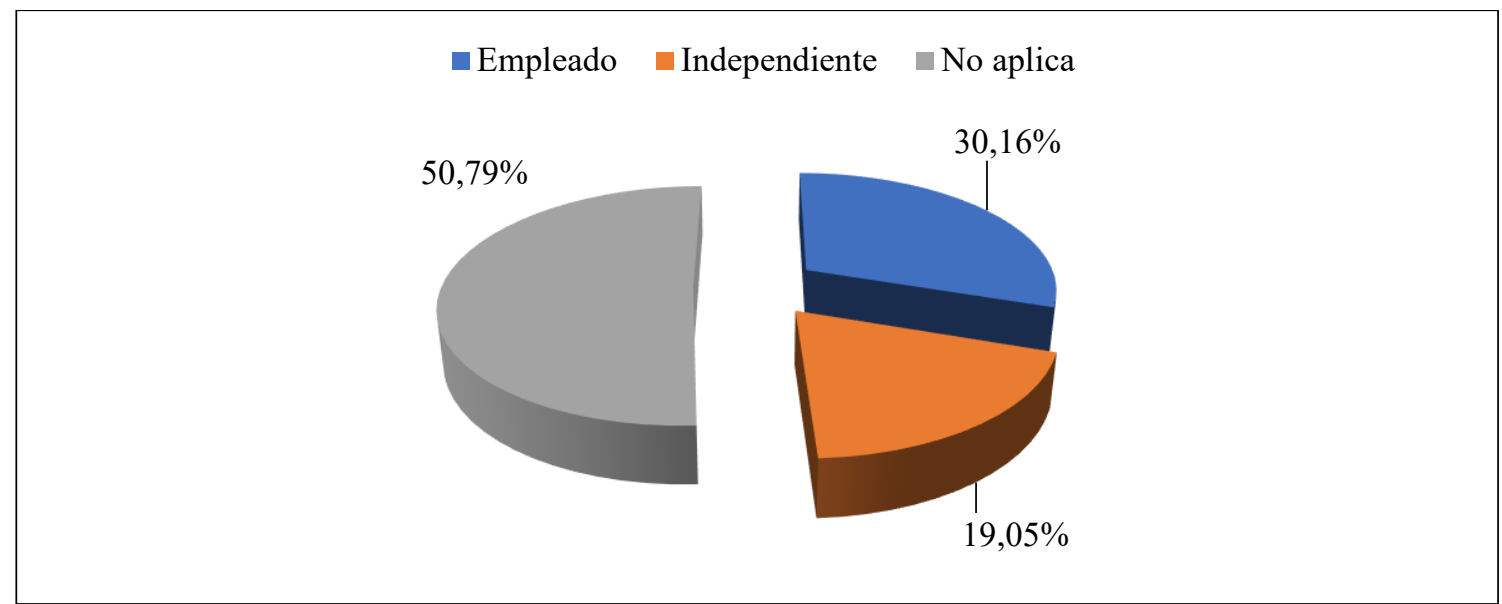

Figura No 18. Condición del trabajo del Tecnólogo en Producción Ganadera Fuente: Elaboración propia, con datos de la entrevista.

Como se puede observar cerca de la mitad de la muestra no podría considerarse en condición laboral, situación que permitiría deducir que la capacidad de generación de empleo en la zona es de nivel medio; pues en la sumatoria de empleados e independientes no alcanza a completar el $50 \%$ de los entrevistados. 
Entre quienes laboral $(n=38), 23,81 \%$ se desempeña en el sector secundario de la economía en actividades como comercio, industria, 20.63\% labora en el sector primario de la economía en actividades agrícolas y pecuarias, 6.35\% en el sector terciario de la economía en servicios.

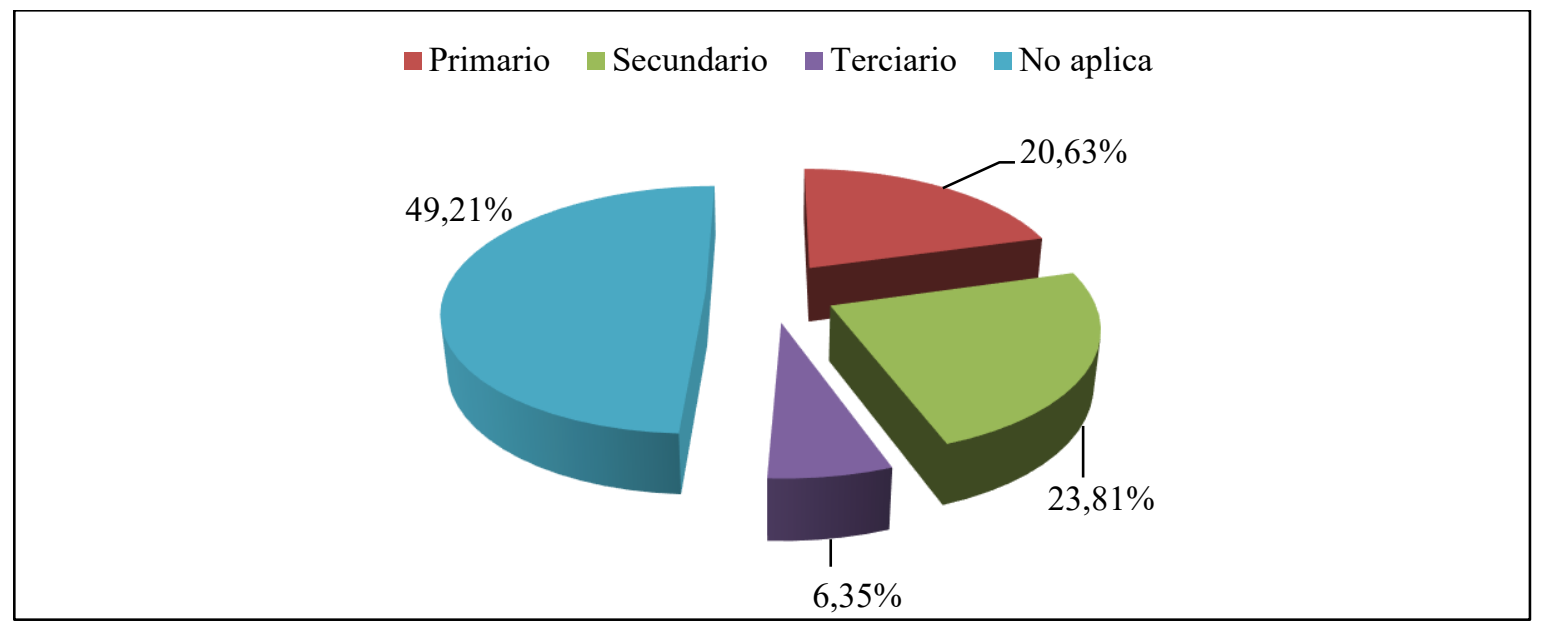

Figura No 19. Sector en que laboran los Tecnólogos en Producción Ganadera Fuente: Elaboración propia, con datos de la entrevista.

En esta información es de particular interés que $49.21 \%$ de entre quienes reportan actividad laboral $(\mathrm{n}=38)$ tienen actividad productiva en áreas informales situación que no permite ser categorizado en ninguno de los sectores por lo que se clasifica como "no aplica (NA)”. La forma de vinculación laboral de los 38 Tecnólogos que tienen empleo o actividad laboral independiente evidencia la categoría "otra" con un predominio en distribución de frecuencias (35.8\%), seguido en orden de frecuencias por "contrato a término fijo" $(25.81 \%)$ y "contrato a término indefinido" con $22.58 \%$. 


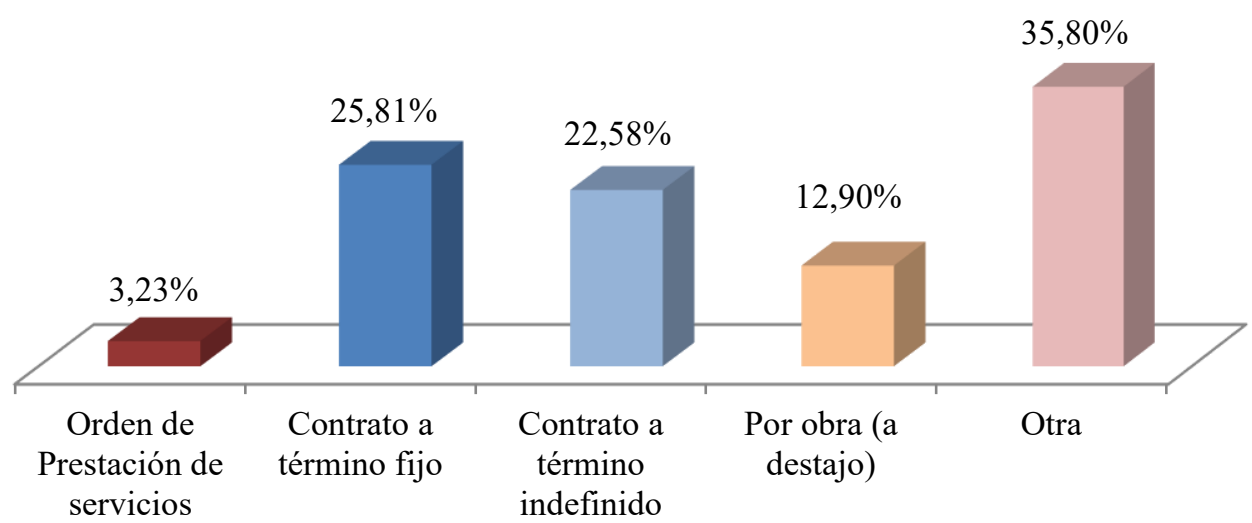

Figura No 20. Tipo de vinculación laboral

Fuente: Elaboración propia, con datos de la entrevista

Con la menor frecuencia (3.23\%) se encuentra la otra forma oficial de vinculación que es la orden de prestación de servicios, 12,9\% labora mediante la figura de pago "por obra"; el resto de la muestra que labora tiene "otra forma" de vinculación laboral (35.8\%) lo cual representa la cifra de informalidad en la vinculación laboral de los Tecnólogos en Producción Ganadera.

Los resultados anteriores fueron dimensionados como "Situación laboral activa" y "Situación laboral inactiva", con el fin de poder avanzar hacia las dimensiones de aplicabilidad de las políticas de desarrollo en este sector primario de la economía.

Al contrastar con la información anterior se observa que quienes hacen parte de la situación laboral activa $(\mathrm{n}=28)$, la mitad de ellos tienen trabajo formal como empleados; el resto, aunque también trabaja al servicio de un patrón y devenga un ingreso carece de oportunidades para tener acceso completo a la seguridad social (cesantías, pensión, riesgos laborales, bonificaciones). 
Es preocupante en esta distribución, que la mitad más uno del porcentaje de entrevistados o no tiene trabajo o está realizando actividades dentro de la economía informal $(n=35)$; situación que será de utilidad para medir la pertinencia de la formación en éste área.

Al interrogar a los participantes que no tienen trabajo o en situación laboral inactiva $(n=35)$ mediante una pregunta abierta, sobre las tres principales razones por las cuales no ha conseguido un empleo, se encontraron siete principales razones susceptibles de ser agrupadas en categorías. La razón que ha predominado es "no encuentro empleo" la cual evidencia la precariedad de la oferta laboral para los Tecnólogos en Producción Ganadera (36.68\%).

Otras situaciones de interés es la inconsistencia entre las aspiraciones del Tecnólogo en Producción Ganadera con las condiciones de trabajo en el sector; es así como 15,87\% responde que los empleos "no cumplen con lo esperado", salario no acorde al nivel de formación y la exigencia de cambio de residencia (11.11\% cada uno) (Figura No 18).

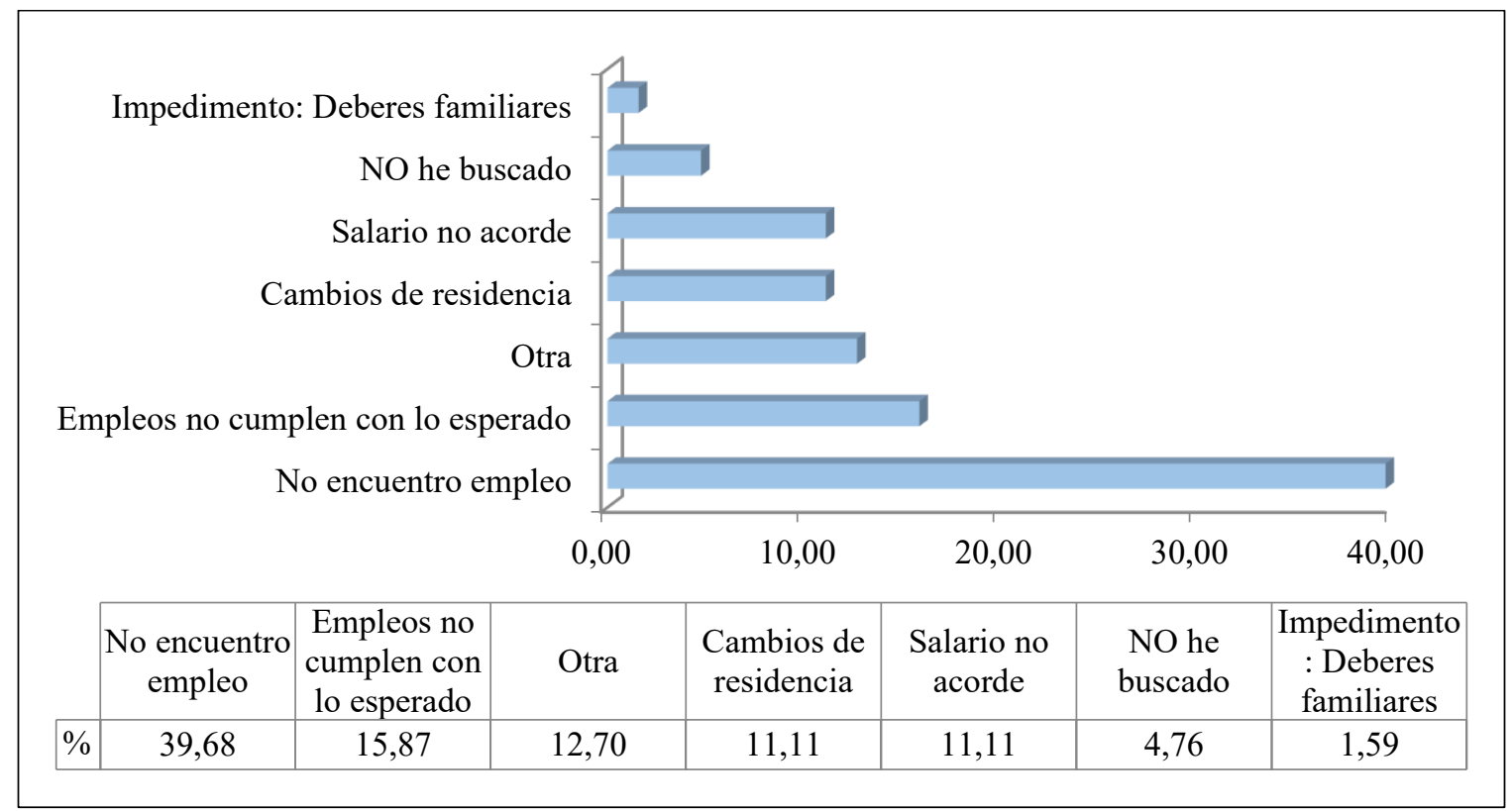

Figura No 21. Razones por las cuales no ha conseguido empleo Fuente: Elaboración propia, con datos de la entrevista 
De dicha distribución, se derivan dos categorías de interés para las políticas de desarrollo de la región que sirve de escenario al estudio que son condiciones relativas a la oferta de trabajo y condiciones del trabajador egresado del Programa de Tecnología en Producción Ganadera. Al dimensionar la información, se obtiene que en dos de cada tres casos (2:1) predomina la situación de inactividad laboral de los Tecnólogos egresados del Programa Tecnología en Producción Ganadera el Centro Agropecuario y de Biotecnología "El Porvenir" del Servicio Nacional de Aprendizaje SENA obedece a dificultades relacionadas con la oferta laboral en la región en términos de condiciones de trabajo, salarios, horarios y acceso a prestaciones sociales o de ley vigentes en Colombia.

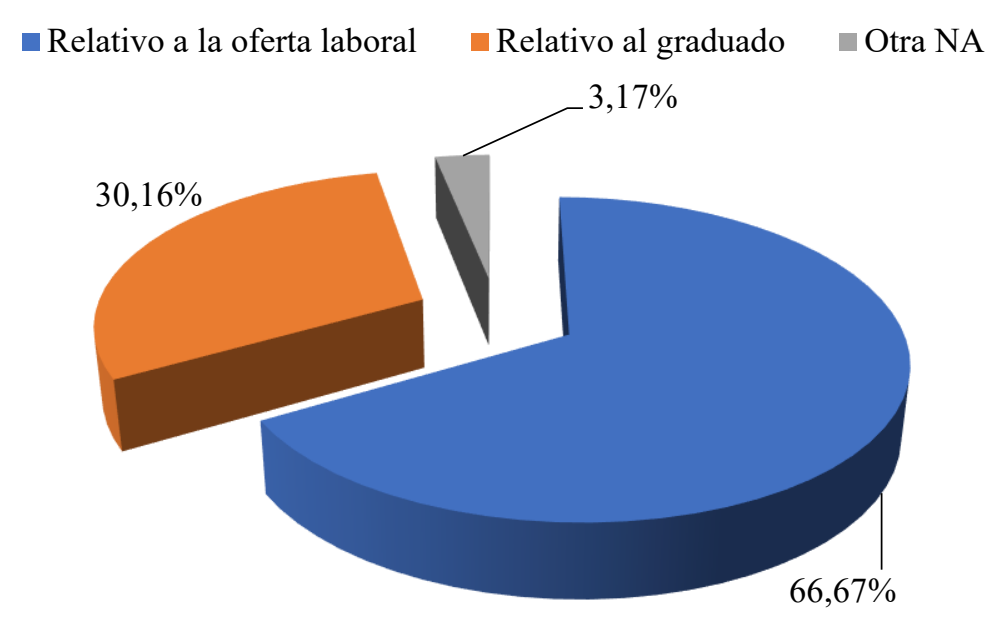

Figura No 22. Origen de las condiciones de inactividad laboral Fuente: Elaboración propia, con datos de la entrevista

Para iniciar el esbozo del análisis de la pertinencia del programa, es pertinente indicar que, si bien el Departamento de Córdoba se caracteriza por su economía agropecuaria, con dominio de la ganadería no se esperaría encontrar una situación como la identificada entre quienes tienen su situación laboral inactiva; pues como se aprecia en los resultados las 
condiciones de trabajo que ofrece la industria ganadera no es afín con lo esperado para un profesional del nivel tecnológico en el área. Lo cual permite deducir que no existe un control eficiente o continuado acerca de las condiciones que permiten la inserción laboral de estos profesionales en el campo propio de su desempeño; con lo cual se presume la presencia de impedimentos para la aplicabilidad de los parámetros establecidos en la política nacional de Colombia que se encuentra contenida en el Plan Nacional de Desarrollo "Pacto por Colombia, pacto por la equidad" que se encuentra vigente entre los años 2018 y 2022 inclusive.

Para clarificar acerca de estas situaciones se analiza los indicadores de empleabilidad con el fin de orientar las acciones requeridas para implementar las políticas que están propuestas para fomento del desarrollo de la región.

\subsection{Impacto generado por la inserción de Tecnólogos Profesionales del SENA en Empresas Agropecuarias del departamento de Córdoba.}

La medición de impactos en general hace referencia al sentido de los efectos (como impacto positivo e impacto negativo) y al orden de dichos efectos como impactos sociales, económicos y productivos para el caso del presente estudio que estimará los impactos de la formación al interior del Programa de Producción Ganadera. 


\begin{tabular}{|c|c|c|c|}
\hline \multirow{2}{*}{ CUESTIONARIO } & \multicolumn{3}{|c|}{ IMPACTOS } \\
\hline & Social & Económico & Productivo \\
\hline $\begin{array}{l}\text { Actividades acordes a la } \\
\text { formación (preguntas } 1 \text { y } 6 \text { ) }\end{array}$ & - & $\begin{array}{c}25.4 \% \\
\text { Salarios } 1-3\end{array}$ & $\begin{array}{c}42.86 \% \\
\text { Trabaja en el área }\end{array}$ \\
\hline $\begin{array}{l}\text { Actividades autónomas del } \\
\text { nivel tecnológico (preguntas } \\
3,4 \text { ) }\end{array}$ & - & $\begin{array}{l}48.78 \% \\
\text { Mediana } \\
\text { empresa }\end{array}$ & $\begin{array}{c}49.21 \% \\
\text { Independiente }+ \\
\text { empleado }\end{array}$ \\
\hline $\begin{array}{l}\text { Programación de actividades } \\
\text { (preguntas } 2,5 \text { ) }\end{array}$ & - & $\begin{array}{c}49.21 \% \\
\text { Actividad } \\
\text { económica } \\
\text { productiva }\end{array}$ & $\begin{array}{c}50.79 \% \\
\text { Trabaja en el } \\
\text { sector }\end{array}$ \\
\hline $\begin{array}{l}\text { Calidad de vida (percepción: } \\
\text { Pregunta 1) }\end{array}$ & $\begin{array}{c}88.89 \% \\
\text { De acuerdo + muy de } \\
\text { acuerdo } \\
\text { (recomendaría el Prog.) }\end{array}$ & - & - \\
\hline $\begin{array}{l}\text { Percepción de impacto } \\
\text { económico (Pregunta } 2 \text { de } \\
\text { percepción) }\end{array}$ & $\begin{array}{c}88.88 \% \\
\text { Recom. Prog. } \\
\text { Agropecuarios } \\
\end{array}$ & & - \\
\hline $\begin{array}{l}\text { Percepción de impacto social } \\
\text { y económico (Empleabilidad: } \\
\text { permanencia) }\end{array}$ & $\begin{array}{c}49.21 \% \\
\text { Empleo después de las } \\
\text { prácticas }\end{array}$ & $\begin{array}{c}14.58 \% \\
\text { Empleo } \\
\text { permanente }\end{array}$ & $\begin{array}{c}100 \% \\
\text { Empleadores; } \\
\text { formación } \\
\text { corresponde a } \\
\text { necesidades }\end{array}$ \\
\hline $\begin{array}{l}\text { Total, Promedio de las cifras } \\
\text { obtenidas }\end{array}$ & 75.66 & $41.43 \%$ & $47.62 \%$ \\
\hline Interpretación del impacto & Alto & Bajo & Bajo \\
\hline
\end{tabular}

Tabla No 1 Medición de impacto social, económico y productivo Fuente: Elaboración propia, consolidación y recategorización de hallazgos

Al seleccionar las tres categorías claves previamente definidas para establecer cada uno de los impactos sociales, económicos y productivos de los egresados del Programa Tecnología en Producción Ganadera el Centro Agropecuario y de Biotecnología "El Porvenir" del Servicio Nacional de Aprendizaje SENA, se observa que 33.3\% correspondieron a bajo nivel de impactos y un impacto a nivel alto (Tabla No 1).

Como se recordará, en este estudio se consideró impacto positivo sobre la industria agropecuaria cuando exista respuesta positiva al $75 \%$ o más de los criterios en medición con respecto a: 1) la idoneidad de la formación y 2) las capacidades para realizar las actividades 
productivas en el sector de la ganadería en las variables y categorías relativas a la aplicación de las competencias y resultados de aprendizaje.

El impacto social se evaluó en términos de Calidad de Vida, Satisfacción con la formación, y percepción de beneficios; con estas tres mediciones se obtuvo un promedio porcentual de $75.66 \%$ que indica un impacto social alto de la formación de los tecnólogos formados en el del Programa Tecnología en Producción Ganadera el Centro Agropecuario y de Biotecnología "El Porvenir" del Servicio Nacional de Aprendizaje SENA.

El impacto económico fue medido con las preguntas del ítem "Información laboral"; siendo los impactos esperados la empleabilidad del egresado, relación entre la formación y el empleo, adecuación de la remuneración a lo establecido para el nivel de formación. Tras la categorización y sistematización consolidada de las variables enunciadas se pudo obtener un promedio porcentual de $41.43 \%$ que indica un bajo nivel de impacto económico sobre el egresado/graduado y sus familias.

En la medición del impacto productivo se utilizó la información que se deriva de las preguntas asociadas a las competencias y resultados de aprendizaje; tras la re categorización de las variables capacidad de realizar actividades profesionales de forma autónoma, capacidad de planear y programar con base en las situaciones del área de trabajo, ejecución de actividades propias del nivel Tecnológico, se obtuvo un promedio porcentual de $47.62 \%$ denotando una clasificación correspondiente a bajo nivel de impactos (Tabla No 1). 
Con los hallazgos es posible establecer que el Programa Tecnología en Producción Ganadera el Centro Agropecuario y de Biotecnología "El Porvenir” del Servicio Nacional de Aprendizaje SENA ha tenido un bajo impacto económico y a nivel productivo en cuanto a lo que se espera en la aplicación de las medidas políticas de desarrollo en esta región de Colombia.

El análisis de impactos del Programa de formación de Tecnólogos en Producción Ganadera ofertado por el Centro Agropecuario y de Biotecnología "El Porvenir” del SENA permite establecer que éste es pertinente para el desarrollo del sector Agropecuario del departamento de Córdoba con lo cual se acepta la hipótesis formulada; pues los aspectos que dan fortaleza a la pertinencia están presentes en la formación según la opinión de egresados y empleadores.

La problemática presente no se relaciona con la pertinencia del programa sino con la visión de "negocio" de los empleadores que de manera general pertenecen al sector privado.

\subsubsection{Cumplimiento de los parámetros establecidos del plan nacional de desarrollo}

Partiendo de lo analizado hasta este punto, y para realizar la contrastación que sugiere el objetivo plantado en este estudio, en cuanto al cumplimiento de los términos contenidos en el Plan de Desarrollo "Pacto por Colombia, pacto por la equidad"4 que propende por la consolidación del Estado Social de Derecho en todo el país mediante el desarrollo de 15 pactos, de los cuales se tratarán los dos pertinentes al tema del presente estudio.

\footnotetext{
${ }^{4}$ CEPAL. Observatorio de Planificación. Observatorio Regional de Planificación para el desarrollo. Plan Nacional de Desarrollo "Pacto por Colombia, pacto por la equidad 2018-2022. Publicación On Linea Disponible en: https://observatorioplanificacion.cepal.org/es/planes/plan-nacional-de-desarrollo-pacto-por-colombia-pacto-por-laequidad-2018-2022. Consultado 23 de julio de 2020
} 
$\mathrm{Al}$ respecto es pertinente analizar el grado del cumplimiento del texto del pacto por el emprendimiento y la productividad contenido dentro del Plan Nacional de Desarrollo de Colombia vigente desde 2018, que dice a la letra:

(..) El pacto por el emprendimiento y la productividad, centrado en la transformación productiva que pretende reducir la dependencia del país de la minería y de los hidrocarburos, así como aumentar la formalización laboral y empresarial, dinamizar el desarrollo y la productividad en las zonas rurales del país (Cepal, Observatorio Regional de Planificación para el desarrollo. Plan Nacional de Desarrollo (2020).

Se ha observado entre los resultados de empleabilidad de los egresados del Programa Tecnología en Producción Ganadera el Centro Agropecuario y de Biotecnología "El Porvenir" del Servicio Nacional de Aprendizaje SENA, que aspectos como los relativos a la formalización laboral no se están implementando en debida forma a pesar de haber transcurrido ya dos años desde inicio de su vigencia.

En cuanto al sentido "empresarial" de la actividad de Producción Ganadera que da el título al nivel de formación de este grupo de tecnólogos, se observa o identifica que la ganadería sigue siendo manejada como "actividad" y no bajo el concepto de una empresa productiva del sector primario de la economía. Esta situación se revierte de manera directa causando un impacto negativo sobre la empleabilidad y la economía de los profesionales graduados del programa enunciado; adicionalmente el sencillo hecho que sus actividades laborales sean ejecutadas por "jornaleros empíricos" dista mucho de lo esperado por los 
graduados quienes entre sus expectativas tienen los incentivos morales y económicos de quienes se forman en el Sistema Educativo de Educación Formal.

Estas prácticas que derivan en desempleo, desmotivación y también en la pérdida de las capacidades de los graduados del Programa Tecnología en Producción Ganadera el Centro Agropecuario y de Biotecnología “El Porvenir” del Servicio Nacional de Aprendizaje SENA, para dinamizar el desarrollo y la productividad en las zonas rurales del país. Lo anterior se interpreta en el sentido que la región de Córdoba (Colombia), si tiene las capacidades de talento humano formado para dinamizar el desarrollo y la productividad mediante la transferencia de tecnología de las Ciencias Veterinarias, pero las mismas están siendo sub utilizadas debido al incumplimiento de las normas que se realiza por parte de los empleadores de este gremio, sin que existan medidas de control y seguimiento a la implementación de las políticas de desarrollo que han sido formuladas, socializadas en los organismos internacionales e implementadas parcialmente en el territorio nacional. La anterior información obedece a que en el OLE hay reportes que indican que si existen sectores productivos en los diferentes departamentos en los cuales a los tecnólogos se les cumple con lo establecido en el Plan de Desarrollo "Pacto por Colombia, pacto por la equidad" como lo reflejan los valores del IBC reportados por los profesionales al observatorio.

De lo cual se desprende la conclusión parcial que el "pacto por el emprendimiento y la productividad no se está cumpliendo en el Departamento de Córdoba pues en este estudio se ha evidenciado que los patrones de contratación, vinculación laboral y remuneración se incumplen; así mismo que no se ha implementado en enfoque centrado en la transformación productiva, ni ha logrado en dos años aumentar la formalización laboral, como tampoco se 
visiona el componente empresarial en la ganadería; sin lo cual no se hace viable el logro de dinamizar el desarrollo y la productividad en las zonas rurales del país; lo anterior permite identificar que en el contexto se sigue manejando la ganadería como "actividad" y no como "empresa"; ya desde el año 2016, el Instituto Geográfico Agustín Codazzi (IGAC) ha indicado que en "Colombia, el departamento ganadero por excelencia es Córdoba, pues es esta actividad es la que más genera ganancias en la región”, es decir la ganadería como negocio no ha logrado evolucionar de actividad a empresa en Córdoba (Colombia).

Por su parte el pacto por la equidad, que es el componente o la Dimensión del Plan de Desarrollo de Colombia que se centra en garantizar la igualdad de oportunidades para la inclusión social y las oportunidades para la inclusión productiva (entendida como el acceso a mercados de trabajo e ingresos dignos), dice a la letra:

(...) El pacto por la equidad se centra en garantizar la igualdad de oportunidades para la inclusión social (el acceso eficiente y con calidad a servicios de salud, cuidado infantil, educación y formación de capital humano, seguridad alimentaria, vivienda y hábitat) y las oportunidades para la inclusión productiva (acceso a mercados de trabajo e ingresos dignos). (Cepal, Observatorio Regional de Planificación para el desarrollo. Plan Nacional de Desarrollo (2020).

Al respecto de esta dimensión del Plan de Desarrollo de Colombia, es clara su orientación a mejorar las condiciones de vida de la población, con una propuesta incluyente en la cual exista igualdad de oportunidades para todos. El pacto por la equidad se enfoca o centra en garantizar las condiciones de igualdad de oportunidades para acceso a los servicios 
de salud, cuidado infantil, educación y formación de capital humano, y a bienes que permitan la seguridad alimentaria, vivienda y hábitat; los cuales a su vez se desprenden, dependen o derivan de la inclusión productiva que permite las oportunidades para acceso a mercados de trabajo e ingresos dignos, con los cuales los trabajadores en el territorio nacional puedan satisfacer sus necesidades básicas y complementarias elevando de manera progresiva y sostenida su calidad de vida.

En los resultados del presente estudio, se puede observar serias deficiencias en el cumplimiento de este pacto en Córdoba (Colombia) que en cuanto a "ingresos dignos" para los Tecnólogos en Producción Ganadera, es así como de los 38 entrevistados que clasifican en "situación laboral activa", se encuentra que $88.9 \%$ de ellos laboran en condiciones de subempleo o en trabajo informal y $11.11 \%$ de los mismos están en condiciones apropiadas. Estableciéndose como medida la razón estadística $(9: 1)$ que indica que 9 de cada 10 Tecnólogos en Producción Ganadera tienen salarios por debajo de lo correspondiente a su nivel de formación, y uno de cada 10 tiene el salario que le corresponde a su nivel de formación.

Estas situaciones evidencian que si bien se cumple lo relativo a la formación de capital humano, esta formación debido a los escasos empleos accesibles y a la precariedad de los salarios devengados no sería un apoyo para que los trabajadores puedan tener en sus hogares la garantía de la seguridad alimentaria y la vivienda que son logros asociados a la dimensión de los medios económicos; esto es asociados a la capacidad adquisitiva del dinero que recibe el individuo por su trabajo. 
Así mismo, tras dos años de implementación del Plan de Desarrollo de Colombia existe una seria falencia en el cumplimiento del estándar sobre "el acceso a mercados de trabajo" en cuanto a que $62 \%(n=63)$ están buscando trabajo, algunos de ellos tienen empleos y están en búsqueda de mejores opciones laborales y otros (39.68\% equivalente a 25 personas de 63$)$ han estado sin acceso a oportunidades de trabajo habiendo egresado entre 2015 y 2018 . Entre los Tecnólogos en Producción Ganadera, se identifica entonces que 4 de cada 10 graduados no ha tenido acceso a oportunidades de trabajo a pesar que existen haciendas ganaderas y que la ganadería es en esencia la principal actividad económica en la región, al punto que Córdoba es el segundo departamento de Colombia con más especies bovinas ${ }^{5}$; por su parte el Banco de la República describe entre los indicadores económicos a Córdoba como "un departamento ganadero por excelencia por cuanto su hato representa el $10 \%$ del inventario ganadero nacional" "6 ya en octubre de 2019 Córdoba se proclamó en el marco del Plan de Desarrollo de Colombia como territorio apto para el logro de "ganadería y agricultura sostenibles".

\subsection{Nivel de satisfacción de empresarios y egresados sobre el programa de}

\section{formación.}

Como se ha visto antes, las condiciones en las que se desarrolla la actividad laboral productiva de los egresados del Programa Tecnología en Producción Ganadera el Centro Agropecuario y de Biotecnología “El Porvenir” del Servicio Nacional de Aprendizaje SENA

\footnotetext{
${ }^{5}$ Federación de Ganaderos (Fedegan)

6 Colombia. Banco de la República. La economía ganadera en el Departamento de Córdoba. En: https://www.banrep.gov.co/es/economia-ganadera-el-departamento-cordoba. Consultado 23 de julio de 2020
} 
no son las esperadas, con lo que se puede suponer la existencia de niveles de insatisfacción al no cumplirse con las expectativas en cuanto a empleabilidad y remuneración salarial.

Al respecto y conforme lo establecido en la ficha técnica metodológica la satisfacción se medirá de acuerdo con el sentido las dos afirmaciones asociadas a este aspecto en el sentido de recomendar la continuidad de los estudios en esta área: ("Recomendaría a mis familiares o amigos estudiar este programa Tecnólogo Producción Ganadera" y "Recomendaría a mis familiares o amigos estudiar programas asociados al sector Agropecuario"); al respecto se pudo identificar que $60.32 \%$ opinan que están "de acuerdo" en que recomendarían estudiar el programa $(n=38), 28.57 \%$ está "muy de acuerdo" $(n=18)$ en que recomendaría el programa y $11.11 \%$ no recomendaría el programa distribuido en las dos alternativas negativas "en desacuerdo" (7.94\%) y "muy en desacuerdo" (3.17\%) (Figura No 20).

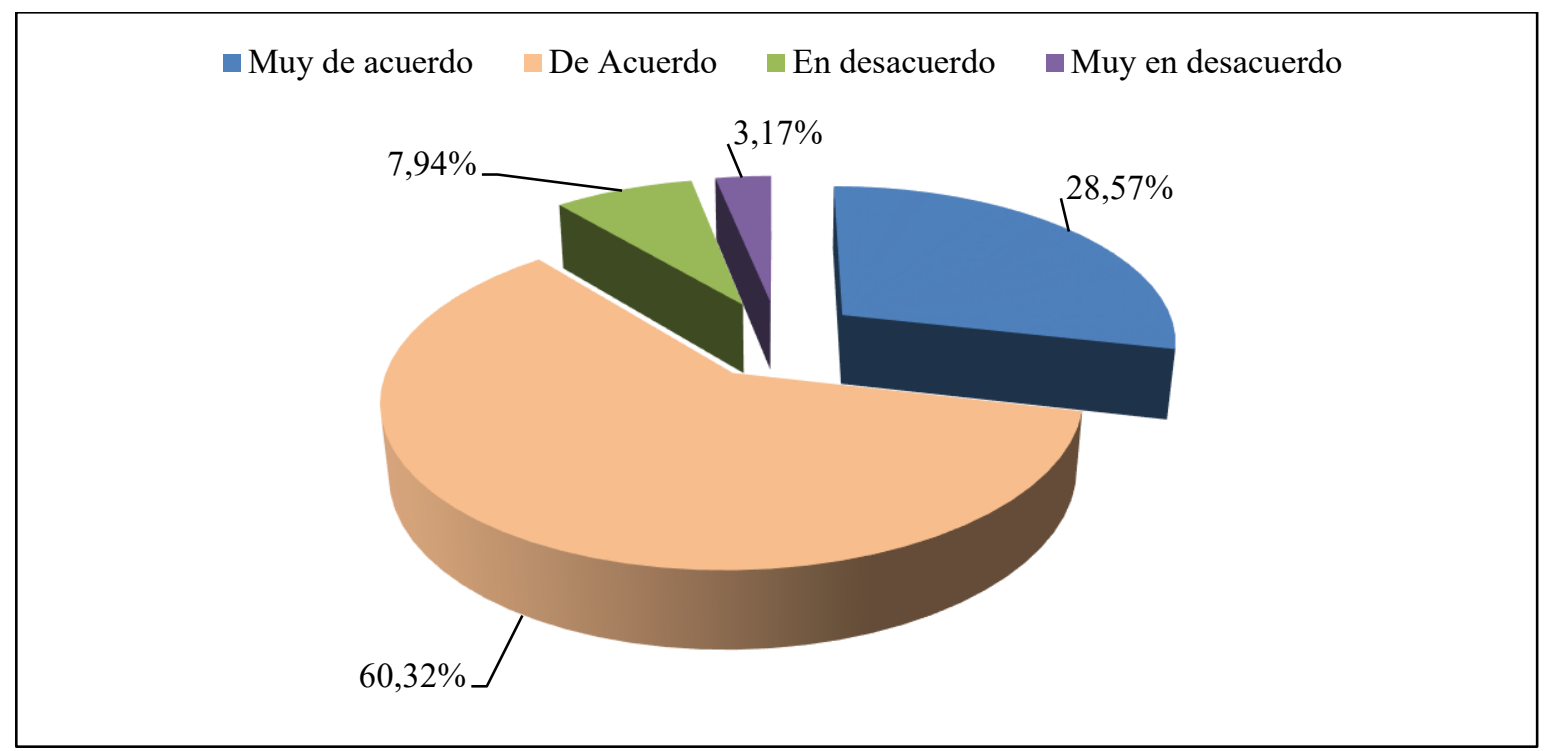

Figura No 23. Recomendaría el Programa

Fuente: Elaboración propia, con datos de la entrevista 
De acuerdo con lo plantado, se aprecia que $88.89 \%$ de los 63 entrevistados ha elegido las opciones positivas, es decir las que evidencian su nivel de satisfacción con la formación en el programa; lo anterior equivale a una medida estadística de razón que indica que 9 de cada 10 entrevistados tiene un adecuado nivel de satisfacción con el programa y con la formación en éste recibida; pues muy a pesar de los resultados de empleabilidad y remuneración las respuestas predominantes son las afirmativas.

En cuanto a la afirmación "Recomendaría a mis familiares o amigos estudiar programas asociados al sector Agropecuario" $88.88 \%$ respondió las opciones positivas de la afirmación y $11.11 \%$ las opciones negativas; de tal forma que $61.9 \%$ está "muy de acuerdo" en recomendar el estudio de programas del sector Agropecuario y 26.98\% está "de acuerdo" con esta afirmación; mientras que 9.52\% está "en desacuerdo" y $1.59 \%$ está "muy en desacuerdo" (Figura No 21).

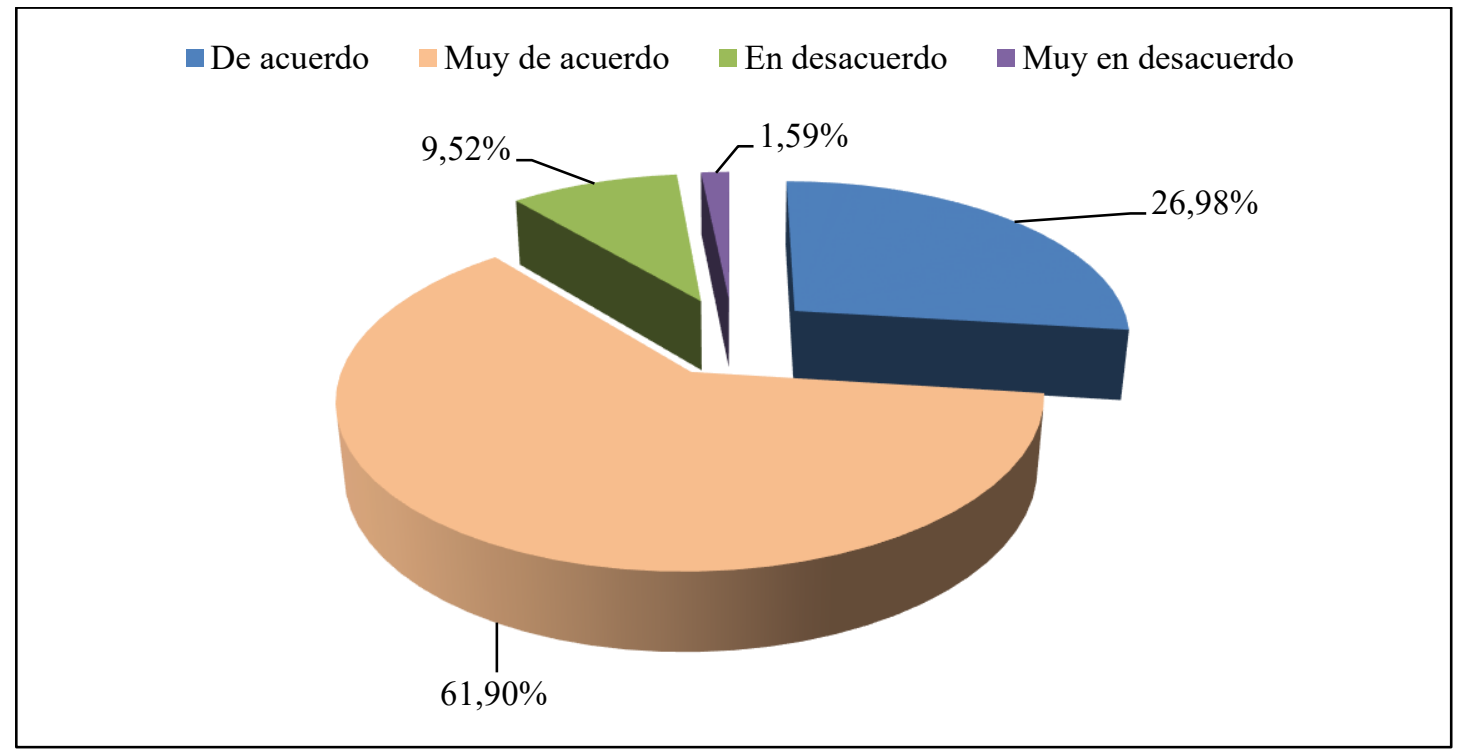

Figura No 24. Recomendaría Programas del sector Agropecuario Fuente: Elaboración propia, con datos de la entrevista 
Los resultados indican que, si bien las condiciones laborales y las oportunidades de empleo no son las esperadas, los egresados del Programa Tecnología en Producción Ganadera del Centro Agropecuario y de Biotecnología "El Porvenir” del Servicio Nacional de Aprendizaje SENA se encuentran satisfechos con su formación en el mismo.

Consideradas las categorías de valor de la satisfacción (complacido, satisfecho, insatisfecho) se identifica entre los entrevistados el predominio de la categoría "satisfecho" en la muestra de participantes.

Para la evaluación del nivel de satisfacción de los empleadores, se utilizó una serie de variables relacionada con diferentes aspectos del trabajo realizado por los pasantes, aprendices y empleados que se han formado en el Programa Tecnología en Producción Ganadera del Centro Agropecuario y de Biotecnología "El Porvenir” del Servicio Nacional de Aprendizaje SENA.

En cuanto a la satisfacción con el cumplimiento de las actividades asignadas, $80,49 \%$ de los empresarios opinan que los aprendices cumplieron con el objetivo de las actividades asignadas de manera satisfactoria, el $12,20 \%$ considera que pueden mejorar y el 7,32\% indican que no cumplieron con el objetivo planteado (Figura No 22). 


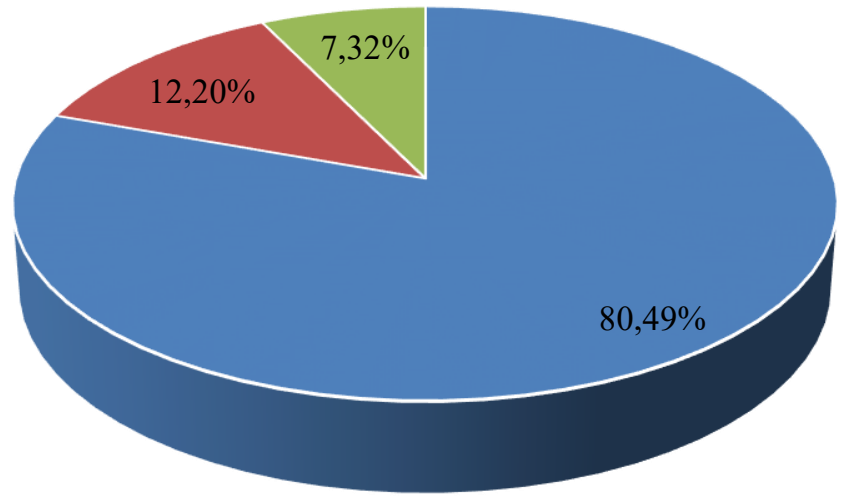

- Cumplió el objetivo, la asistencia fue buena

- Cumplió parcialmente el objetivo, pero pudo ser mejor

- No cumplió el objetivo

Figura No 25. Satisfacción con el cumplimiento de las actividades laborales Fuente: Elaboración propia, con datos de la entrevista

Estos hallazgos permiten identificar que la formación que reciben los estudiantes en el Programa Tecnología en Producción Ganadera del Centro Agropecuario y de Biotecnología "El Porvenir" del Servicio Nacional de Aprendizaje SENA es apropiada para la realización de las actividades de asistencia técnica; existiendo aún algunos aspectos menores por mejorar que están impidiendo la satisfacción al $100 \%$ en cuanto al logro de metas o expectativas que tienen los empleadores.

Otro aspecto valorado en cuanto a la satisfacción con el cumplimiento de los objetivos empresariales con el trabajo de los egresados, pasantes y aprendices del Programa Tecnología en Producción Ganadera del Centro Agropecuario y de Biotecnología "El Porvenir" del Servicio Nacional de Aprendizaje SENA se valoró a través de la calificación de cuatro aspectos centrales de la labor realizada por el aprendiz, pasante o empleado en cuanto al 
cumplimiento de los objetivos, correspondencia entre las necesidades de la empresa y la formación del empleado, calidad del trabajo y contribución de los egresados en el cumplimiento de los objetivos; al empleador se le permitió calificar la satisfacción en cinco (5) opciones a saber "muy satisfecho", "satisfecho", "normal”, "poco satisfecho" y "nada satisfecho".

En los resultados desagregados se aprecia que, en cuanto a la correspondencia entre las necesidades de la empresa y la formación del empleado, 61,9\% expresa que se encuentra muy satisfecho, 19\% se encuentra satisfecho; un 16,7\% indica que la correspondencia es normal.

Respecto a la calidad del trabajo realizado por el egresado $47,6 \%$ señala estar muy satisfecho; 26,2\% indicó encontrarse satisfecho; un 19\% considera que la calidad del trabajo es normal; un 4,8\% respondió estar poco satisfecho con la calidad de la formación y un 2,4\% mostró encontrarse nada satisfecho.

Finalmente, referente a la contribución de los egresados en el cumplimiento de los objetivos el 40,5\% respondió estar muy satisfecho, el 38,1\% se encuentra satisfecho, 11,9\% considera la contribución es normal, 7,1\% se encuentra poco satisfecho y 2,4\% señaló estar nada satisfecho.

Al consolidar los resultados de satisfacción entendida como variable dicotómica (Satisfecho, Insatisfecho) se observa que existe 100\% de satisfacción en cuanto a la correspondencia de la formación con las nececesidasdes de la empresa de producción 
ganadera, $95.12 \%$ de satisfección con la calidad del tranajo realizado y $87,8 \%$ de satisfacción en cuanto a la contribución del logro de los objetivos empresariales (Figura No 23).

En el procesamiento estadístico, los cinco criterios de la encuesta a los empresarios fueron categorizados en variables dicotómicas afines con la medición de los niveles de satisfacción. En este sentido las opciones "muy satisfecho, "satisfecho" y "normal" se categorizaron como "Satisfacción" y las opciones "poco satisfecho" y "nada satisfecho" se categorizaron como "Insatisfacción".

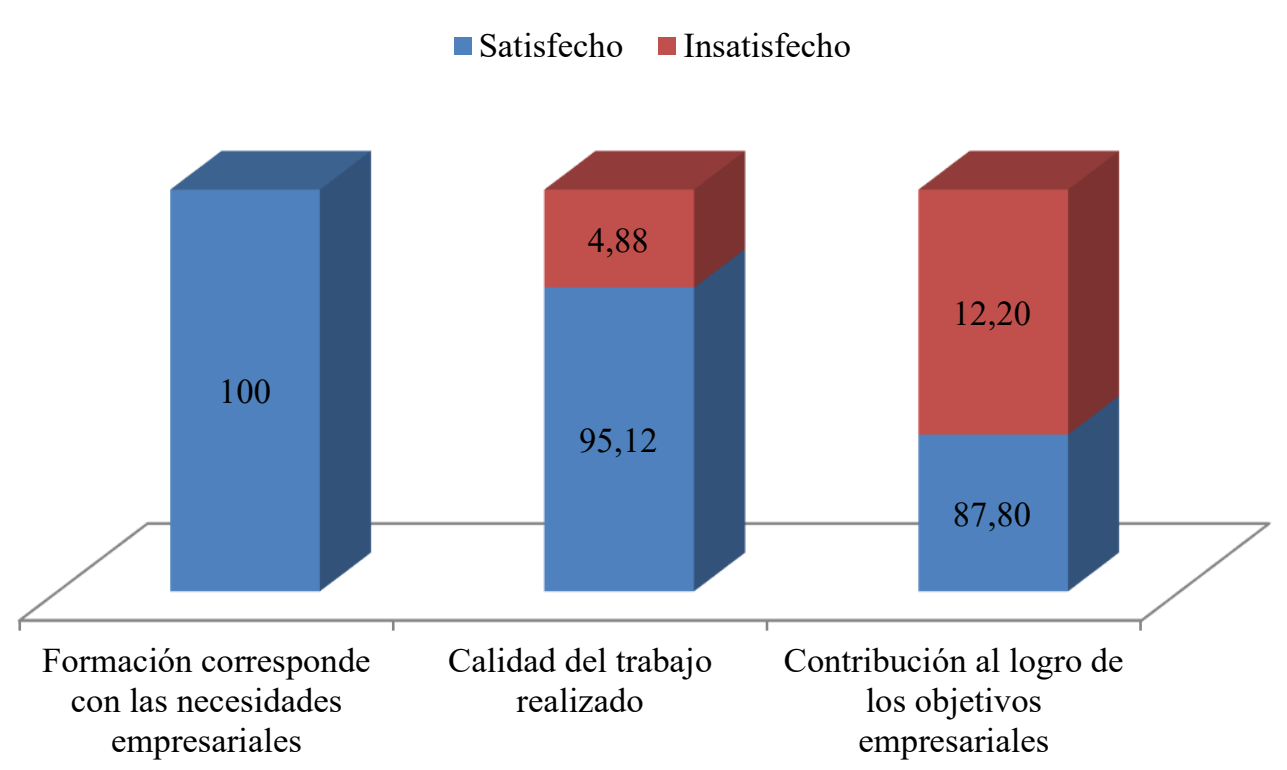

Figura No 26. Satisfacción con el cumplimiento de los objetivos empresariales Fuente: Elaboración propia, con datos de la entrevista

Estos resultados permiten identificar dos áreas de importancia para mejorar en cuanto al trabajo de los pasantes, aprendices y empleados en la industria de la producción ganadera en cuanto al compromiso en la contribución al logro de los objetivos empresariales y la calidad del trabajo realizado que obtuvieron porcentajes de insatisfacción de 12,2\% y 4.8\% respectivamente. 
Principales satisfacciones de los empleadores con los aprendices, pasantes y graduados. Para la evaluación del nivel de satisfacción con respecto a los egresados y su nivel de formación se evaluaron 10 criterios distribuidos por categorías de variable relacionadas con la satisfacción del empleador.

De tal manera que al igual que en el caso anterior, los cinco criterios de la encuesta a los empresarios fueron categorizados en variables dicotómicas afines con la medición de los niveles de satisfacción como "Satisfacción" e "Insatisfacción".

En los resultados se evidencia que las principales satisfacciones de los empleadores con los aprendices, pasantes y graduados del Programa Tecnología en Producción Ganadera del Centro Agropecuario y de Biotecnología “El Porvenir" del Servicio Nacional de Aprendizaje SENA, se encuentran en las capacidades para trabajar bajo presión, los principios y valores éticos con 100\%. En orden de frecuencias las capacidades de planificación con 95,2\%, de trabajar en equipo (92,9\%); identificar, plantear y resolver problemas $(92,9 \%)$. 


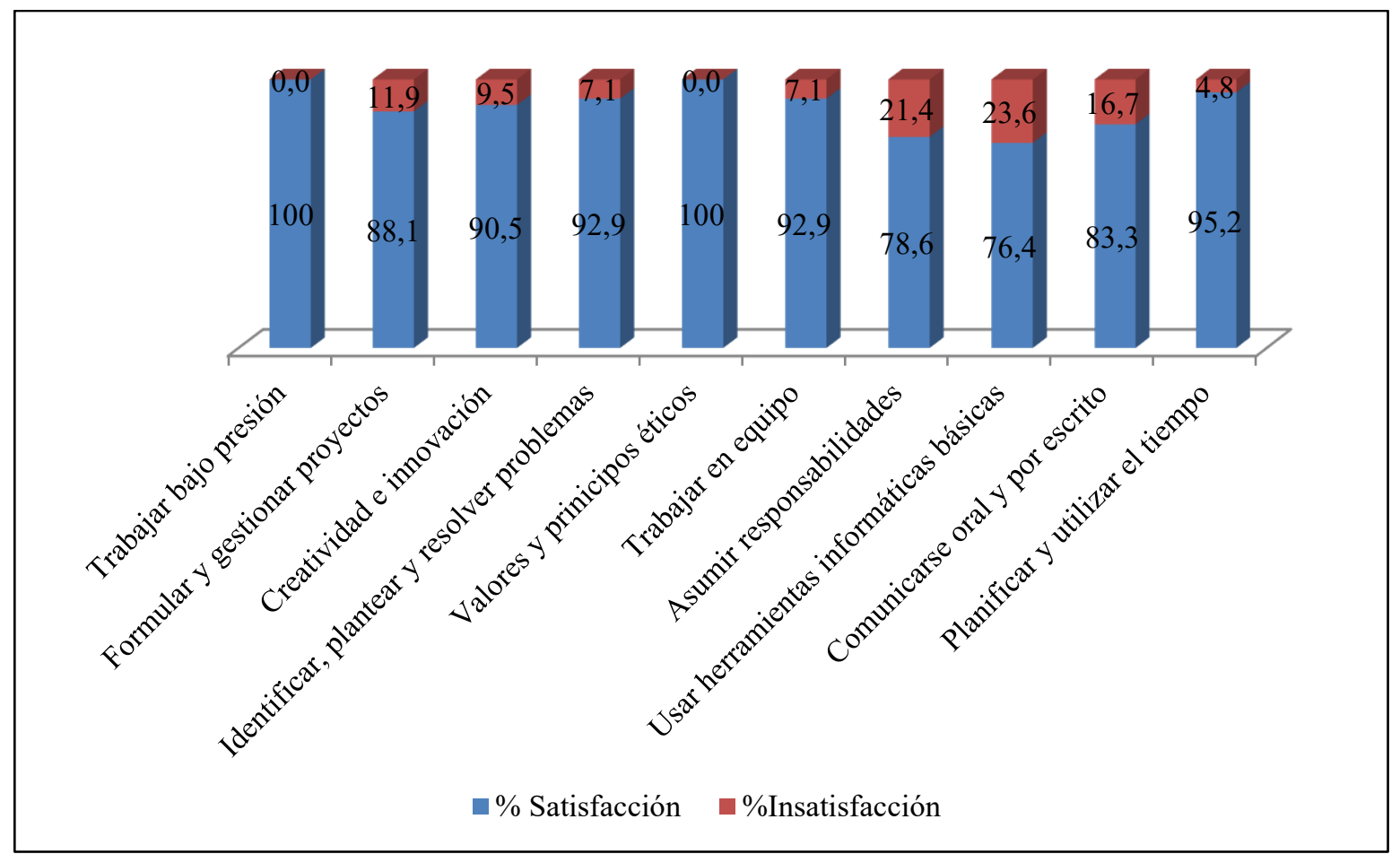

Figura No 27. Opinión de los empleadores: Capacidades requeridas en los Tecnólogos.

Fuente: Elaboración propia, con datos de la entrevista

Al consolidar los hallazgos, se identifica que los 10 criterios en medición obtuvieron porcentajes iguales o superiores a $75 \%$; lo cual permite evidenciar que si bien hay debilidades de interés en aspectos como "asumir responsabilidades", "manejo de herramientas informáticas" y "comunicación oral y escrita" tales habilidades corresponden más a complementos personales de la formación, que a logros académicos en básicos para la producción ganadera; en todo caso se resalta que en cuanto a la insatisfacción de los empleadores se presentan resultados de interés en las capacidades para el uso de herramientas informáticas (23,6\%), para asumir responsabilidades $(21,4 \%)$ y formular y gestionar proyectos (11.9\%) (Figura No 24). 
Un indicador de interés es el referido a la intención de contratar nuevamente aprendices del Centro, el 90,48\% $(\mathrm{n}=37)$ respondió de manera positiva, mientras el 9,52\% $(\mathrm{N}=4)$ indicó no tener interés en contratar nuevamente a aprendices (Figura No 25).

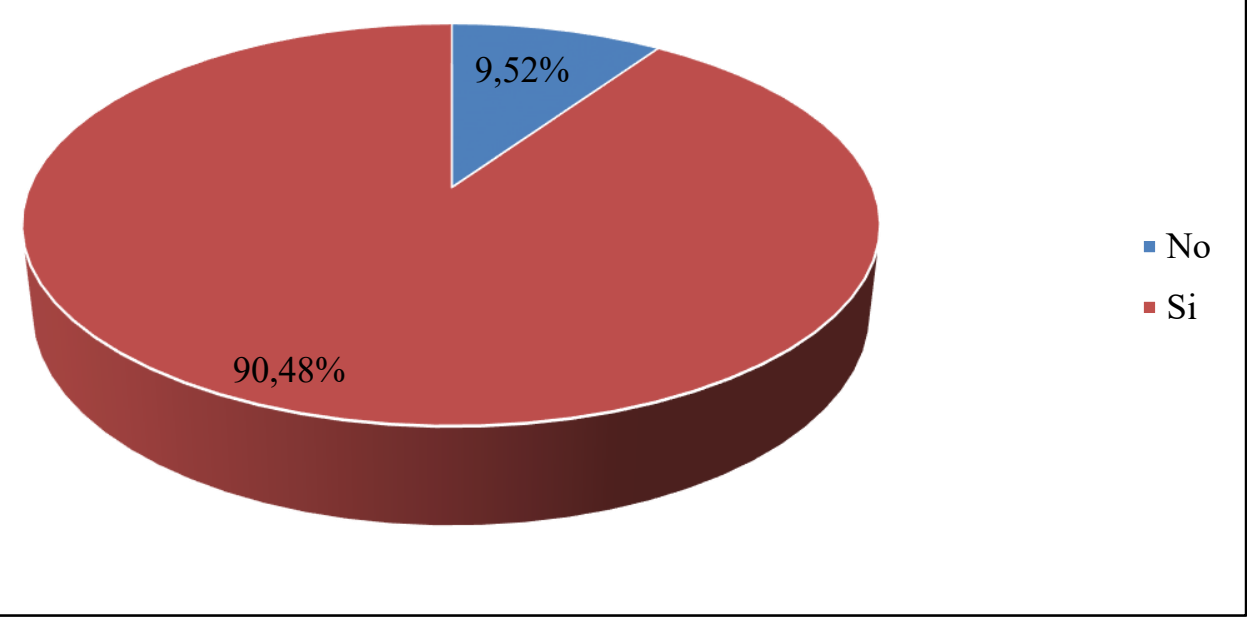

Figura No 28. Opinión de los empleadores: Capacidades requeridas en los Tecnólogos Fuente: Elaboración propia, con datos de la entrevista

La distribución da cuenta de la intencionalidad de los empleadores de mantener a su personal siempre bajo la figura de pasantes o de aprendices que le significan o representan una menor inversión en el proceso productivo; esta situación afecta de forma negativa la empleabilidad de los graduados Programa Tecnología en Producción Ganadera del Centro Agropecuario y de Biotecnología "El Porvenir" del Servicio Nacional de Aprendizaje SENA, afectando el potencial de desarrollo personal, familiar y de calidad de vida que se espera tras finalizar los estudios profesionales.

Con la finalidad de establecer la apreciación objetiva por parte de los empresarios que bajo diferentes modalidades han tenido aprendices del Centro Agropecuario y de Biotecnología El Porvenir del SENA en la regional Córdoba se tomó información cualitativa; en tal sentido se les preguntó acerca de "Si desea hacer alguna observación o recomendación 
adicional dirigida al SENA o al programa académico" a lo cual respondieron 15 de los 42 empresarios. La información fue agrupada por similitud hasta conformar categorías analíticas que permiten vislumbrar opciones de mejora continua; las cuales se organizaron de la siguiente manera:

- Fortalecer las habilidades personales complementarias: Formación integral. En esta categoría se obtuvieron expresiones como "deberían trabajar más en la parte práctica, que sean estudiantes con iniciativa, ganas de aprender, con ganas de trabajar y hacerlo mejor cada día”; "que tengan conceptos claves básicos que les permitan tener un criterio sólido a la hora de tomar decisiones"; "se deben fortalecer las habilidades ofimáticas de los aprendices"; “en general los aprendices del SENA son buenos otro que otro con debilidad es donde se tiene que trabajar".

\section{- Continuidad y trazabilidad de las competencias de los estudiantes en el trabajo}

en campo. Al respecto de esta categoría analítica cualitativa, se obtuvieron expresiones como las siguientes: “seguimiento y acompañamiento al aprendiz por parte de funcionarios del SENA durante su etapa productiva”, "incluir durante la etapa productiva, el seguimiento a las competencias de los aprendices". "se ha observado la falta de acompañamiento de funcionarios del SENA durante las prácticas de los aprendices”. Estas tres observaciones están destinadas a sugerir que el SENA debe brindar apoyo o realizar trazabilidad del producto final (graduado) de tal forma que durante el proceso se logre corregir la desviación que tenga en cuanto a la formación recibida. 
- Alianzas estratégicas de doble beneficio. Los empresarios del sector ganadero tienen intereses formados en cuanto a la dinámica de la formación con la entidad; al respecto hubo expresiones como: "dispuestos a fortalecer la alianza",; "quisiéramos contar con base de datos para ir involucrando en el equipo de vacunados, programadores del personal capacitado por SENA”; “Ahondar un poco más frente a las responsabilidades del sector productivo frente a cumplimiento de normas internas y reglamentos del campo laboral"; "En estos tiempos es recomendable generar en los aprendices conciencia de proyectarse en lo que les gusta hacer, ir más allá de hacer lo que deben hacer"; con la finalidad de formarlo con un mayor nivel de competencias en el oficio de vacunar animales; su propósito es incrementar la inserción de los egresados en la empresa bajo condiciones de beneficio mutuo de tal manera que exista relación entre el sector educativo formador y el sector empresarial como empleador.

\section{- Análisis de los criterios de validez o características personales para el trabajo} con semovientes. Los empresarios consideran de interés que el SENA debe realizar tamizaje dirigido a clasificar los estudiantes de manera precoz, de tal forma que se identifique de manera oportuna a aquellos que no tienen afinidad por el área de la producción ganadera; lo cual expresan en mensajes como los siguientes: "buenos aprendices con competencias sólidas y ganas de salir adelante, reforzar la innovación en los aprendices", "seguir formando aprendices, de excelente calidad, con criterio y responsables"; "se debe fortalecer el componente de competencias blandas, cumplimiento de horarios y recomiendo que se trabaje en aprendices más proactivos". 
En estos hallazgos cualitativos se observa o identifica que los empresarios tienen unas expectativas que no han logrado ser satisfechas en cuanto a la integralidad de la formación y en cuanto al compromiso o seguimiento del SENA para con las empresas que reciben los aprendices, pasantes y empleados; en tal sentido los empresarios como sector productivo esperan tener mayores y más fuertes vínculos con el sector formador.

\subsection{Describir la contribución del programa de formación sobre la calidad de vida de los egresados.}

Percepción del Programa de Formación. Desde la percepción del egresado del Programa Tecnología en Producción Ganadera el Centro Agropecuario y de Biotecnología “El Porvenir" del Servicio Nacional de Aprendizaje SENA, el haber desarrollado esta carrera es uno de los aspectos que le ha ayudado a mejorar su calidad de vida. En la respuesta al interrogante $92.06 \%$ expresan opiniones positivas $(69.84 \%$ "muy de acuerdo" y $22.22 \%$ "de acuerdo"); en la muestra se encuentra $7.60 \%$ de egresados que opinan que esta carrera no le ha permitido mejorar su calidad de vida, es así como estar $6.35 \%$ expresa estar "en desacuerdo" y 1.25\% “muy en desacuerdo" (Figura No 26). 


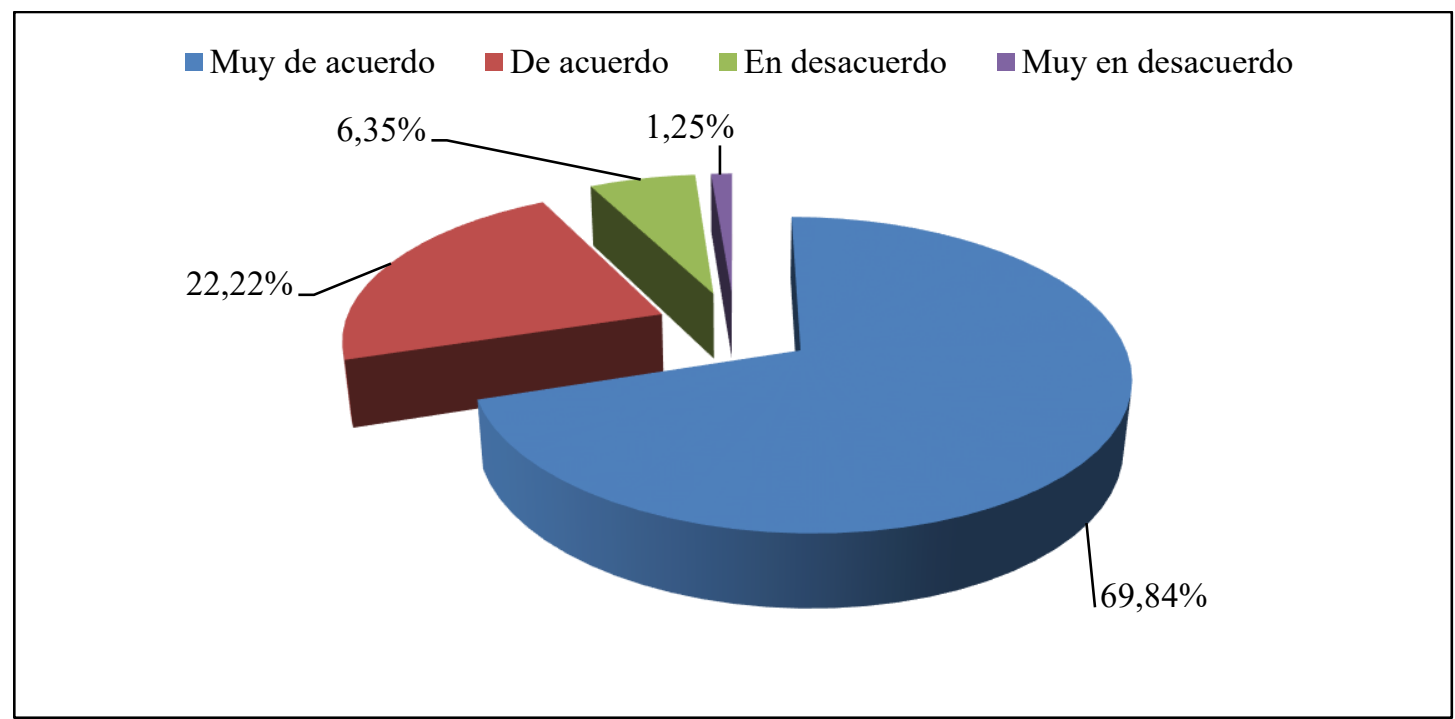

Figura No 29. Opinión sobre mejora en la calidad de vida Fuente: Elaboración propia, con datos de la entrevista

Los resultados en este aspecto de la mejora en la calidad de vida, dan cuenta que al parecer existen pocas expectativas de parte de los graduados en cuanto a su futuro profesional y a las mejores opciones de vida que le debe permitir su desarrollo académico.

Para efecto del análisis de las políticas de desarrollo, parecería que la formación a un nivel superior no hace parte de los indicadores personales de desarrollo, como tampoco parece hacer parte del concepto de desarrollo territorial; lo cual en términos precisos parecería indicar que el Plan de Desarrollo de Colombia "Pacto por Colombia, pacto por la equidad" es letra muerta en el Departamento de Córdoba, en cuanto al sector de producción agrícola se refiere, pues en principio ninguno de los parámetros de las dimensiones de éste se está cumpliendo en la actividad ganadera y segundo los actores implicados están satisfechos con los débiles logros personales obtenidos, los cuales le aportan no solo la condición de satisfacción, sino que también le permite percibir que ha mejorado su calidad de vida aún dadas las precarias condiciones laborales del entorno. 
Un importante indicador de pertinencia de un programa académico es la cobertura territorial, la cual en este estudio está siendo medida con base en el lugar de procedencia de los entrevistados.

La principal ciudad de origen de los encuestados es Montería con un total de 18 aprendices que registraron como lugar de nacimiento esta ciudad capital del departamento de Córdoba, seguidos de los municipios; Planeta Rica y Tierralta con siete (7) egresados del Programa Tecnología en Producción Ganadera el Centro Agropecuario y de Biotecnología "El Porvenir" del Servicio Nacional de Aprendizaje SENA respectivamente; la mayor parte de los municipios de origen de los graduados son Cereté, Chinú y Lorica los cuales corresponden a la subregión del Sinú Medio y Bajo registrando cuatro (4) egresados cada una; las demás ciudades registran entre uno (1) y dos (2) egresados. Se identifica la presencia de graduados cuyos orígenes son de otros departamentos del país como lo son Arboletes (Antioquia), Bogotá D.C., Cali (Valle del Cauca), Sampués y Sincelejo (Sucre), lo cual da cuenta del nivel de cobertura del programa en la región y en país. El siguiente mapa, permite evidenciar la concentración de aprendices por municipio. Importante señalar, que no se muestra la totalidad de municipios del Departamento de Córdoba, sólo se reflejan aquellos en los cuales existen aprendices relacionados a la investigación.

La procedencia de los lugareños o cordobeses corresponde a 11 de los 30 municipios que conforman el Departamento de Córdoba (36.66\%). La gráfica 20 permite apreciar que el área territorial de cobertura del Programa Tecnología en Producción Ganadera el Centro Agropecuario y de Biotecnología "El Porvenir" del Servicio Nacional de Aprendizaje SENA, 
se extiende en densidad de graduados desde la capital del Departamento en la cual tiene el área de mayor cobertura, hacia los municipios más distantes que tienen un nivel medio de cobertura en la región; lo cual es indicativo de la necesidad del programa en el departamento pues en éste estudian personas procedentes de municipios distantes geográficamente como Puerto Libertador, Ayapel (Figura No 27).

En cuanto a las subregiones se observa que la segunda mayor área territorial de cobertura del Programa Tecnología en Producción Ganadera el Centro Agropecuario y de Biotecnología "El Porvenir" del Servicio Nacional de Aprendizaje SENA corresponde a la subregión del Alto Sinú y San Jorge que son zonas geográficas de difícil acceso y con historia reciente de violencia sociopolítica.

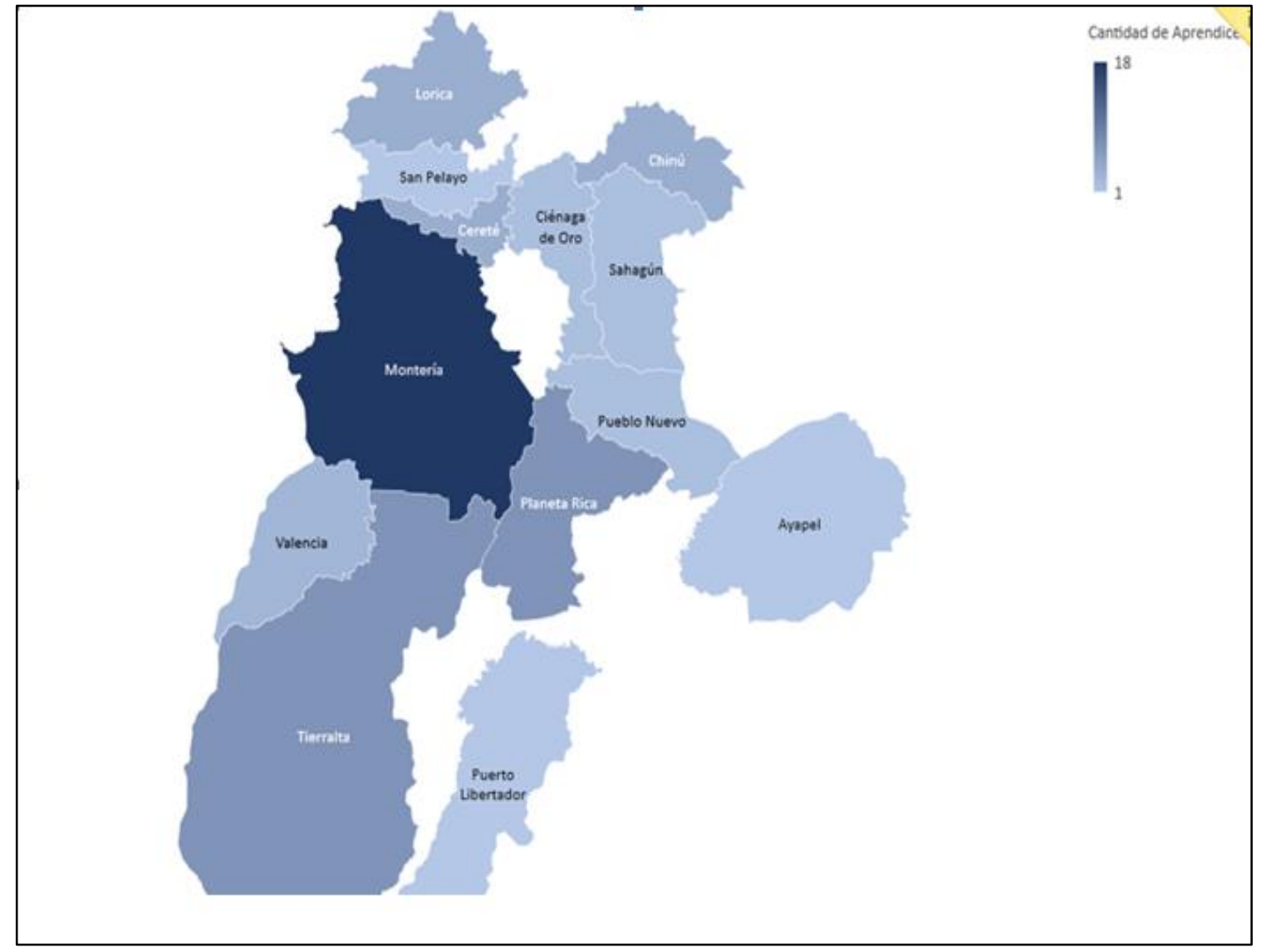

Figura No 30. Procedencia de los graduados 
Fuente: Elaboración propia, con datos de la entrevista

Este aspecto es de singular importancia en el análisis de la pertinencia de la formación, pues permite el desarrollo de regiones distantes de la capital del Departamento de Córdoba.

La tercera densidad en frecuencias corresponde a la región de sabanas de Córdoba, subregión que se caracteriza por ser de economía eminentemente agropecuaria.

En la subregión de sabanas de Córdoba el nivel de cobertura es medio, pero como se observa en el plano, es superada por municipios que son geográficamente más distantes de la capital; lo anterior permite identificar un primer nivel de pertinencia relacionado con las oportunidades de acceso que permite el Programa Tecnología en Producción Ganadera el Centro Agropecuario y de Biotecnología "El Porvenir" del Servicio Nacional de Aprendizaje SENA a la formación profesional en áreas compatibles con la vocación económica de las subregiones.

El segundo nivel de pertinencia está dado por ser un área que se adiciona a la oferta de formación en áreas de interés para todo el departamento; es un programa de educación formal, que permite obtener un título profesional a nivel tecnológico para las regiones del Departamento.

Ahora bien, ya se ha analizado antes en el capítulo anterior que el Programa de Tecnología en Producción Ganadera es pertinente debido a la actividad económica predominante en el departamento; en este punto la cobertura geográfica de los graduados 
permite apreciar que la pertinencia del mismo supera lo departamental y trasciende al ámbito nacional al tener egresados de Bogotá, Valle del Cauca y Sucre.

Como puede recordarse, la delimitación del plan de análisis expresado en la ficha técnica en la metodología, indica que para este estudio se considera alta pertenencia con porcentajes superiores al 70\% en las categorías: Trabajando continuamente, o en más de un trabajo al mismo tiempo; se considera mediana pertenencia con similares porcentajes en las categorías "en trabajos temporales" o "creando empresa" y baja pertinencia cuando predominen "desempleado" o "buscando trabajo".

Los resultados de esta valoración permitieron identificar una amplia varianza en las respuestas que impiden la interpretación de la pertinencia según lo planteado; es así como al recategorizar las respuestas se aprecia que el valor máximo obtenido (50\%) se obtuvo entre los indicadores que clasifican de "baja pertinencia", pero sin alcanzar el tope de $70 \%$ que se había indicado en la ficha técnica; los demás tuvieron un comportamiento estadístico similar ( $27 \%$ en indicadores de alta pertinencia y $23 \%$ en los indicadores de media pertinencia).

Debido a lo anterior puede entonces asumirse que con base en el historial de trabajo de los egresados del Programa Tecnología en Producción Ganadera el Centro Agropecuario y de Biotecnología "El Porvenir" del Servicio Nacional de Aprendizaje SENA evidencia baja pertinencia con una tendencia a mejorar ésta, en la medida en que se den las condiciones laborales y salariales que hacen parte del Plan de Desarrollo de Colombia. 


\section{Capítulo V}

\section{Las conclusiones}

El objeto de este trabajo fue determinar la pertinencia del programa tecnólogo en producción ganadera que ofrece el Centro Agropecuario y de biotecnología “El Porvenir” del SENA para el sector Agropecuario del departamento de Córdoba, desde la perspectiva de empresarios y egresados del programa en el período 2015 - 2018.

Para lograr la consecución del objetivo, se inició con la focalización de los aspectos que soportaron la investigación, partiendo del marco teórico que permitió la identificación de conceptos y bibliografía relacionada con el trabajo, así como permitió vislumbrar la necesidad y utilidad de la medición de los procesos formativos en aras de lograr el direccionamiento de la formación en un mundo globalizado y complejo, buscando el desarrollo individual y mejora de la calidad de vida de las personas; además, se estableció el estado del arte, en el cual se relacionaron los avances y trabajos relacionados con la medición de la formación del SENA, logrando establecer que a nivel del departamento de Córdoba y en específico en relación a la formación impartida en el Centro Agropecuario y de Biotecnología no se habían desarrollados estudios de medición de la formación, lo cual además de posibilitar el trabajo, afianzó y ratificó su utilidad dado el vacío identificado en la literatura.

De otra parte, y a modo de contexto, se logró realizar una descripción detallada del sistema de educación en Colombia, logrando determinar cómo se posiciona la educación impartida en el SENA y cómo el estado como regulador establece los mecanismos de inspección y vigilancia a través del Ministerio de Educación Nacional. Alineado a estoy para comprender la 
dinámica y evolución del sistema, se hace necesario considerar que la transformación de una sociedad requiere tiempo, lo cual supone la adaptación de las personas y la continuidad de las políticas públicas a través del mismo, el modelo de educación colombiano y las políticas de desarrollo, no se aleja de esta realidad.

En cuanto al plan de desarrollo "Pacto por Colombia, pacto por la equidad", se pudo evidenciar que su cumplimiento es fraccionado hasta la fecha, dado que si bien se cumple lo relativo a la formación de capital humano, el logro se ve influenciado negativamente por la escasez de empleos accesibles y la precariedad de los salarios devengados, los cuales no se constituyen en un apoyo para que los trabajadores puedan tener en sus hogares la garantía de la seguridad alimentaria y la vivienda que son logros asociados a la dimensión de los medios económicos. El departamento de Córdoba, no escapa a esta realidad y en específico con el programa de formación objeto de estudio, se pudo evidenciar que los salarios de gran parte de las personas que al momento del estudio se encontraban laborando eran inferiores al mínimo legal establecido, además, se evidenciaron serias deficiencias en el cumplimiento de la política de "ingresos dignos"; tras la presencia de un amplio margen de tecnólogos que laboran en condiciones de sub-empleo o en trabajo informal.

El Programa de Tecnología en Producción Ganadera fue clasificado como pertinente debido a la actividad económica predominante en el departamento; así mismo logra cobertura geográfica que supera lo departamental y trasciende al ámbito nacional al tener egresados laborando Bogotá, Valle del cauca y Sucre. La clasificación general de la pertinencia se ha visto afectada por el historial de empleo de los graduados, pues debido al desempleo y al 
subempleo de los graduados en esta categoría de interés la pertinencia fue clasificada como "baja".

La satisfacción de los graduados y de los empleadores con respecto a la formación de los egresados, pasantes y aprendices del Programa Tecnología en Producción Ganadera del Centro Agropecuario y de Biotecnología "El Porvenir" del Servicio Nacional de Aprendizaje SENA ha sido bien evaluada por ambos actores; quienes tienen desarrolladas todas las competencias a realizar en el ámbito laboral en sentido estricto, los empleadores sugieren alternativas de desarrollo personal, humano y tecnológico para mejorar el nivel de los graduados, pasantes y aprendices Abreo Loza ((2018).

La problemática laboral de los graduados, aprendices y pasantes al parecer están relacionados con el contexto, debido a que la mayoría de los empleos en el sector de la ganadería corresponden al sector privado; los ganaderos no tienen visión empresarial del negocio y por tanto a pesar de la existencia de la política de formación para el trabajo y desarrollo humano contratan personal sin formación para retribuir con bajos salarios o por fuera de lo establecido en las normas nacionales; los propietarios de las haciendas contratan de preferencia "jornaleros" o "cuidanderos" para que estén al tanto de las actividades de las fincas, cuyos ingresos son liquidados por jornal (o a destajo) y utilizan el servicio de los aprendices y pasantes por periodos de tiempo definido, sin intención de mantener la contratación. 


\section{Recomendaciones}

El autor del presente estudio, basado en los principales hallazgos presenta una serie de recomendaciones a las empresas y entidades abajo relacionadas con el fin de propender por la natural aplicabilidad de los contenidos explícitos del Plan de Desarrollo "Pacto por Colombia, pacto por la equidad"; a saber:

\section{- Al sector ganadero}

Visionar el negocio de la ganadería como una empresa productiva, susceptible de generar ingresos sustanciales e incluso generar divisas al país.

Superar la visión "tradicional” de la ganadería, e innovar en tecnologías de cría, levante, ceba, producción de leche y carne utilizando los conocimientos y habilidades de los graduados del Centro Agropecuario y de Biotecnología “El Porvenir” del Servicio Nacional de Aprendizaje SENA, no de forma esporádica durante los periodos de prácticas de éstos sino de manera permanente creando fuentes de empleo, con salarios dignos que retribuyan al profesional parte de la ganancia que ayuda a generar con su actividad profesional.

\section{- Al sector formativo}

Fomentar entre los ganaderos o empleadores la formación en cuanto a Responsabilidad Social Empresarial debido a que este aspecto está fallando en los vínculos del SENA con los empleadores de los pasantes, aprendices y graduados quienes están siendo tomados en el Departamento de Córdoba como "mano de obra barata" durante la formación y no existe al parecer intencionalidad de los ganaderos empleadores de vincular al sector 
productivo a los graduados que han demostrado en las instalaciones de su finca sus habilidades y destrezas.

Promover entre el estudiantado el desarrollo de las habilidades comunicativas y de manejo de tecnología que sugieren los empleadores y empresarios. Así mismo promover entre ellos la necesidad de abrir sus horizontes geográficos para buscar mejores opciones laborales para ellos y sus familias en áreas nacionales en las cuales si se cumple lo contemplado en el Plan Nacional de Desarrollo.

\section{- Al sector gubernamental}

Propender porque el contenido del Plan de Desarrollo "Pacto por Colombia, pacto por la equidad" no sea letra muerta, o letra sobre el papel, sino que se haga una realidad; las alcaldías municipales disponen de la Secretaría de agricultura, de la Secretaría de Hacienda, Oficinas municipales y regionales del trabajo que estén atentos a reducir y aún eliminar las prácticas de precariedad laboral que se han evidenciado en el sector de la producción ganadera. 


\section{Referencias bibliográficas}

Abreo Loza, S. E. A., \& others (2018). Análisis a la evaluación educativa estandarizada en Colombia.

Arteaga, I. H., Meneses, J. R., \& Luna, J. A. (2015). Estrategia didáctica: una competencia docente en la formación para el mundo laboral. Revista Latinoamericana de Estudios Educativos (Colombia), 11(1), 73-94.

Belth, M. (1971). La educación como disciplina cientiífica. In El Ateneo. Buenos Aires.

Berrio, M., Espitia, J., Ferrari, C., González, J. I., Hernández, I., Tassara, C., \& Zafra, G. (2020). El plan nacional de desarrollo 2018-2022, "Pacto por Colombia, pacto por la equidad”. Reflexiones y propuestas. Revista de Economía Institucional, 22(43), 195.

Bachelard, G. (1993). La formación del espíritu científico. Siglo XXI.

Braslavsky, C. (1999). Bases, orientaciones y criterios para el diseño de programas de formación de profesores. Revista iberoamericana de educación, 19, 13-50

Camargo López, P. C., \& Rivera Làzaro, F. O. (2019). Evaluación del programa de jóvenes rurales emprendedores del centro de desarrollo Agropecuario y agroindustrial CEDEAGROSena y su contribución al desarrollo sostenible local en el Departamento de Boyacá bajo el período 2012-2015.

Congreso de la república de Colombia. (1994). Ley 115 de febrero de 1994. Diario Oficial No. 41.214 del 08 de febrero de 1994. Santa Fé de Bogotá.

Consejo Nacional de Acreditación. (2015). Sistema Nacional de Acreditación en Colombia CNA. Retrieved from http://www.cna.gov.co/1741/article-186365.html

Consejo Nacional de Política Económica y Social. (2008). Documento Conpes 3527. Departamento Nacional de Planeación, pp. 87-135. Bogotá. 
De Colombia, C. P. (1991). Constitución política de Colombia. Bogotá, Colombia: LeyerArticulo 67 CPC.

Galeano, M. E. (2004). Diseño de proyectos en la investigación Cualitativa. Revista Teoria y Praxis Investigativa, 2(2), 78-79.

Glass, G., \& Hopkins, K. (1996). Statistical methods in education and psychology. Psyccritiques, 41(12).

Garcia-Corredor, J. C., Rodriguez-HernandeZ, A. A., \& Forero-Romero, A. (2018).

Diagnóstico de estilos de aprendizaje para estudiantes del SENA en formación técnica y tecnológica en el área agropecuaria y agroindustrial en Boyacá (Colombia). Revista ESPACIOS, 39(35).

García García, W. R. (2016). ¿Qué efectos tienen la formación técnica, tecnológica y el contrato de aprendizaje sobre la calidad del empleo de los egresados del SENA? (Master's thesis, Uniandes).

Hernandez Sampieri, R., Fernandez Collado, C., \& Baptista Lucio, M. del P. (2010). Definición del alcance de la investigación a realizar: exploratoria, descriptiva, correlacional o explicativa. In Metodología de la investigación. Retrieved from http://www.casadellibro.com/libro-metodologia-de-la-investigacion-5-ed-incluye-cdrom/9786071502919/1960006

Ministerio de Educación Nacional. (1998). Decreto 0641 de 1998. Diario Oficial, Vol. 4, pp. 1-9. https://doi.org/.1037//0033-2909.I26.1.78

Ministerio de Educación Nacional. (2007). Decreto No 4904 de 2007 (p. 15). p. 15. Retrieved from https://www.mineducacion.gov.co/1621/articles216551_archivo_pdf_decreto4904.pdf

Ministerio de Educación Nacional. (2013). Condiciones de programa para el otorgamiento y la renovación del registro cali $\square$ cado (p. 29). p. 29. Bogotá.

Ministerio de Educación Nacional de Colombia. (2007). Decreto No 2888 de 2007 (pp. 19). pp. 1-9. Retrieved from http://www.mineducacion.gov.co/1759/articles130244_archivo_pdf.pdf 
Ministerio del Gobierno Colombiano. (1880). Ley 10 de 1880. Diario Oficial.

Ministerio del Gobierno Colombiano. (1886, August 21). Ley 7 de 1886. Diario Oficial, pp. 1-2. Retrieved from http://www.suinjuriscol.gov.co/viewDocument.asp?ruta=Leyes/1562549

NISIS, S. (1997). Formación humana y capacitación. Santiago de Chile. Dolmen.

ONU, A. G. (1948). Declaración Universal de Derechos Humanos. 10 Diciembre 1948. Derechos Humanos, 217 A(III), 1-9. Retrieved from http://www.ohchr.org/EN/UDHR/Documents/UDHR_Translations/spn.pdf\%5Cnhttp:/ /www.jocecyl.org/puzzle/descargas/declaracion.doc

Presidencia de la república colombiana. (1995). Decreto Ley 2150 de 1995. Diario Oficial, $1-53$.

Rodríguez Martínez, A. (2006). Conocimiento de la educación como marco de interpretación de la Teoría de la Educación como disciplina. Tendencias Pedagógicas, 11(11), 31-54.

Servicio Nacional de Aprendizaje - SENA. (2013). Planeación y Publicación de la Oferta Educativa (p. 7). p. 7.

Steiner, R., Rojas, N., \& Millán, N. (2010). Evaluación de impacto del programa jóvenes rurales emprendedores del Servicio Nacional de Aprendizaje-SENA.

Tobón, S. T. (2015). Formación integral y competencias. Editorial Macro.

Uriel, A., \& Cárdenas, A. (2016). Políticas Públicas en educación: el caso de la educación terciaria. Rutas de La Formación, (3), 8-13.

Vessuri, H. (1993). Desafíos de educación superior en relación con la formación y la investigación ante los procesos económicos actuales y los nuevos desarrollos tecnológicos. Revista Iberoamericana de Educaci n, (2), 205-235.

Vieytes, R. (2010). Desarrollo de competencias par ala construcción de problemas de investigación en cursos de metodológía de la investigación con estudiantes de carreras de negocios de las UCES. Universidad de ciencias empresariales y sociales. 
Anexos 


\section{Anexo 1. Ficha técnica la encuesta aprendices}

\begin{tabular}{|c|c|}
\hline 1 Objetivo de la Encuesta & $\begin{array}{l}\text { Conocer la percepción de los egresados del } \\
\text { Programa Tecnólogo en Producción Ganadera }\end{array}$ \\
\hline \multicolumn{2}{|l|}{2 Diseño Muestral } \\
\hline 2.1 Población & $\begin{array}{l}\text { Totalidad de egresados del Programa Tecnólogos } \\
\text { en Producción Ganadera, correspondiente a } 73 \\
\text { egresados entre hombres y mujeres }\end{array}$ \\
\hline 2.2 Tamaño de la Muestra & $\begin{array}{l}\text { El valor estimado de la muestra corresponde a } 68 \\
\text { egresados }\end{array}$ \\
\hline 2.3 Error Muestral & $+/-5 \%$ \\
\hline 2.4 Nivel de Confianza & $95 \%$ \\
\hline 2.5 Heterogeneidad & $\mathrm{P}=50 \% \mathrm{Q}=50 \%$ \\
\hline \multicolumn{2}{|l|}{ 3. Trabajo de Campo } \\
\hline 3.1 Instrumento de Recolección & $\begin{array}{l}\text { Cuestionario de preguntas cerradas. Anexo } 2 . \\
\text { Formato Encuesta Aprendices }\end{array}$ \\
\hline 3.2 Técnica de Recolección & $\begin{array}{l}\text { Correo Electrónico } \\
\text { Telefónicamente }\end{array}$ \\
\hline $\begin{array}{l}\text { 3.3 Fecha de Recolección de la } \\
\text { Información }\end{array}$ & Del 07 de junio al 13 de junio de 2020 \\
\hline
\end{tabular}

Tabla No 2 Ficha técnica la encuesta aprendices

Fuente: Elaboración propia

${ }^{7}$ Si bien es el estimado, se deben tomar en consideración el apartado 3.2.3.1. 


\section{Anexo 2. Modelo encuesta aprendices}

Estudio sobre seguimiento a egresados, impacto social y pertinencia, programa en producción ganadera

Apreciado egresado, el objetivo de la presente encuesta es recopilar información relacionada con su contexto socioeconómico, educativo y laboral para determinar la proyección del programa de formación.

\section{Información general}

Nombres y apellidos:

Año en que se certificó como tecnólogo:

Lugar de residencia: Dirección de residencia:

Nombre de la empresa donde labora

Nombre del Cargo que desempeña o desempeñó:

Sexo: $\mathrm{F} \_\mathrm{M} \_$Edad en años:

Correo electrónico:

Información socioeconómica

Por favor, marque con $\mathrm{X}$ la(s) opción(es) que considere apliquen en su caso:

1. ¿Ha continuado con sus estudios a nivel profesional?

\begin{tabular}{|l|l|}
\hline No & \\
\hline $\mathrm{Si}$ & \\
\hline
\end{tabular}

¿Cuál (s)?

\section{Información laboral}

Por favor, marque con $\mathrm{X}$ la(s) opción(es) que considere apliquen en su caso

2. Cómo egresado, la mayor parte del tiempo ha estado:

\begin{tabular}{|l|l|}
\hline Trabajando continuamente & \\
\hline En trabajos temporales & \\
\hline En más de un trabajo al mismo tiempo & \\
\hline Desempleado & \\
\hline Buscando trabajo & \\
\hline Estudiando & \\
\hline Incapacitado para trabajar & \\
\hline Dedicado a la familia & \\
\hline Creando empresa & \\
\hline
\end{tabular}


Otro. ¿Cuál?

3. ¿Cuánto tiempo transcurrió después de certificarse como tecnólogo para conseguir su primer empleo relacionado con la formación recibida en el SENA?

\begin{tabular}{|l|l|}
\hline Menor a 3 meses (después de certificarse) & \\
\hline Entre 3 y 6 meses & \\
\hline Entre 6 y 9 meses & \\
\hline Entre 9 y 12 meses & \\
\hline Más de 12 meses & \\
\hline No ha conseguido trabajo relacionado con la formación SENA & \\
\hline
\end{tabular}

4. Actualmente usted:

\begin{tabular}{|l|l|}
\hline Trabaja & \\
\hline Estudia & \\
\hline Está desempleado & Si esta es su respuesta, pase a la pregunta 15 \\
\hline
\end{tabular}

5. Si usted actualmente trabaja, lo hace como:

\begin{tabular}{|l|l|}
\hline Empleado & \\
\hline Independiente & \\
\hline
\end{tabular}

6. ¿Su trabajo está relacionado con la formación recibida en el SENA?

\begin{tabular}{|l|l|}
\hline SI & \\
\hline NO & \\
\hline
\end{tabular}

7. La empresa con la que usted labora pertenece al sector:

\begin{tabular}{|l|l|}
\hline Industria & \\
\hline Servicios & \\
\hline Comercio & \\
\hline Agrícola & \\
\hline Ganadero & \\
\hline Otro. ¿Cuál? & \\
\hline
\end{tabular}

8. ¿Qué tipo de vinculación tiene con la(s) empresa(s) donde labora?

\begin{tabular}{|l|l|}
\hline Término indefinido & \\
\hline Término fijo & \\
\hline Orden de prestación de servicios & \\
\hline Por obra o labor contratada & \\
\hline Otro tipo de contrato. ¿Cuál? & \\
\hline
\end{tabular}

9. ¿Cuánto son sus ingresos mensuales aproximadamente?

\begin{tabular}{|l|l|}
\hline Menos de un salario mínimo (de \$828.116) & \\
\hline Un salario mínimo (\$828.116) & \\
\hline Entre uno y tres salarios mínimos (\$828.116 a \$2.484.348) & \\
\hline Más de tres salarios mínimos (+ de \$2.484.348) & \\
\hline
\end{tabular}


10. ¿Cuánto tiempo lleva desarrollando la actividad señalada en la pregunta anterior?

\begin{tabular}{|l|l|}
\hline Menos de tres meses & \\
\hline Entre tres y seis meses & \\
\hline Entre siete meses y un año & \\
\hline Más de un año & \\
\hline
\end{tabular}

\section{Como desempleado}

11. ¿Cuánto tiempo lleva usted tratando de conseguir un empleo?

\begin{tabular}{|l|l|}
\hline Menos de tres meses & \\
\hline Entre tres y seis meses & \\
\hline Entre siete meses y un año & \\
\hline Más de un año & \\
\hline
\end{tabular}

12. Mencione tres (3) razones por las cuales usted considera que no ha conseguido empleo

\begin{tabular}{|l|l|}
\hline No he puesto interés en buscar en empleo. & \\
\hline He buscado activamente empleo pero no lo he encontrado. & \\
\hline Deberes familiares me lo han dificultado. & \\
\hline Posibles empleos supondrían cambios de residencia que no deseo. & \\
\hline Mi titulación es muy inadecuada para los trabajos que se ofrecen. & \\
\hline $\begin{array}{l}\text { Carezco de formación adicional imprescindible para los puestos de } \\
\text { trabajo que se ofrecen }\end{array}$ & \\
\hline $\begin{array}{l}\text { Los empleos que me han ofrecido no cumplían mis expectativas } \\
\text { (salariales, condiciones, etc.) }\end{array}$ & \\
\hline Otras & \\
\hline
\end{tabular}

\section{Percepción del programa de formación}

1. Haber desarrollado esta carrera de tecnólogo Producción Ganadera le ha ayudado a mejorar su calidad de vida
a. Muy de acuerdo
b. De acuerdo
c. Ni de acuerdo ni en desacuerdo
d. En desacuerdo
e. Muy en desacuerdo

2. Recomendaría a un familiar o amigo estudiar este programa tecnólogo Producción Ganadera
a. Muy de acuerdo
b. De acuerdo

c. Ni de acuerdo ni en desacuerdo

d. En desacuerdo

e. Muy en desacuerdo

3. Recomendaría a un familiar o amigo estudiar programas asociados al sector Agropecuario
a. Muy de acuerdo
b. De acuerdo
c. Ni de acuerdo ni en desacuerdo
d. En desacuerdo
e. Muy en desacuerdo 


\section{Anexo 3. Ficha técnica encuesta empresarios}

\begin{tabular}{|c|c|}
\hline 1. Objetivos de la Encuesta & $\begin{array}{l}\text { Conocer la percepción de los empresarios a los cuales se le } \\
\text { han remitido egresados y/o pasantes del programa } \\
\text { Tecnólogos en Producción Ganadera } \\
\text { Identificar el nivel de favorabilidad de los empresarios con } \\
\text { los egresados } \\
\text { Registrar las apreciaciones de los empresarios en lo } \\
\text { referente a las actitudes y formación integral de los } \\
\text { egresados }\end{array}$ \\
\hline \multicolumn{2}{|l|}{ 2. Diseño Muestral } \\
\hline 2.1 Población & Totalidad de empresas 45 \\
\hline 2.2 Tamaño de la Muestra & $\begin{array}{l}\text { El valor estimado de la muestra corresponde a } 41 \\
\text { egresados }\end{array}$ \\
\hline 2.3 Error Muestral & $+/-5 \%$ \\
\hline 2.4 Nivel de Confianza & $95 \%$ \\
\hline 2.5 Heterogeneidad & $\mathrm{P}=50 \% \mathrm{Q}=50 \%$ \\
\hline \multicolumn{2}{|l|}{ 3. Trabajo de Campo } \\
\hline 3.1 Instrumento de Recolección & $\begin{array}{l}\text { Cuestionario de preguntas cerradas. Anexo 4. Formato } \\
\text { Encuesta Física Empresarios }{ }^{9}\end{array}$ \\
\hline 3.2 Técnica de Recolección & Correo Electrónico \\
\hline $\begin{array}{l}\text { 3.3 Fecha de Recolección de la } \\
\text { Información }\end{array}$ & Del 10 al 17 de agosto al de 2020 \\
\hline
\end{tabular}

Tabla No 3 Ficha técnica la encuesta empresarios

Fuente: Elaboración propia

${ }^{8} \mathrm{Si}$ bien es el estimado, se deben tomar en consideración el apartado 3.1.3.2.

${ }^{9}$ El Formato Encuesta Física, es un referente, dadas las condiciones actuales ligada a la Pandemia por COVID-19, el instrumento fue digitalizado y suministrado virtualmente a los empresarios 


\section{Anexo 4. Modelo encuesta empresarios}

Estudio del Impacto de la formación tecnológica en producción ganadera ofertado por el SENA en el desarrollo del sector Agropecuario de un departamento de Colombia, 2015-2018

Apreciado Empresario. El objetivo de la presente encuesta es recopilar información relacionada con el nivel de satisfacción de la empresa con el egresado, la adecuación del perfil de egresado al mercado de trabajo, preferencias de la empresa para contratar egresados y la promoción en la empresa luego de concluir el curso.

El tratamiento de la información y su uso se encuentra limitados al desarrollo del trabajo de investigación en el marco de la Maestría en Políticas de Desarrollo de la Universidad Oficial de la Plata-Argentina

\section{INFORMACIÓN GENERAL}

Razón Social:

Dirección:

Departamento:

Municipio:

Tipo de Empresa: _ Micro__ _ Pequeña _ Mediana _ _ Grande

Actividad Económica Principal de la Empresa:

Teléfono:

E-mail:

Entrevistado:

Puesto de Trabajo del Entrevistado:

Por favor, marque con $\mathrm{X}$ la(s) opción(es) que considere apliquen en su caso:

13. Tipo de contratación con la que vincula a los aprendices

Contrato de Aprendizaje

Pasantía

Contrato de Trabajo

Otra modalidad

¿Cuál?

14. ¿Cómo califica la labor realizada por el aprendiz, en cuanto al cumplimiento de los objetivos?

Cumplió el obietivo, la asistencia fue buena
Cumplió parcialmente el objetivo, pero pudo ser mejor
No cumplió el objetivo

15. ¿Su empresa ha contratado egresados del Centro Agropecuario y de Biotecnología El Porvenir de uno o de varios programas académicos?

$\begin{array}{ll}\square & \text { No } \\ \square & \text { Si, ¿Cuál (es)? }\end{array}$


16. Por favor indíquenos su nivel de satisfacción con respecto a los egresados y la formación del programa académico señalado

\begin{tabular}{|l|c|c|c|c|c|}
\hline & $\begin{array}{c}\text { Muy } \\
\text { Alto(a) }\end{array}$ & Alto(a) & Medio(a) & Bajo(a) & $\begin{array}{c}\text { Muy } \\
\text { Bajo(a) }\end{array}$ \\
\hline $\begin{array}{l}\text { La formación ofrecida por el } \\
\text { programa que usted señaló, } \\
\text { corresponde a las } \\
\text { necesidades de su empresa } \\
\text { en un nivel: }\end{array}$ & 0 & 0 & 0 & \\
\hline $\begin{array}{l}\text { La calidad del trabajo } \\
\text { realizado por los egresados } \\
\text { del programa que usted } \\
\text { señaló, es: }\end{array}$ & - & 0 & & & \\
\hline $\begin{array}{l}\text { La contribución al logro de } \\
\text { los objetivos de la empresa, } \\
\text { por parte de los egresados } \\
\text { del programa que usted } \\
\text { señaló, es: }\end{array}$ & - & 0 & 0 & & \\
\hline
\end{tabular}

17. ¿Qué grado de incidencia tienen las siguientes competencias de los colaboradores en las metas de su empresa o área de trabajo?

\begin{tabular}{|l|c|c|c|c|c|}
\hline & $\begin{array}{c}\text { Muy } \\
\text { Alto(a) }\end{array}$ & Alto(a) & Medio(a) & Bajo(a) & $\begin{array}{c}\text { Muy } \\
\text { Bajo(a) }\end{array}$ \\
\hline $\begin{array}{l}\text { Capacidad para planificar y } \\
\text { utilizar el tiempo de manera } \\
\text { efectiva }\end{array}$ & $\bigcirc$ & $\bigcirc$ & $\bigcirc$ & $\bigcirc$ & $\bigcirc$ \\
\hline $\begin{array}{l}\text { Capacidad para comunicarse } \\
\text { oralmente y por escrito, de } \\
\text { manera asertiva }\end{array}$ & $\bigcirc$ & $\bigcirc$ & $\bigcirc$ & $\bigcirc$ & $\bigcirc$ \\
\hline $\begin{array}{l}\text { Facilidad para utilizar } \\
\text { herramientas informáticas } \\
\text { básicas y especializadas }\end{array}$ & $\bigcirc$ & $\bigcirc$ & $\bigcirc$ & $\bigcirc$ & $\bigcirc$ \\
\hline $\begin{array}{l}\text { Capacidad para asumir } \\
\text { responsabilidades y tomar } \\
\text { decisiones }\end{array}$ & $\bigcirc$ & $\bigcirc$ & $\bigcirc$ & $\bigcirc$ & $\bigcirc$ \\
\hline $\begin{array}{l}\text { Capacidad para trabajar en } \\
\text { equipo para alcanzar una } \\
\text { meta común }\end{array}$ & $\bigcirc$ & $\bigcirc$ & $\bigcirc$ & $\bigcirc$ & $\bigcirc$ \\
\hline $\begin{array}{l}\text { Formación en valores y } \\
\text { principios éticos. }\end{array}$ & $\bigcirc$ & $\bigcirc$ & $\bigcirc$ & $\bigcirc$ & $\bigcirc$ \\
\hline $\begin{array}{l}\text { Capacidad para identificar, } \\
\text { plantear y resolver } \\
\text { problemas }\end{array}$ & $\bigcirc$ & $\bigcirc$ & $\bigcirc$ & $\bigcirc$ & $\bigcirc$ \\
\hline $\begin{array}{l}\text { Capacidad creativa e } \\
\text { innovadora }\end{array}$ & $\bigcirc$ & $\bigcirc$ & $\bigcirc$ & $\bigcirc$ & $\bigcirc$ \\
\hline $\begin{array}{l}\text { Capacidad para formular y } \\
\text { gestionar proyectos }\end{array}$ & $\bigcirc$ & $\bigcirc$ & $\bigcirc$ & $\bigcirc$ & $\bigcirc$ \\
\hline $\begin{array}{l}\text { Capacidad de trabajar bajo } \\
\text { presión }\end{array}$ & $\bigcirc$ & $\bigcirc$ & $\bigcirc$ & $\bigcirc$ & $\bigcirc$ \\
\hline
\end{tabular}


18. ¿Qué grado de competencia ha percibido usted en los egresados del SENA?

\begin{tabular}{|c|c|c|c|c|c|}
\hline & $\begin{array}{l}\text { Muy } \\
\text { Alto(a) }\end{array}$ & Alto(a) & Medio(a) & Bajo(a) & $\begin{array}{c}\text { Muy } \\
\text { Bajo(a) }\end{array}$ \\
\hline $\begin{array}{l}\text { Capacidad para planificar y } \\
\text { utilizar el tiempo de manera } \\
\text { efectiva }\end{array}$ & & & & & ) \\
\hline $\begin{array}{l}\text { Capacidad para comunicarse } \\
\text { oralmente y por escrito, de } \\
\text { manera asertiva }\end{array}$ & & & & & ) \\
\hline $\begin{array}{l}\text { Facilidad para utilizar } \\
\text { herramientas informáticas } \\
\text { básicas y especializadas }\end{array}$ & & & & & ) \\
\hline $\begin{array}{l}\text { Capacidad para asumir } \\
\text { responsabilidades y tomar } \\
\text { decisiones }\end{array}$ & & & & & ) \\
\hline $\begin{array}{l}\text { Capacidad para trabajar en } \\
\text { equipo para alcanzar una } \\
\text { meta común }\end{array}$ & & & & & \\
\hline $\begin{array}{l}\text { Formación en valores y } \\
\text { principios éticos. }\end{array}$ & & & & & \\
\hline $\begin{array}{l}\text { Capacidad } \\
\text { plantear } \\
\text { problemas }\end{array}$ & & & & & \\
\hline $\begin{array}{lll}\begin{array}{l}\text { Capacidad } \\
\text { innovadora }\end{array} & \text { creativa } & \text { e } \\
\end{array}$ & & & & & \\
\hline $\begin{array}{l}\text { Capacidad para formular y } \\
\text { gestionar proyectos }\end{array}$ & & $\bigcap$ & & & \\
\hline $\begin{array}{l}\text { Capacidad de trabajar bajo } \\
\text { presión }\end{array}$ & & $\bigcirc$ & & & \\
\hline
\end{tabular}

19. Está dispuesta la empresa a contratar nuevos aprendices SENA, egresados del programa

Si $\mathrm{So}$

20. Si su respuesta a la pregunta anterior fue negativa, exprese las razones que motivan a su empresa a tomar esta determinación.

21. Si desea hacer alguna observación o recomendación adicional dirigida al SENA o al programa académico, escríbala aquí: 
